Florida International University FIU Digital Commons

\title{
Theory of Gender and Power: Intimate Partner Violence, HIV Status and Sexual Risk Behaviors in Haitian Women
}

Anshul Saxena

Florida International University, dr.anshul@live.com

DOI: $10.25148 /$ etd.FIDC001770

Follow this and additional works at: https://digitalcommons.fiu.edu/etd

Part of the Community Health and Preventive Medicine Commons, Epidemiology Commons, International Public Health Commons, Public Health Education and Promotion Commons, and the Women's Health Commons

\section{Recommended Citation}

Saxena, Anshul, "Theory of Gender and Power: Intimate Partner Violence, HIV Status and Sexual Risk Behaviors in Haitian Women" (2017). FIU Electronic Theses and Dissertations. 3200.

https://digitalcommons.fiu.edu/etd/3200 


\section{FLORIDA INTERNATIONAL UNIVERSITY}

Miami, Florida

THEORY OF GENDER AND POWER: INTIMATE PARTNER VIOLENCE, HIV STATUS AND SEXUAL RISK BEHAVIORS IN HAITIAN WOMEN

A dissertation submitted in partial fulfillment of the

requirements for the degree of

DOCTOR OF PHILOSOPHY

in

PUBLIC HEALTH

by

Anshul Saxena

2017 
To: Dean Tomás R. Guilarte

Robert Stempel College of Public Health and Social Work

This dissertation, written by Anshul Saxena, and entitled Theory of Gender and Power: Intimate Partner Violence, HIV Status and Sexual Risk Behaviors in Haitian Women, having been approved in respect to style and intellectual content, is referred to you for judgment.

We have read this dissertation and recommend that it be approved

H. Virginia McCoy

Consuelo M. Beck-Sagué

Jessy G. Dévieux, Major Professor

Date of Defense: March 28, 2017

The dissertation of Anshul Saxena is approved.

Dean Tomás R. Guilarte Robert Stempel College of Public Health and Social Work

Andrés G. Gil Vice President for Research and Economic Development and Dean of the University Graduate School

Florida International University, 2017 
(C) Copyright 2017 by Anshul Saxena

All rights reserved. 


\section{DEDICATION}

I dedicate this dissertation to my parents Shesha and Alok, my dearest wife

Praveena, my daughter Sia, my mentors Dr. Jessy G Dévieux, Dr. H. Virginia McCoy, Dr. Consuelo M. Beck-Sagué, and Dr. Stefany Coxe and above all Goddess of knowledge and wisdom - Saraswati. 


\section{ACKNOWLEDGMENTS}

I express my sincere gratitude to all the people who made this dissertation a reality, especially my committee members who helped me all these years. Dr. Jessy G. Dévieux, my Major Professor and Principal Investigator of the parent study, "Intervening with Haitian HIV-positive Alcohol Users: An Environmental Psychosocial Framework," a special appreciation for allowing me to use your data for the current study as well as the continuous support in terms of funding and guidance over the years. The parent study was supported by Grant R01AA018084 from the National Institute on Alcohol Abuse and Alcoholism (NIAAA). Dr. H. Virginia McCoy, all my admiration for your understanding, unrelenting encouragement and support. Dr. Consuelo M. Beck-Sagué, my sincere gratitude for your constructive opinions and limitless flow of ideas. Dr. Stefany Coxe, my respect for accommodating me amidst your busy schedule and your willingness to help and provide hours of unconditional support. Dr. Elena Bastida, Professor and Chair, Department of Health Promotion and Disease Prevention, my sincere thanks for prodding me to meet the deadlines, as well as funding and support through the department. I would also like to thank Dr. Michele Jean-Gilles for helping me extract my data for the secondary analyses. My sincere thanks to Dr. Rhonda Rosenberg and Dr. Deanne Samuels for providing intellectual content to this study. My sincere gratitude to all my fellow Ph.D. students, especially Vekataraghavan Ramamoorthy and Muni Rubens for their immense support during the entire process of this dissertation. 


\title{
ABSTRACT OF THE DISSERTATION \\ THEORY OF GENDER AND POWER: INTIMATE PARTNER VIOLENCE, HIV \\ STATUS AND SEXUAL RISK BEHAVIORS IN HAITIAN WOMEN
}

\author{
by
}

Anshul Saxena

Florida International University, 2017

Miami, Florida

\section{Professor Jessy G. Dévieux, Major Professor}

Among women in Haiti, there are a number of factors, including intimate partner violence (IPV), childhood sexual abuse, and alcohol abuse that lead to increased vulnerability to STI/HIV and its sequelae. This study examined the factors associated with IPV and the associations between IPV and HIV in a sample of adult Haitian women.

The current study is a secondary analysis of data collected from HIV+ and HIVwomen attending the GHESKIO centers in Haiti. The measures include: Self-reported Questionnaire-20 (SRQ-20); Attitudes Towards Gender Roles; Partner Violence; Alcohol Use Disorders Identification Test (AUDIT); Partner Support; Sexual Relationship Power Scale (SRPS); Centers for Epidemiological Studies Depression Scale (CES-D); the StateTrait Anxiety Inventory (STAI); and, Vaginal Episode Equivalent (VEE). Descriptive statistics were used for demographic characteristics. Pearson correlations, t-Test, Generalized linear model, Logistic regression, and Generalized linear mixed models were used for estimating the strength of associations.

The mean $(S D)$ age of the participants was $25.5(5.4)$ years. Approximately $68.4 \%$ had some secondary school education and only $0.9 \%$ had a college or professional 
degree. The majority of participants $(82.2 \%)$ had a partner, but did not live with them. Generalized linear mixed modelling showed that lack of family support $(\beta=0.28, \mathrm{p}<$ $0.05)$, history of childhood sexual abuse $(\beta=0.66, \mathrm{p}<0.05)$, and traditional gender-based attitudes $(\beta=0.10, \mathrm{p}<0.001)$ predicted major IPV. Results from logistic regression analysis showed that age at sexual debut (AOR: 0.745; 95\% CI: 0.585, 0.948) and physical violence (AOR: 3.482; 95\% CI: 2.316, 5.235) were significantly associated with HIV seropositive status. Generalized linear mixed modelling analysis showed that decreased relationship control subscale scores $(\beta=-0.26, p<0.05)$ and alcohol use problems $(\beta=0.18, \mathrm{p}<0.05)$ were significantly associated with high levels of risky sexual behaviors over time.

In summary, a history of IPV was significantly associated with traditional gender based attitudes, history of childhood sexual abuse, and lack of family support. History of IPV and age of first sexual experience were significantly associated with HIV seropositive status. Finally, relationship control and alcohol use problems were significantly associated with sexual risk behavior. These findings indicate potential areas of further study and intervention among Haitian women. 


\section{TABLE OF CONTENTS}

CHAPTER

PAGE

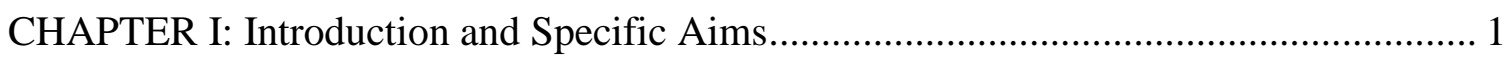

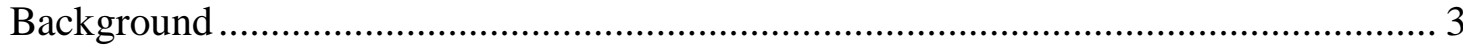

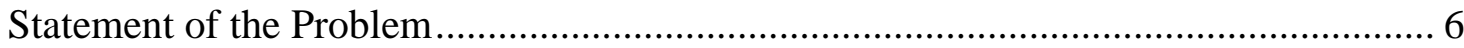

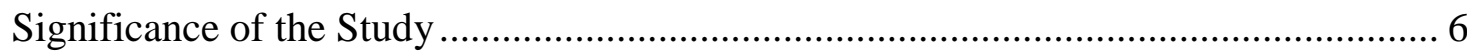

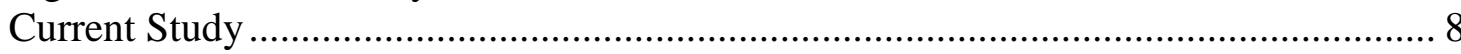

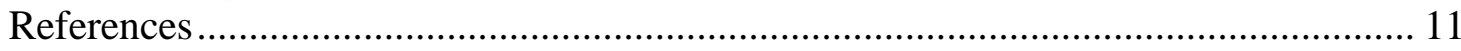

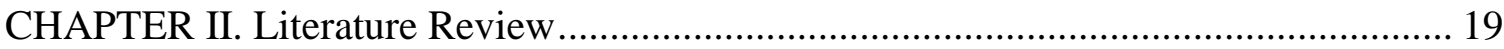

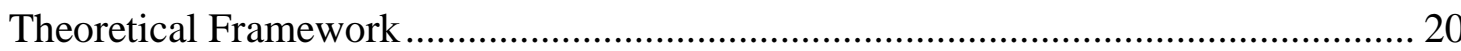

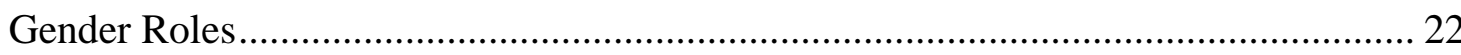

Risky Sexual Behaviors among Women and Youth in Haiti....................................... 22

Condom Use among Haitian Women ........................................................................ 24

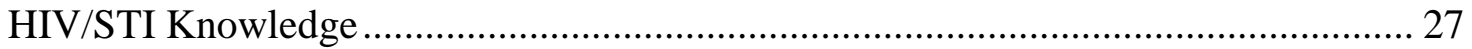

The Role of Gender-based Attitudes in HIV Disease Transmission ........................... 28

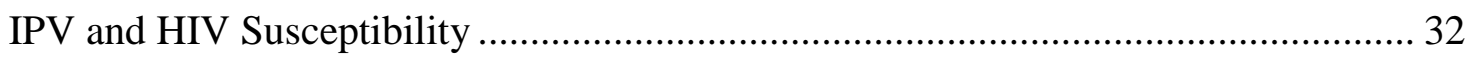

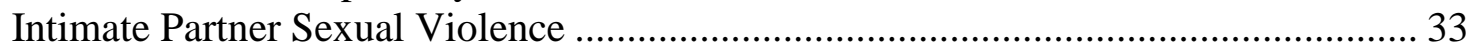

IPV, History of Childhood Sexual Abuse and HIV .................................................... 34

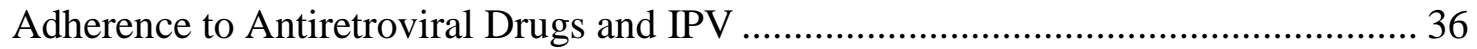

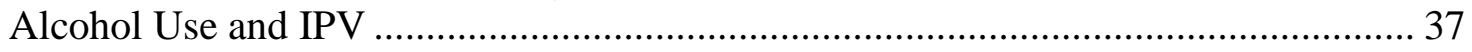

IPV and Mental and Physical Health ......................................................................... 39

Effect of Intimate Partner Violence (IPV) on Depression in Women .......................... 40

Effect of Intimate Partner Violence (IPV) on Anxiety in Women ............................... 43

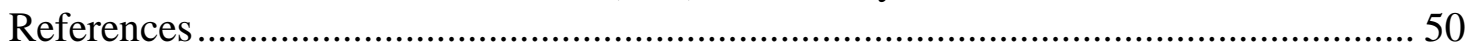

CHAPTER III: Factors Associated with Intimate Partner Violence (IPV) in a Sample of

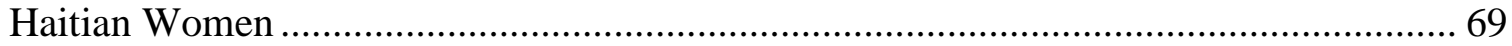

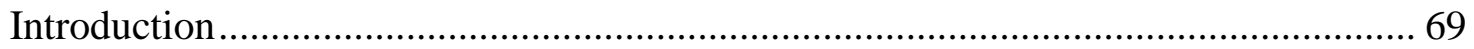

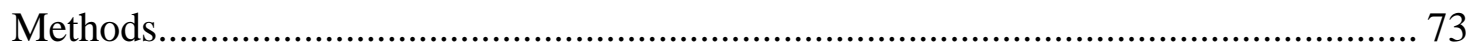

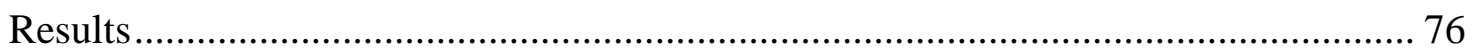

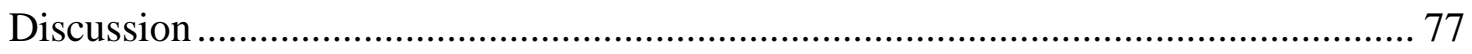

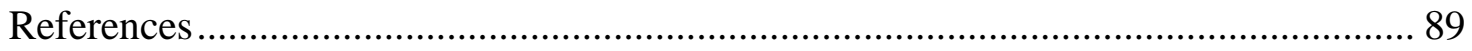

CHAPTER IV: Association between Intimate Partner Violence and HIV Status among

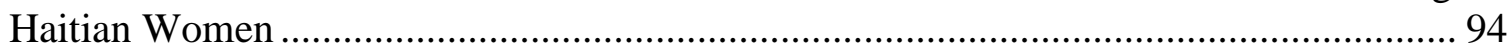

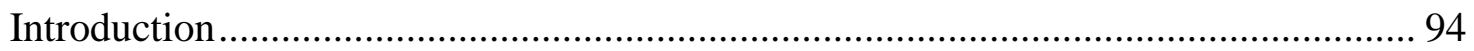

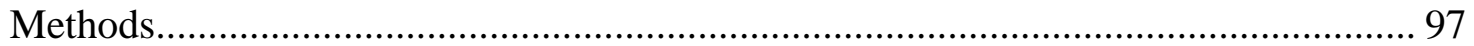

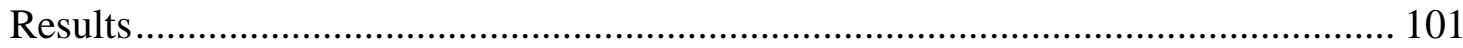

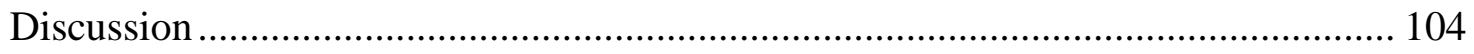

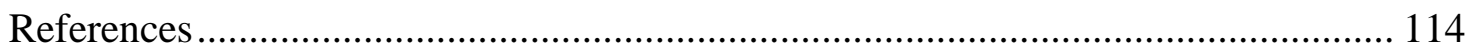


CHAPTER V: Effect of Relationship Control on Sexual Risk Behavior ...................... 117

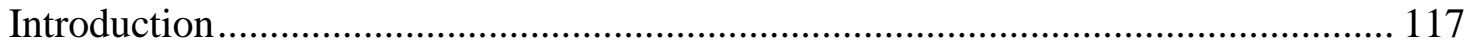

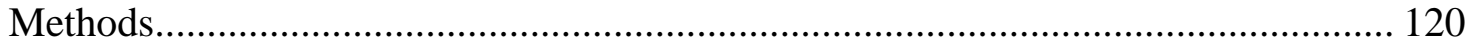

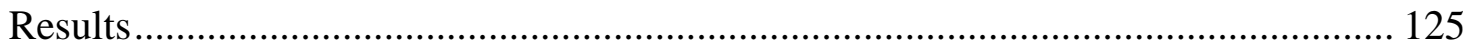

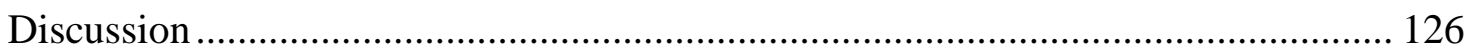

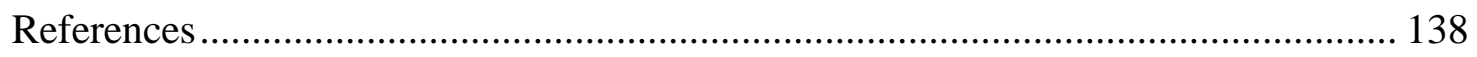

CHAPTER VI: Summary, Limitations and Future Extensions ................................... 143

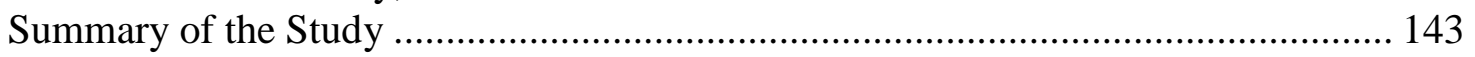

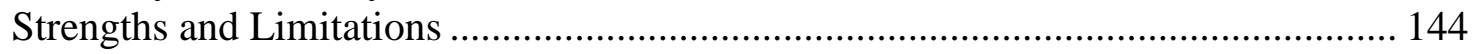

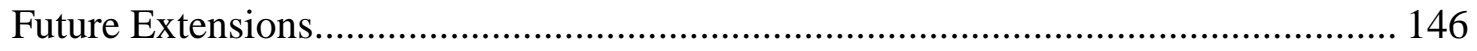

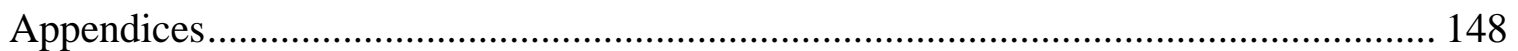

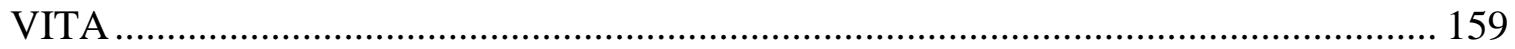




\section{LIST OF TABLES}

TABLE

PAGE

Table 2.1. Proposed model conceptualizing the influence of the theory of gender and power on women's health.

Table 2.2. Independent and dependent measures/variables identified from the structures of TGP

Table 3.1. Demographics characteristics of the participants $(n=231)$.

Table 3.2. History of partner control, psychological violence, and physical violence among participants $(n=231)$.

Table 3.3. Comparison of attitudes towards gender roles between participants with minor and major IPV $(n=231)$.

Table 3.4. Correlation between demographics, age at sexual debut, partner alcohol, family support, mental health, IPV, CSA, and TGBA $(n=231)$.

Table 3.5. Generalized linear mixed modeling predicting major IPV $(n=231) \ldots \ldots \ldots 88$

Table 4.1. Demographics characteristics of the participants $(n=165) \ldots \ldots \ldots \ldots \ldots . . .109$

Table 4.2. WHO Self-Reported questionnaire-20 score by HIV status $(n=165) \ldots \ldots .110$

Table 4.3. Attitudes towards gender roles among HIV positive and negative participants $(n=165)$

Table 4.4. Partner violence among HIV positive and negative participants $(n=165) . .112$

Table 4.5. Logistic regression analysis showing association between IPV and HIV+ status $(n=165)$.

Table 5.1. Demographic characteristics $(n=173)$

Table 5.2. Sexual relationship power and subscale scores of the participants at baseline, Mean and SE of Mean $(n=173)$

Table 5.3. Alcohol use problem, partner support, mental health, and risky sexual behavior among participants over time, Mean and SE of Mean $(n=173)$.

Table 5.4. Generalized Linear Mixed Modelling analysis predicting risky sexual behavior $(n=173)$ 


\section{ABBREVIATIONS AND ACRONYMS}

\begin{tabular}{|c|c|}
\hline ART & Antiretroviral Therapy \\
\hline AUDIT & Alcohol Use Disorders Identification Test \\
\hline CBSM-A & Cognitive-Behavioral Stress Management - Adapted \\
\hline CES-D & Centers for Epidemiological Studies Depression Scale \\
\hline $\mathrm{CDC}$ & Centers for Disease Control and Prevention \\
\hline CSA & Childhood Sexual Abuse \\
\hline GBA & Gender-Based Attitudes \\
\hline GHESKIO & $\begin{array}{l}\text { Groupe Haitien d'Etude du Sarcome de Kaposi et des Infections } \\
\text { Opportunistes }\end{array}$ \\
\hline IMB & Information-Motivation-Behavioral Skills Theory \\
\hline IPV & Intimate Partner Violence \\
\hline IRB & Institutional Review Board \\
\hline PLWH & People living with HIV/AIDS \\
\hline SRPS & Sexual Relationship Power Scale \\
\hline SRQ-20 & Self-reported Questionnaire-20 \\
\hline STAI & State-Trait Anxiety Inventory \\
\hline STI & Sexually Transmitted Infection \\
\hline TGBA & Traditional Gender-based Attitudes \\
\hline TGP & Theory of Gender and Power \\
\hline UNAIDS & Joint United Nations Programme on HIV/AIDS \\
\hline VEE & Vaginal Episode Equivalent \\
\hline WHO & World Health Organization \\
\hline
\end{tabular}




\section{CHAPTER I: Introduction and Specific Aims}

Haiti has faced nearly 35 years of the HIV/AIDS epidemic since the identification of the first case in the country in 1982 (Koenig et al., 2010; Pape \& Johnson, 1993). The epidemic initially began in Port-au-Prince, an urban area and the capital of the country,

and later spread to small towns and rural areas. Haiti has the second highest prevalence of HIV in the Caribbean region, with approximately 130,000 (estimated range, 110000 160 000) people living with HIV (PLWH) in 2015 (UNAIDS, 2015). The adult HIV prevalence rate is estimated to be between $1.4 \%$ and $2.1 \%$, which, in the Caribbean, is second only to the prevalence of $3.1 \%$ in the Bahamas (UNAIDS, 2015). Among women in Haiti, there are a number of factors, including intimate partner violence (IPV), childhood sexual abuse (CSA), and alcohol abuse, that lead to increased vulnerability to HIV and its sequelae (Carver, Dévieux, Gaston, Altice, \& Niccolai, 2014; Conserve, Whembolua, \& Surkan, 2016; Cyrus et al., 2016; Dévieux, Jean-Gilles, Frankel, et al., 2016; Dévieux, Rosenberg, Saint-Jean, Bryant, \& Malow, 2015; Sumner, Marcelin, et al., 2015). This introduction will detail several of these factors and how they contribute to women's increased vulnerability to HIV.

Women account for nearly half of all HIV-infected individuals worldwide (WHO, 2015b). Currently, heterosexual contacts constitute the most common route of transmission of sexually transmitted infections (STI) and HIV among women, followed by transmission through intravenous drug use (WHO, 2015a). Women are disproportionately affected by the virus compared to their male counterparts; in the 15 24 age group, the HIV transmission rate among women was 1.4 per 100,000 compared to 0.6 per 100,000 among men (UNICEF, 2013). In Haiti, in the 15 - 24-year-old age group, 
an estimated 78,000 women are living with HIV, with a prevalence rate of $0.9 \%$, compared to $0.6 \%$ in men. Condom use among young people with multiple partners is also lower in females (51.6\%) compared to males (61.8\%; UNICEF, 2013).

Intimate partner violence (IPV) and the impact of gender roles may significantly affect the likelihood of risky sexual behaviors among women. In 2015, one in three women reported experiencing either physical or sexual violence from their partners during their lifetime (WHO, 2015a). Women who have experienced IPV have a greater likelihood of having sexual contact without condoms or having unprotected sex while they or their partner are under the influence of drugs or alcohol (WHO, 2005, 2015a). These statistics suggest that IPV may be an important contributing factor in the rates of HIV seen among vulnerable women (Li et al., 2014).

Persons living with HIV/AIDS have higher levels of alcohol consumption when compared to HIV negative individuals (Dévieux, Jean-Gilles, Frankel, et al., 2016; Dévieux et al., 2013). The average alcohol consumption in Haiti among the population aged 15 years or older is approximately 5.2 liters per person per year, which is approximately about $19 \%$ of the total average alcohol consumption per capita in the world (WHO, 2016). Alcohol use has been found to negatively affect the physical and mental health outcomes of HIV+ women, potentially increasing their vulnerability to disease outcomes and resulting in poor ART medication adherence (Berg et al., 2004; de Fatima Bonolo et al., 2013; Ortego et al., 2012; Remien et al., 2014b; Rosen et al., 2013; Turner, Laine, Cosler, \& Hauck, 2003).

Several studies have documented a strong relationship among increased HIV transmission risk, IPV, and childhood sexual abuse. Most victims of childhood sexual 
abuse show higher risk of re-victimization, multiple partners in adulthood, early age of sexual debut, increased vulnerabilty to engaging in transactional sex, risky sexual behaviors, such as not using condoms, history of IPV, and increased risk of HIV/STI acquisition compared to non-abused counterparts (Cohen et al., 2000; Coker et al., 2012; Cubellis, Peterson, Henninger, \& Lee, 2016; Engstrom, El-Bassel, \& Gilbert, 2012; Jaffe, Cranston, \& Shadlow, 2012; LeGrand et al., 2015; Malow, Dévieux, \& Lucenko, 2006; Richter et al., 2014; Willie, Overstreet, Sullivan, Sikkema, \& Hansen, 2016). Although several studies have demonstrated these links, there is limited information on victims of childhood sexual abuse in Haiti, and very few that examine the interrelationship between IPV, alcohol use, and CSA among a sample living with HIV (Sumner, Marcelin, et al., 2015; Sumner, Mercy, et al., 2015).

\section{Background}

According to the United Nations Development Program, the Human Development Index (HDI) "is a summary measure of average achievement in key dimensions of human development: a long and healthy life, being knowledgeable and having a decent standard of living." Currently Haiti ranks $163^{\text {rd }}$ out of 187 countries, which constitutes five positions lower than the country's $158^{\text {th }}$ ranking in the year 2011 (UNDP, 2016). In comparison, the HDI for the Dominican Republic, which shares the island of Hispaniola with Haiti, was at the $101^{\text {th }}$ rank in 2015,62 positions higher than that of Haiti (UNDP, 2016).

Because of the poor economic conditions in the country, the health care system in Haiti lacks resources to implement low-cost interventions that are effective in increasing heathy behaviors. Condom use and behavioral risk reduction for risky sexual behaviors, 
for example, are cheap and effective strategies that could be used in resource-poor settings such as Haiti for decreasing the risk of transmitting HIV among sexually active individuals. Consistent and correct condom use, better condom negotiation skills, and a decrease in risky sexual behaviors lower new HIV transmissions, and hence have been recommended by public health professionals globally (Ahmed et al., 2001; CDC, 1993; Holmes, Levine, \& Weaver, 2004; Rietmeijer, Krebs, Feorino, \& Judson, 1988).

High rates of STI/HIV transmission in Haiti are further complicated by genderbased health disparities, imbalance of power in sexual relationships, and sexual violence against women (Dévieux et al., 2009). Social-cultural factors in Haiti also promote multiple sexual partners (Conserve et al., 2016; Dévieux, Jean-Gilles, Frankel, et al., 2016). In addition, approximately $30 \%$ of Haitian couples report that they have never discussed or very rarely discussed healthy sexual practices (Hempstone, Diop-Sidibe, N., Lauredent, \& Heerey, 2004; UNAIDS, 2010). These factors act as barriers against interventions such as teaching condom negotiation skills and behavioral risk reduction strategies (Dévieux et al., 2009).

Considerable research has documented that power imbalances in relationships between men and women often lead to IPV, which in turn has a significant impact on women's physical and mental well-being (DePadilla, Windle, Wingood, Cooper, \& DiClemente, 2011; Dévieux, Jean-Gilles, Rosenberg, et al., 2016; Hahm, Lee, Rough, \& Strathdee, 2012; Jewkes, Dunkle, Nduna, \& Shai, 2010; Lewis \& Simpson, 2012). Research has shown that physical and mental health deteriorates as the degree, proximity, and duration of violence increases (Brody et al., 2014; Ferrari et al., 2016; Pitpitan et al., 2012; Satyanarayana, Chandra, \& Vaddiparti, 2015; Umubyeyi, Mogren, Ntaganira, \& 
Krantz, 2014). Bonomi et al. (2006) reported that the depression rate among victims of IPV was about 2.6 times higher for victims of physical abuse and about 2.0 times higher for victims of emotional abuse compared to those without these conditions. Women who experienced IPV also reported greater difficulty performing their daily work activities and reported additional symptoms such as joint pain, back pain, insomnia, and shortness of breath when compared to women without a history of IPV (Bonomi et al., 2006; Pitpitan et al., 2012; Satyanarayana et al., 2015; WHO, 2005). Other associated but indirect health risks such as abortions and miscarriages due to IPV are common (de Sousa, Burgess, \& Fanslow, 2014; Dillon, Hussain, Loxton, \& Khan, 2016; Lacey \& Mouzon, 2016; Wathen, MacGregor, \& MacQuarrie, 2016). Finally, IPV is also associated with lower rates of contraception use; women who experienced IPV were less likely to report using condoms during sexual encounters (Kacanek et al., 2013; Stephenson, Jadhav, \& Hindin, 2013). These studies support the multiple levels of impact of IPV on women.

In many patriarchal societies, male children are valued over females, leading, very early in life, to gender-based preferences and power imbalances (Deuba, Mainali, Alvesson, \& Karki, 2016; Islam, Tareque, Sugawa, \& Kawahara, 2015; Khera, Jain, Lodha, \& Ramakrishnan, 2014). Gender-based attitudes (GBAs) and norms are largely shaped and perpetuated by the society. When they result in power imbalances they constitute an important factor in the transmission of sexually transmitted infections (STIs)/HIV, as women living in male-dominated societies have significantly higher odds of being coerced to engage in risky sexual behaviors (Hatcher, Colvin, Ndlovu, \& Dworkin, 2014; Stockman, Lucea, \& Campbell, 2013; Zembe, Townsend, Thorson, 
Silberschmidt, \& Ekstrom, 2015). However, most of the interventions designed to reduce risky sexual behaviors do not consider GBAs, nor do they adequately explain the low adherence or follow-up to these interventions among female participants (Choo et al., 2015; Ellsberg et al., 2015; Haberland, 2015). The gap in the literature about GBAs, and the interaction with personal and contextual factors, demands further exploration.

\section{Statement of the Problem}

To fill existing gaps in the literature, studies that examine how gender roles and IPV affect risk for HIV acquisition and transmission as well as treatment outcomes are needed. Moreover, there is a definite need for studies on health disparities and risky sexual behaviors among HIV-positive women in comparison to their HIV-negative counterparts. Though some researchers have proposed IPV as a significant predictor of HIV transmission among women, studies about the potential mediating and moderating variables are lacking (Pitpitan et al., 2013; Wechsberg et al., 2013; I. M. Wilson, Graham, $\&$ Taft, 2014).

This dissertation examined factors associated with severe forms of IPV among HIV negative women, the association of IPV on risky sexual behaviors among HIV positive women, and the association between IPV and HIV status among women from Haiti. In addition, this dissertation explored how measures of social support, depression, anxiety, unhealthy alcohol use, and history of CSA, are associated with IPV.

\section{Significance of the Study}

There are a number of interconnected vulnerability factors that put HIV-positive women at risk for poor outcomes. The literature shows that women fear violence from intimate partners if/when they disclose their HIV serostatus, and thus they may not seek 
antiretroviral treatment or comprehensive care (Li et al., 2014; Osinde, Kaye, \& Kakaire, 2011). Societies with higher prevalence of traditional gender roles restrict women's access to economic and educational resources thus indirectly playing a part in poor treatment adherence and negative treatment outcomes among women, especially those who are HIV-positive (Arrivillaga, Ross, Useche, Alzate, \& Correa, 2009). Some studies have documented gender-based disparities in treatment adherence, with HIV-positive females being 1.5 - 2 times more likely to be non-adherent to ART when compared to their male counterparts (Hampanda, 2016; Roberts et al., 2016; Willie et al., 2016). In addition to these personal risk factors, partner risk factors, such as risky sexual behaviors, and low adherence to antiretroviral therapy (ART) and other treatments among male partners put their intimate partners at higher risk of acquiring STI/ HIV (Remien et al., 2014a; Willie et al., 2016; S. M. Wilson, Sikkema, \& Ranby, 2014).

Being HIV positive may be associated with increased risk in a number of realms. For example, studies have shown that the prevalence of IPV was higher among female people living with HIV (PLWH) when compared to their HIV-negative counterparts (Li et al., 2014; Maman et al., 2011; Osinde et al., 2011). Many international studies conducted among female PLWH experiencing abuse from intimate partners have reported increased risky sexual behaviors when compared to HIV-negative counterparts (Durevall \& Lindskog, 2015; Jewkes et al., 2010; Li et al., 2014; Maman et al., 2011).

Research has consistently shown that traditional gender norms and power inequalities in relationships predispose women to higher rates of HIV transmission, adverse outcomes of pregnancy, alcohol and other drug dependence, and experiences of more severe forms of IPV (Dunkle et al., 2004; Durevall \& Lindskog, 2015; 
Kouyoumdjian et al., 2013; Silverman, 2010). Though there are many studies on the correlates of HIV transmission among women (Kouyoumdjian et al., 2013), there are very few studies (Cook et al., 2002; McDonnell, Gielen, O'Campo, \& Burke, 2005; Wingood, DiClemente, \& Seth, 2013; Wisniewski et al., 2005) that have methodically examined the effects of GBAs.

\section{Current Study}

The current dissertation was a secondary analysis of data collected for two parent studies; data from each of these were analyzed individually. Parent Study 1 was used to examine the relationship between childhood sexual abuse and history of IPV (among HIV- women) as well as the association between IPV and HIV+ status among adult Haitian females (in an HIV+ and HIV- matched sample). Parent Study 2 was used to examine the relationship between relationship control, partner support, and risky sexual behavior among adult Haitian females (among HIV+ women). Both datasets from the two parent studies were included in this study to determine if there were any differences in the aforementioned factors between HIV-positive and HIV-negative women. Variables in both datasets are not identical but explore common themes, hence they were not merged, but results were compared. These two datasets were examined individually to explore these hypotheses and to allow for greater in-depth analysis of inter-related variables.

Variables were identified by utilizing the Theory of Gender and Power (TGP). The Parent study-1 was a cross-sectional survey of data collected in Haiti over a year, from January 2013 to December 2013, in the context of a U.S. Agency for International Development (USAID) funded project on gender-based violence. The main objective of the study was to gain a better understanding of lives of Haitian women $(N=513)$ who 
were victims of IPV. These women were asked questions related to attitudes towards gender roles, recent history of intimate partner violence, their general and mental health conditions in the past four weeks and 12 months, and questions related to their perception of social and community support. Parent study-2 was an intervention study where longitudinal data was collected at four time points over a period of six months (baseline and post-intervention assessments, 3-, and 6-months follow ups). The main objective of this study was to understand how HIV intervention outcomes were influenced by environmental and psychosocial factors. This study included 396 alcohol using, HIVpositive men and women living in Haiti and receiving care the Haitian Group for the Study of Kaposi's Sarcoma and Opportunistic Infections (GHESKIO) Centers.

The following aims and hypotheses were tested in this study:

Aim 1. To understand the factors associated with IPV in a sample of adult Haitian women (Parent Study 1).

Research Question 1. Is IPV associated with the age of sexual debut, traditional gender based attitudes, history of childhood sexual abuse, and family support?

Hypothesis 1a. IPV will be significantly associated with early age of sexual debut in a sample of adult Haitian women.

Hypothesis 1 b. IPV will be significantly associated with traditional gender based attitudes in a sample of adult Haitian women.

Hypothesis 1c. IPV will be significantly associated with a history of childhood sexual abuse in a sample of adult Haitian women.

Hypothesis 1d. IPV will be significantly associated with the lack of family support in a sample of adult Haitian women. 
Aim 2. To understand the associations between IPV and HIV in a sample of adult Haitian women (Parent Study 1).

Research Question 2. Is IPV significantly associated with HIV seropositive status in a sample of adult Haitian women?

Hypothesis 2. IPV will be significantly associated with HIV seropositive status in a sample of adult Haitian women.

Aim 3. To understand the relationship between gender related power equity and risky sexual behavior in a sample of adult Haitian women (Parent Study 2).

Research Question 3. Does gender related power equity predict risky sexual behavior in a sample of adult Haitian women?

Hypothesis 3. Gender related power equity will predict risky sexual behavior in a sample of adult Haitian women.

\section{Summary}

The first case of HIV was identified in Haiti in 1982. Since that time, the disease has ravaged the country, leaving Haiti with the second highest prevalence of HIV in the Caribbean. Women are disproportionately affected by HIV and intimate partner violence (IPV) and the impact of gender roles may significantly affect the likelihood of risky sexual behaviors among women. Several studies have documented a strong relationship among increased HIV transmission risk, IPV, and childhood sexual abuse. This dissertation examined factors associated with severe forms of IPV among HIV negative women, the association between IPV and HIV status among a mixed HIV+/HIV- sample of women from Haiti, and relationship between gender-related power equity and risky sexual behaviors among HIV positive women. In addition, this dissertation explored how 
measures of social support, depression, anxiety, unhealthy alcohol use, and history of

CSA, are associated with IPV.

\section{References}

Ahmed, S., Lutalo, T., Wawer, M., Serwadda, D., Sewankambo, N. K., Nalugoda, F., ... \& Kiddugavu, M. (2001). HIV incidence and sexually transmitted disease prevalence associated with condom use: a population study in Rakai, Uganda. AIDS, 15(16), 2171-2179.

Arrivillaga, M., Ross, M., Useche, B., Alzate, M. L., \& Correa, D. (2009). Social position, gender role, and treatment adherence among Colombian women living with HIV/AIDS: social determinants of health approach. Revista Panamericana de Salud Pública, 26(6), 502-510.

Berg, K. M., Demas, P. A., Howard, A. A., Schoenbaum, E. E., Gourevitch, M. N., \& Arnsten, J. H. (2004). Gender differences in factors associated with adherence to antiretroviral therapy. Journal of General Internal Medicine, 19(11), 1111-1117.

Bonomi, A. E., Thompson, R. S., Anderson, M., Reid, R. J., Carrell, D., Dimer, J. A., \& Rivara, F. P. (2006). Intimate partner violence and women's physical, mental, and social functioning. American Journal of Preventive Medicine, 30(6), 458-466.

Brody, L. R., Stokes, L. R., Dale, S. K., Kelso, G. A., Cruise, R. C., Weber, K. M., ... \& Cohen, M. H. (2014). Gender roles and mental health in women with and at risk for HIV. Psychology of Women Quarterly, 38(3), 311-326.

Carver, J. W., Dévieux, J. G., Gaston, S. C., Altice, F. L., \& Niccolai, L. M. (2014). Sexual risk behaviors among adolescents in Port-au-Prince, Haiti. AIDS and Behavior, 18(8), 1595-1603.

CDC. (1993). Update: barrier protection against HIV infection and other sexually transmitted diseases. MMWR, 42, 589-591.

Choo, E. K., Gottlieb, A. S., DeLuca, M., Tape, C., Colwell, L., \& Zlotnick, C. (2015). Systematic Review of ED-based Intimate Partner Violence Intervention Research. Western Journal of Emergency Medicine, 16(7), 1037-1042.

Cohen, M., Deamant, C., Barkan, S., Richardson, J., Young, M., Holman, S., . . . Melnick, S. (2000). Domestic violence and childhood sexual abuse in HIVinfected women and women at risk for HIV. American Journal of Public Health, $90(4), 560-565$. 
Coker, A. L., Follingstad, D., Garcia, L. S., Williams, C. M., Crawford, T. N., \& Bush, H. M. (2012). Association of intimate partner violence and childhood sexual abuse with cancer-related well-being in women. J Womens Health, 21(11), 11801188 .

Conserve, D. F., Whembolua, G. L., \& Surkan, P. J. (2016). Attitudes Toward Intimate Partner Violence and Associations With Condom Use Among Men in Haiti: An Analysis of the Nationally Representative Demographic Health Survey. $J$ Interpers Violence, 31(6), 989-1006.

Cook, J. A., Cohen, M. H., Burke, J., Grey, D., Anastos, K., Kirstein, L., . . Young, M. (2002). Effects of depressive symptoms and mental health quality of life on use of highly active antiretroviral therapy among HIV-seropositive women. Journal of Acquired Immune Deficiency Syndromes, 30(4), 401-409.

Cubellis, M. A., Peterson, B. E., Henninger, A. M., \& Lee, D. (2016). Childhood Sexual Abuse and Antisocial Traits and Behaviors: A Gendered Examination of the Factors Associated With Perpetration of Intimate Partner Violence. J Interpers Violence. [Epub ahead of print].

Cyrus, E., Gollub, E. L., Jean-Gilles, M., Neptune, S., Pelletier, V., \& Dévieux, J. (2016). An Exploratory Study of Acculturation and Reproductive Health Among Haitian and Haitian-American Women in Little Haiti, South Florida. J Immigr Minor Health, 18(3), 666-672.

de Fatima Bonolo, P., Ceccato, Md, Rocha, G. M., de Assis Acurcio, F., Campos, L. N., \& Guimaraes, M. D. (2013). Gender differences in non-adherence among Brazilian patients initiating antiretroviral therapy. Clinics, 68(5), 612-620.

de Sousa, J., Burgess, W., \& Fanslow, J. (2014). Intimate partner violence and women's reproductive health. Obstetrics, Gynaecology \& Reproductive Medicine, 24(7), 195-203.

DePadilla, L., Windle, M., Wingood, G., Cooper, H., \& DiClemente, R. (2011). Condom use among young women: modeling the theory of gender and power. Health Psychology, 30(3), 310.

Deuba, K., Mainali, A., Alvesson, H. M., \& Karki, D. K. (2016). Experience of intimate partner violence among young pregnant women in urban slums of Kathmandu Valley, Nepal: a qualitative study. BMC Women's Health, 16(1), 11.

Dévieux, J. G., Deschamps, M. M., Malow, R. M., Pape, J. W., Rosenberg, R., \& JeanGilles M. (2009). Barriers to care among HIV+ Haitians: An examination of sociocultural factors. HIV/AIDS: Global frontiers in prevention/intervention. New York: Routledge, 238-245. 
Dévieux, J. G., Jean-Gilles, M., Frankel, A., Attonito, J., Saxena, A., \& Rosenberg, R. (2016). Predictors of Sexual Activity in Haitian-American Adolescents. J Immigr Minor Health, 18(1), 161-172.

Dévieux, J. G., Jean-Gilles, M., Rosenberg, R., Beck-Sague, C., Attonito, J. M., Saxena, A., \& Stein, J. A. (2016). Depression, Abuse, Relationship Power and Condom Use by Pregnant and Postpartum Women with Substance Abuse History. AIDS and Behavior, 20(2), 292-303.

Dévieux, J. G., Malow, R. M., Attonito, J. M., Jean-Gilles, M., Rosenberg, R., Gaston, S., ... Deschamps, M. M. (2013). Post-traumatic stress disorder symptomatology and alcohol use among HIV-seropositive adults in Haiti. AIDS Care, 25(10), 1210-1218.

Dévieux, J. G., Rosenberg, R., Saint-Jean, G., Bryant, V. E., \& Malow, R. M. (2015). The Continuing Challenge of Reducing HIV Risk among Haitian Youth: The Need for Intervention. J Int Assoc Provid AIDS Care, 14(3), 217-223.

Dillon, G., Hussain, R., Loxton, D., \& Khan, A. (2016). Rurality and self-reported health in women with a history of intimate partner violence. PLoS One, 11(9), e0162380.

Dunkle, K. L., Jewkes, R. K., Brown, H. C., Gray, G. E., McIntryre, J. A., \& Harlow, S. D. (2004). Gender-based violence, relationship power, and risk of HIV infection in women attending antenatal clinics in South Africa. Lancet, 363(9419), 14151421.

Durevall, D., \& Lindskog, A. (2015). Intimate partner violence and HIV in ten subSaharan African countries: what do the Demographic and Health Surveys tell us? The Lancet Global Health, 3(1), e34-e43.

Ellsberg, M., Arango, D. J., Morton, M., Gennari, F., Kiplesund, S., Contreras, M., \& Watts, C. (2015). Prevention of violence against women and girls: what does the evidence say? Lancet, 385(9977), 1555-1566.

Engstrom, M., El-Bassel, N., \& Gilbert, L. (2012). Childhood sexual abuse characteristics, intimate partner violence exposure, and psychological distress among women in methadone treatment. Journal of Substance Abuse Treatment, 43(3), 366-376.

Ferrari, G., Agnew-Davies, R., Bailey, J., Howard, L., Howarth, E., Peters, T. J., . . . Feder, G. S. (2016). Domestic violence and mental health: a cross-sectional survey of women seeking help from domestic violence support services. Global health action, 9. 
Haberland, N. A. (2015). The case for addressing gender and power in sexuality and HIV education: a comprehensive review of evaluation studies. Int Perspect Sex Reprod Health, 41(1), 31-42.

Hahm, H. C., Lee, J., Rough, K., \& Strathdee, S. A. (2012). Gender power control, sexual experiences, safer sex practices, and potential HIV risk behaviors among young Asian-American women. AIDS and Behavior, 16(1), 179-188.

Hampanda, K. M. (2016). Intimate partner violence and HIV-positive women's nonadherence to antiretroviral medication for the purpose of prevention of mother-tochild transmission in Lusaka, Zambia. Social Science and Medicine, 153, 123130.

Hatcher, A. M., Colvin, C. J., Ndlovu, N., \& Dworkin, S. L. (2014). Intimate partner violence among rural South African men: alcohol use, sexual decision-making, and partner communication. Culture, Health \& Sexuality, 16(9), 1023-1039.

Hempstone, H., Diop-Sidibe, N., Ahanda, K. S., Lauredent, E., \& Heerey, M. (2004). HIV/AIDS in Haiti: A literature review. Retrieved from http://www.popline.org/node/265958

Holmes, K. K., Levine, R., \& Weaver, M. (2004). Public Health reviews: Effectiveness of condoms in preventing sexually transmitted infections. Bulletin of the World Health Organization, 82, 454-461.

Islam, T. M., Tareque, Md I., Sugawa, M., \& Kawahara, K. (2015). Correlates of intimate partner violence against women in Bangladesh. Journal of Family Violence, 30(4), 433-444.

Jaffe, A. E., Cranston, C. C., \& Shadlow, J. O. (2012). Parenting in females exposed to intimate partner violence and childhood sexual abuse. J Child Sex Abus, 21(6), 684-700.

Jewkes, R. K., Dunkle, K., Nduna, M., \& Shai, N. (2010). Intimate partner violence, relationship power inequity, and incidence of HIV infection in young women in South Africa: a cohort study. Lancet, 376(9734), 41-48.

Kacanek, D., Bostrom, A., Montgomery, E. T., Ramjee, G., de Bruyn, G., Blanchard, K., . . van der Straten, A. (2013). Intimate partner violence and condom and diaphragm nonadherence among women in an HIV prevention trial in southern Africa. Journal of Acquired Immune Deficiency Syndromes (1999), 64, 400-408.

Khera, R., Jain, S., Lodha, R., \& Ramakrishnan, S. (2014). Gender bias in child care and child health: global patterns. Archives of Disease in Childhood, 99(4), 369-374. 
Koenig, S., Ivers, L. C., Pace, S., Destine, R., Leandre, F., Grandpierre, R., . . Pape, J. W. (2010). Successes and challenges of HIV treatment programs in Haiti: aftermath of the earthquake. HIV Therapy, 4(2), 154-160.

Kouyoumdjian, F. G., Calzavara, L. M., Bondy, S. J., O'Campo, P., Serwadda, D., Nalugoda, F., . . Gray, R. (2013). Intimate partner violence is associated with incident HIV infection in women in Uganda. AIDS, 27(8), 1331-1338.

Lacey, K. K., \& Mouzon, D. M. (2016). Severe physical intimate partner violence and the mental and physical health of US Caribbean Black women. Journal of Women's Health, 25(9), 920-929.

LeGrand, S., Reif, S., Sullivan, K., Murray, K., Barlow, M. L., \& Whetten, K. (2015). A Review of Recent Literature on Trauma Among Individuals Living with HIV. Current HIV/AIDS Reports, 12(4), 397-405.

Lewis, P., \& Simpson, R. (2012). Kanter Revisited: Gender, Power and (In)Visibility. International Journal of Management Reviews, 14, 141-158.

Li, Y., Marshall, C. M., Rees, H. C., Nunez, A., Ezeanolue, E. E., \& Ehiri, J. E. (2014). Intimate partner violence and HIV infection among women: a systematic review and meta-analysis. Journal of the International AIDS Society, 17, 18845.

Malow, R. M., Dévieux, J. G., \& Lucenko, B. (2006). History of childhood sexual abuse as a risk factor for HIV risk behavior. Journal of Trauma Practice, 5(3), 13-32.

Maman, S., Mbwambo, J. K., Hogan, N. M., Kilonzo, G. P., Campbell, J. C., Weiss, E., $\&$ Sweat, M. D. (2011). HIV-Positive Women Report More Lifetime Partner Violence: Findings From a Voluntary Counseling and Testing Clinic in Dar es Salaam, Tanzania. American Journal of Public Health, 92(8): 1331-1337.

McDonnell, K. A., Gielen, A. C., O'Campo, P., \& Burke, J. G. (2005). Abuse, HIV status and health-related quality of life among a sample of HIV positive and HIV negative low income women. Quality of Life Research, 14(4), 945-957.

Ortego, C., Huedo-Medina, T. B., Santos, P., Rodríguez, E., Sevilla, L., Warren, M., \& Llorca, J. (2012). Sex differences in adherence to highly active antiretroviral therapy: a meta-analysis. AIDS Care, 24, 1519-1534.

Osinde, M. O., Kaye, D. K., \& Kakaire, O. (2011). Intimate partner violence among women with HIV infection in rural Uganda: critical implications for policy and practice. BMC Women's Health, 11, 50.

Pape, J., \& Johnson, W. D. (1993). AIDS in Haiti: 1982-1992. Clinical Infectious Diseases, 17(Supplement 2), S341-S345. 
Pitpitan, E. V., Kalichman, S. C., Eaton, L. A., Cain, D., Sikkema, K. J., Skinner, D., . . . Pieterse, D. (2013). Gender-based violence, alcohol use, and sexual risk among female patrons of drinking venues in Cape Town, South Africa. Journal of Behavioral Medicine, 36(3), 295-304.

Pitpitan, E. V., Kalichman, S. C., Eaton, L. A., Sikkema, K. J., Watt, M. H., \& Skinner, D. (2012). Gender-based violence and HIV sexual risk behavior: alcohol use and mental health problems as mediators among women in drinking venues, Cape Town. Social Science and Medicine, 75(8), 1417-1425.

Remien, R. H., Dolezal, C., Wagner, G. J., Goggin, K., Wilson, I. B., Gross, R., . . Liu, H. (2014a). The association between poor antiretroviral adherence and unsafe sex: differences by gender and sexual orientation and implications for scale-up of treatment as prevention. AIDS and Behavior, 18(8), 1541-1547.

Remien, R. H., Dolezal, C., Wagner, G. J, Goggin, K., Wilson, I. B., Gross, R., . . Liu, H. (2014b). The association between poor antiretroviral adherence and unsafe sex: differences by gender and sexual orientation and implications for scale-up of treatment as prevention. AIDS and Behavior, 18, 1541-1547.

Richter, L., Komarek, A., Desmond, C., Celentano, D., Morin, S., Sweat, M., . . Coates, T. (2014). Reported physical and sexual abuse in childhood and adult HIV risk behaviour in three African countries: findings from Project Accept (HPTN-043). AIDS and Behavior, 18(2), 381-389.

Rietmeijer, C. A., Krebs, J. W., Feorino, P. M., \& Judson, F. N. (1988). Condoms as physical and chemical barriers against human immunodeficiency virus. JAMA, 259(12), 1851-1853.

Roberts, S. T., Haberer, J., Celum, C., Mugo, N., Ware, N. C., Cohen, C. R., . . Partners Pr, E. P. Study Team. (2016). Intimate partner violence and adherence to HIV pre-exposure prophylaxis (PrEP) in African women in HIV serodiscordant relationships: A prospective cohort study. Journal of Acquired Immune Deficiency Syndromes.

Rosen, M. I., Black, A. C., Arnsten, J. H., Goggin, K., Remien, R. H., Simoni, J. M., . . . Liu, H. (2013). Association between use of specific drugs and antiretroviral adherence: findings from MACH 14. AIDS and Behavior, 17, 142-147.

Satyanarayana, V. A., Chandra, P. S., \& Vaddiparti, K. (2015). Mental health consequences of violence against women and girls. Curr Opin Psychiatry, 28(5), 350-356.

Silverman, J. G. (2010). Key to prevent HIV in women: reduce gender-based violence. Lancet, 376(9734), 6-7. 
Stephenson, R., Jadhav, A., \& Hindin, M. (2013). Physical domestic violence and subsequent contraceptive adoption among women in rural India. Journal of Interpersonal Violence, 28, 1020-1039.

Stockman, J. K., Lucea, M. B., \& Campbell, J. C. (2013). Forced sexual initiation, sexual intimate partner violence and HIV risk in women: a global review of the literature. AIDS and Behavior, 17(3), 832-847.

Sumner, S. A., Marcelin, L. H., Cela, T., Mercy, J. A., Lea, V., Kress, H., \& Hillis, S. D. (2015a). Sentinel events predicting later unwanted sex among girls: A national survey in Haiti, 2012. Child Abuse and Neglect, 50, 49-55.

Sumner, S. A., Mercy, A. A., Saul, J., Motsa-Nzuza, N., Kwesigabo, G., Buluma, R., . . . Hillis, S. D. (2015b). Prevalence of sexual violence against children and use of social services - seven countries, 2007-2013. MMWR: Morbidity and Mortality Weekly Report, 64(21), 565-569.

Turner, B. J., Laine, C., Cosler, L., \& Hauck, W. W. (2003). Relationship of gender, depression, and health care delivery with antiretroviral adherence in HIV-infected drug users. Journal of General Internal Medicine, 18, 248-257.

Umubyeyi, A., Mogren, I., Ntaganira, J., \& Krantz, G. (2014). Intimate partner violence and its contribution to mental disorders in men and women in the post genocide Rwanda: findings from a population based study. BMC Psychiatry, 14(1), 1.

UNAIDS. (2010). Global report: UNAIDS report on the global AIDS epidemic 2010. Retrieved from http://www.unaids.org/globalreport/Global_report.htm

UNAIDS. (2015). HIV and AIDS estimates in Haiti, 2015. Retrieved from http://www.unaids.org/en/regionscountries/countries/haiti/

UNDP. (2016). 2015 Human Development Report. Retrieved from http://hdr.undp.org/en/2015-report

UNICEF. (2013). Statistics At a glance: Haiti. Retrieved from https://www.unicef.org/infobycountry/haiti_statistics.html

Wathen, C. N., MacGregor, J. C. D., \& MacQuarrie, B. J. (2016). Relationships among intimate partner violence, work, and health. Journal of Interpersonal Violence, 0886260515624236 .

Wechsberg, W. M, Myers, B., Reed, E., Carney, T., Emanuel, A. N., \& Browne, F. A. (2013). Substance use, gender inequity, violence and sexual risk among couples in Cape Town. Culture, Health \& Sexuality, 15, 1221-1236. 
WHO. (2005). WHO multi-country study on women's health and domestic violence against women. Retrieved from

http://www.who.int/reproductivehealth/publications/violence/9241593512/en/

WHO. (2015a). Gender inequalities and HIV. Retrieved from

http://apps.who.int/gender/hiv_aids/en/

WHO. (2015b). Global summary of the AIDS epidemic, 2015. Retrieved from http://www.who.int/hiv/data/en/

WHO. (2016). Haiti: statistics summary (2002 - present). Retrieved from http://apps.who.int/searo-rho/node.country.country-HTI?lang=en

Willie, T. C., Overstreet, N. M., Sullivan, T. P., Sikkema, K. J., \& Hansen, N. B. (2016). Barriers to HIV medication adherence: examining distinct anxiety and depression symptoms among women living with hiv who experienced childhood sexual abuse. Behavioral Medicine, 42(2), 120-127.

Wilson, I. M., Graham, K., \& Taft, A. (2014). Alcohol interventions, alcohol policy and intimate partner violence: a systematic review. BMC Public Health, 14, 881.

Wilson, S. M., Sikkema, K. J., \& Ranby, K. W. (2014). Gender moderates the influence of psychosocial factors and drug use on HAART adherence in the context of HIV and childhood sexual abuse. AIDS Care, 26(8), 959-967.

Wingood, G. M., DiClemente, R. J., \& Seth, P. (2013). Improving health outcomes for IPV-exposed women living with HIV. Journal of Acquired Immune Deficiency Syndromes, 64(1), 1.

Wisniewski, A. B., Apel, S., Selnes, O. A., Nath, A., McArthur, J. C., \& Dobs, A. S. (2005). Depressive symptoms, quality of life, and neuropsychological performance in HIV/AIDS: the impact of gender and injection drug use. Journal of Neurovirology, 11(2), 138-143.

Zembe, Y. Z., Townsend, L., Thorson, A., Silberschmidt, M., \& Ekstrom, A. M. (2015). Intimate partner violence, relationship power inequity and the role of sexual and social risk factors in the production of violence among young women who have multiple sexual partners in a peri-urban setting in South Africa. PloS One, 10(11), e0139430. 


\section{CHAPTER II. Literature Review}

In the past decade, with better access to testing, improved treatment alternatives, and advanced HIV care, there has been an increase in the prevalence of the disease, despite declining incidence, because of the increasing length of survival (Maartens, Celum, \& Lewin, 2014; Tanser, Barnighausen, Grapsa, Zaidi, \& Newell, 2013). For example, with approximately 130,000 (estimated range, 110000 - 160 000) people living with HIV (PLWH) in 2015 (UNAIDS, 2015) in Haiti, the adult HIV prevalence rate is estimated to be between $1.4 \%$ and $2.1 \%$, which, in the Caribbean, is second only to the prevalence of $3.1 \%$ in the Bahamas (UNAIDS, 2015). Women account for nearly half of all HIV-infected individuals worldwide (WHO, 2015a). Currently, heterosexual contacts constitute the most common route of transmission of STI/HIV among women, followed by transmission through intravenous drug use (WHO, 2015b).

As noted in Chapter 1, a number of factors contribute to the increased risk of HIV/STI transmission. Many of these factors serve as predictors and are commonly used in epidemiologic, psychosocial, and behavioral research. Some of these predictors include the age of the participant, knowledge of HIV /STI transmission, communication with a partner about safe sex, and perceived risk of acquiring HIV/STI infection (Carver, Dévieux, Gaston, Altice, \& Niccolai, 2014; Conserve, Whembolua, \& Surkan, 2016; Cyrus et al., 2016; Dévieux, Jean-Gilles, Frankel, et al., 2016; Dévieux, Rosenberg, Saint-Jean, Bryant, \& Malow, 2015; Sumner, Marcelin, et al., 2015). Evidence from previous studies indicates that using these socio-demographic predictors to evaluate risky sexual behaviors provides modest but inconsistent results (Fawzi et al., 2003; Kershaw, 2006; Magee, Small, Frederic, Joseph, \& Kershaw, 2006). These predictions could be 
improved by including variables that reflect gender-based attitudes. This chapter explores the multiple factors that contribute to increased vulnerability to HIV and its sequelae among women in Haiti, including IPV, childhood sexual abuse, and alcohol abuse. An examination of how gender roles and IPV affect risk for HIV acquisition, transmission, and treatment outcomes will also be conducted.

\section{Theoretical Framework}

Many authors have provided their views on the evolution of gender-based norms. For example, Lewis Henry Morgan Chapais (2014) postulated a four-stage model of society in the nineteenth century. In this model, the first stage was sexual promiscuity, the second stage was matriarchy, the third stage was patriarchy, where the father owned the wife and the children as property, and the fourth stage was the nuclear family of Victorian England and the "modern" United States. A more modern understanding was provided by Evelyn Reed who documented the changes in women's roles in her “Women’s Evolution from Matriarchal Clan to Patriarchal Family" (Reed, 1975). And most recently, Charlotte Perkins Gilman proposed the concept of power imbalances in the subordination of women in the early twentieth century (Gilman, 2010).

The present study will utilize a relatively new theory, the Theory of Gender and Power (TGP), to guide the current study and explore the relationship between independent and dependent variables, and the mediating and moderating effects of the variables noted in Chapter 1 (Connell, 1987). The TGP was originally developed by Robert Connell and is a social structural theory based on existing theories that explain sexual inequality, gender, and power imbalances in different societies. Connell described gender-based attitudes and power structures based on three interlocked constructs: sexual 
division of labor, sexual division of power, and structure of cathexis (DiClemente, Crosby, \& Kegler, 2009). These constructs of TGP are described in greater detail in Table 1. These three categories explain how gender-based inequities and disparities exist in the society which limit women's earning potential, power in relationships, and control of resources such as property, choice of contraceptive methods, and access to care. These inequities and disparities act as exposures and make women vulnerable to several environmental and biological risk factors, which increase their susceptibility to STI/HIV.

Researchers have hypothesized the importance of power in sexual relationships (Emerson, 1962; Greer \& Bendersky, 2013) and identified many key factors using the TGP (Haberland, 2015; Raiford, Seth, \& DiClemente, 2013; Salud, Marshak, Natto, \& Montgomery, 2014). Several popular individual-level theoretical frameworks (Wilson et al., 2015) such as the AIDS Risk Reduction Model (Catania, Kegeles, \& Coates, 1990), the Information Motivation Behavioral Skills Model (Fisher \& Fisher, 1992), and the Multiple Domain Model (Xiao, Palmgreen, Zimmerman, \& Noar, 2010) have been used by researchers to plan their interventions. However, these individual-level behavioral theories cannot completely explain gender disparities in health outcomes, HIV status, and increased sexually risky behaviors among women due to their parsimonious approach. In contrast, the constructs from the TGP are broad and more inclusive and may be beneficial in studies about the effects of gender disparities in HIV transmission (Harvey, 2000). Though there are some targeted interventions that use the TGP to develop approaches for managing the impact of gender-based health disparities, such studies are relatively few (Moore, 2015; Robillard, 2012). Identifying and including these constructs in research will give more insight into the relationships among these variables. 


\section{Gender Roles}

Generally, gender roles are divided into two broad categories: traditional and nontraditional. Societies with traditional gender roles expect women to be physically, financially, and emotionally dependent on the male members of the society. Women who follow traditional gender norms tend to be more submissive, and have lower decision making power in their intimate relationships or domestic affairs (Husnu \& Mertan, 2015; McDermott \& Lopez, 2013; Mugweni, Pearson, \& Omar, 2012; Shen, Chiu, \& Gao, 2012; Swan \& O'Connell, 2012). These women are often expected to work more compared to males and experience disparity in wages (Ragins \& Winkel, 2011). In comparison, nontraditional gender roles would constitute lifestyle and responsibility sharing between male and female partners, which is generally uncommon in many societies; these roles include stay at home fathers, higher financial contribution to the family by a woman, role reversal in traditional care-giving positions and household work, etc. (Williams, Muller, \& Kilanski, 2012).

Religious, cultural and socioeconomic factors, education, history of childhood abuse, alcohol drinking habits of the intimate partner, and family structures affect the extent to which women accept or reject traditional gender roles (Leonard \& Quigley, 2016; Li et al., 2014; Osinde, Kaye, \& Kakaire, 2011; Richardson et al., 2014; Richter et al., 2014). The decision to accept or not accept these roles may have an impact on women's vulnerability to sexual risk.

\section{Risky Sexual Behaviors among Women and Youth in Haiti}

Several studies have reported higher prevalence of STIs among Haitian women when compared to men. This finding may be due to low condom use (4\%) by women as 
compared to men during higher-risk sex (WHO, 2013a). In a study conducted among 476 pregnant Haitian women, Fitzgerald and colleagues (2000) found that approximately $25 \%$ tested positive for trichomoniasis, $11 \%$ for chlamydia, $7 \%$ for syphilis, and $2 \%$ for gonorrhea. According to this study, 1 in every 2.5 women tested positive for at least one STI (Fitzgerald et al., 2000). Fawzi et al. (2003) conducted a similar study among 1,742 pregnant women who attended prenatal health clinics in the Central Plateau location in Haiti. In this study, approximately $13 \%$ tested positive for trichomoniasis, $6 \%$ had chlamydia and gonorrhea, and around 4\% were found positive for syphilis (Fawzi et al., 2003).

Adolescent girls who experience intimate partner violence or sexual violence are known to be at a higher risk of re-victimization (Lundgren \& Amin, 2015). Evidence from previous research has suggested that initiation of sexual activity among Haitian adolescents may begin as early as 13 years of age. In a study on sexual debut in Haiti, about $20 \%$ males and $12 \%$ females reported sexual intercourse before 15 years of age (UNAIDS/WHO 2006). Similarly, another study conducted among 200 Haitian adolescents showed that the mean age of first sexual activity was 13 years among males and 14.5 years for females. A study by Holschneider and Alexander (2003), which included 845 adolescents between 15-19 years and attending secondary school in Haiti, found that $58 \%$ of the participants were sexually active. Among the 490 participants who reported sexual activity, only $132(27 \%)$ reported condom use during their previous sexual encounters and, only $18 \%$ reported that they always used condoms during all their sexual encounters, thereby indicating the low levels of safe sexual practices and the 
relatively high risk of acquiring HIV/ STI among Haitian adolescents (Holschneider \& Alexander, 2003).

\section{Condom Use among Haitian Women}

Currently several gaps in knowledge have been identified with regards to safe sex practices among Haitian women: 1) limited research exists on the factors affecting condom use and condom use skills among Haitian women; 2) correlates of traditional gender roles and attitudes among Haitian women that may influence safe sex practices or perception of condom use as a convenient, safe, and reliable method for STI prevention are not studied in detail; and 3) despite a large number of condoms being distributed, their usage is limited (Brown, Brady, \& LeMay, 2013).

In Haiti, the total condom market distribution in the year 2011 by several NGOs was approximately 48.69 million, which was $7.1 \%$ higher than 2010 . This number translated to approximately 9.3 condoms per person per year among 15-49-year-old Haitians in 2011. However, actual condom use during high-risk sex in the Haitian population is significantly lower $($ Females $=43 \%$, Males $=47 \%)$ than this number would suggest, and varies across different regions within the country as well as by gender (Dévieux et al., 2015; Brown et al., 2013; United Nations Population Fund (UNFPA), 2011; WHO, 2013a).

In 2008, Haiti was sixth among countries in terms of aid received per capita; Haiti received approximately $10 \%$ of the total number of contraceptives, which included male condoms, which were provided to Latin America and the Caribbean regions (UNFPA, 2008). NGOs such as PSI/Haiti have either sold or distributed approximately 100 million male condoms and 300,000 female condoms since 1989. In 2015, approximately 200,000 
Haitian men were reached as part of a social marketing project to promote condom use (PSI, 2015). However, the actual number of Haitians who use condoms is significantly lower than would be expected based on the quantity that have been distributed. For example, only $19 \%$ of women aged between 15 to 24 years and $30 \%$ of men in the same age group used condoms during their last sexual encounter (Dévieux et al., 2015). Thus, the differences between the number of condoms allocated by health care agencies and the actual number of condoms put to use reflects gaps in knowledge and awareness about safe sex practices. These rates, however, are slightly better than several other countries with high prevalence of HIV, for example, $12 \%$ condom use in South Africa and $8 \%$ in Uganda (Maharaj, Neema, Cleland, Busza, \& Shah, 2012).

The 2012 Haiti Mortality, Morbidity, and Service Utilization Survey (EMMUSV) reported an increase in IPV from approximately $25 \%$ to $29 \%$ over a period of two years (Republique d'Haiti Ministère de La Santé Publique et de La Population (MSPP), 2012). Many participants in the survey reported that their first sexual encounter was forced. Although earlier studies have shown moderate increases in condom use over time, Haitian women often reported dissatisfaction with condoms, negative beliefs associated with condom use, such as those who use condoms indulge in illicit sexual behaviors, and condom use may result in harmful side effects resulting in poor health (Allman, Desse, \& Rival, 1985). This study also reported that condom use was adversely affected by traditional gender-based attitudes, such as associating condom use by women with illicit sexual behavior and perceiving condoms as a 'barrier/intruder' between a man and a woman. In addition, men exercised higher levels of control and decision making with regards to condom use or disuse compared to women (Allman et al., 1985). 
A similar study was conducted among 706 sexually active Haitian men enrolled from marginalized neighborhoods around Port-au-Prince (Boulos, Boulos, \& Nichols, 1991). These participants were interviewed to study and examine: attitudes and knowledge about condom use; efficiency of programs that distributed condoms for STI prevention; and programs that may increase or promote condom use in the Haitian community. Results from this study showed that although the participants were aware of the benefits of condom use, they were indifferent towards using this method for safe sex practices. The majority of the male participants who were opposed to condom use expressed the belief that only women should be responsible for contraception and family planning. Evidence from this study suggests that condom use is not popular in the Haitian population. Promoting condom use may have significant beneficial effects in terms of HIV/AIDS and STI prevention, which could be further enhanced by empowering women to make decisions about condom use. Increased communication about sex might also contribute to increased use of condoms with intimate partners (Kershaw, 2006; Magee et al., 2006).

Recent statistics from WHO show that young adult Haitian women are less likely to use condoms compared to men (WHO, 2013a). In a study that included non-pregnant Haitian women between the ages 15 and 49 years, condom use was estimated between six and ten percent (Couture, Soto, Akom, Joseph, \& Zunzunegui, 2010b; Desormeaux et al., 1996; Fawzi et al., 2005). Similar studies also showed that the frequency of condom use during the most recent sexual activity was significantly lower in women when compared to men (Conserve et al., 2016). The frequency of condom use in the general population was also very low, with about $36 \%$ of population using it with the most recent partner 
(Conserve et al., 2016). In another study, conducted among men who were expecting fathers, and enrolled from the rural parts of Haiti, it was found that only $32 \%$ reported condom use with their partners in the previous year (Magee et al., 2006).

These studies show that low condom use and traditional gender-based attitudes may be responsible for significantly higher levels of HIV/STI transmission in this population. Other significant factors that predict HIV/STI transmission include higher sexual self-efficacy (Holschneider \& Alexander, 2003), fewer barriers to using condoms (Holschneider \& Alexander, 2003), multiple sexual partners, and sexual initiation at a younger age (Carver et al., 2014; Dévieux et al., 2015; Fawzi et al., 2003; Fitzgerald et al., 2000).

\section{HIV/STI Knowledge}

In general, knowledge about HIV/STI transmission is low among Haitians. Data from 2007-2013 show that 35\% of Haitian females aged 15-24 years had comprehensive knowledge of preventing HIV transmission through sexual contact (e.g., using condoms, limiting sex to one faithful partner; WHO, 2013a). In the same sample, male participants scored $7 \%$ lower than females with regards to questions on HIV/STI knowledge, thereby indicating their lower awareness about the disease (WHO, 2013a). Irrespective of the low level of knowledge among female participants, it was also observed that they were more receptive to the knowledge given to them about condom use as an effective prevention method. This trend was also reported in recent studies along with improvement of knowledge about STI/HIV transmission among HIV+ and HIV- women (Dévieux et al., 2009; Kershaw, 2006). 


\section{The Role of Gender-based Attitudes in HIV Disease Transmission}

In a number of high prevalence pockets for HIV/STI and IPV in the Caribbean, South Africa, South Asia, and the U.S., traditional gender-based attitudes and relationship power-dynamics play significant roles in HIV/STI transmission among women.

However, there are very few studies conducted among the Haitian population that explored factors related to gender-related power imbalances to predict condom use, HIV/ STI acquisition, and risky sexual behaviors in addition to these traditional factors (Fawzi et al., 2003; Gage \& Suzuki, 2006; Gardella, 2006; Gomez, Speizer, \& Beauvais, 2009; Gupta, Small, \& Kershaw, 2009; Kershaw, 2006; Kershaw et al., 2006; Magee et al., 2006; Malow et al., 2013). These studies showed that women with traditional gender norms were at higher risk of acquiring STIs/HIV.

Women who were in a relationship with men who had traditional and rigid gender-based attitudes reported high prevalence of IPV, poor mental health, higher alcohol and substance use, inconsistent condom use, difficulty in performing daily work due to adverse physical conditions or symptoms, higher prevalence of STI/HIV as compared to those who were not in a relationship or had partners with non-traditional gender-based attitudes (Mulrenan et al., 2015; Rubens, McCoy, \& Shehadeh, 2014; Wechsberg et al., 2013; WHO, 2015a; Wingood \& DiClemente, 2000). Thus, there is limited utilization of constructs and predictors that incorporate gender-based attitudes to systematically explain HIV/STI transmission in Haiti.

Traditional gender norms and power imbalances in an intimate relationship may directly or indirectly influence risky sexual behaviors and increase the vulnerability to HIV/STI transmission (Zierler \& Krieger, 1997). Many HIV/STI prevention programs 
have tried to improve condom use skills and negotiation among women (Peasant, Sullivan, Weiss, Martinez, \& Meyer, 2016). These activities may favourably overcome the adverse effects of power imbalance between men and women with respect to condom use (Dunkle, Jewkes, Brown, Gray, et al., 2004; Dunkle, Jewkes, Brown, Yoshihama, et al., 2004; Dunkle et al., 2007; Dunkle et al., 2006).

It is culturally acceptable for men to have multiple partners in Haiti, therefore Haitian women have very little control over preventing these behaviors among their intimate partners. For example, previous studies have shown that $58 \%$ to $61 \%$ of Haitian men and women reported having multiple partners (Dévieux et al., 2009; Dévieux et al., 2013; Dévieux et al., 2015; Fawzi et al., 2003; Kershaw, 2006; Kershaw et al., 2006; Malow et al., 2013). These studies have reported that 33\% - 61\% of women who were monogamous believed that their partners had relationships with other women. Though these women were faithful toward their partners, they could not predict or control their partner's experimentation and sensation-seeking behavior.

After the earthquake, the economic conditions of many Haitians, especially women, deteriorated (Landry, O'Connell, Tardif, \& Burns, 2010). The Haitian population was already facing the burden of tuberculosis and the HIV/AIDS epidemic, and this tragedy pushed Haitian women into a spiral of poverty, social instability, stigmatization, and multiple partner relationships (Farmer, 1995, 1998; Hempstone, Diop-Sidibe, Lauredent, \& Heerey, 2004). In an economically disadvantaged Haitian society, women have limited opportunities for income autonomy. As a result, many women engage in transactional sexual relationships for money, food, shelter, or other means of support (Allen et al., 2013; Couture, Soto, Akom, Joseph, \& Zunzunegui, 2010a; Couture et al., 
2008; Gomez et al., 2009; Hunter, Reid-Hresko, \& Dickinson, 2011; Padilla, GuilamoRamos, Bouris, \& Reyes, 2010; Speizer, Beauvais, Gomez, Outlaw, \& Roussel, 2009). The economic dependence of women on men, worsened by the earthquake, may increase the power disparities in a relationship, thereby affecting a woman's ability to use condoms, resulting in higher prevalence of HIV/STIs (Farmer, 1995; Landry et al., 2010). Several studies have reported that Haitian women engage in transactional sexual relationships due to poor economic conditions. A study by Fitzgerald et al. (2000) among pregnant women who attended antenatal services in Haiti, reported that approximately $30 \%$ of the participants consented to an intimate sexual relationship to support their acute financial need. In Haiti, the term "plasaj," is used for cohabiting couples who are not married; as mentioned previously, women often engage in this type of relationship for economic stability, and through these relationships, may increase their vulnerability to STI/HIV (Devin \& Erickson, 1996; Maynard-Tucker, 1996; Purcell, 2012).

Many of the women in plasaj relationships experience abuse and uneven power dynamics due to their economic dependence, thus increasing their vulnerability for HIV/ STI acquisition (Fitzgerald et al., 2000). Fitzgerald et al., (2000) also reported these women are susceptible to poor decision-making about their physical and mental health. In his study, women involved in plasaj had six times higher risk of being infected with HIV compared to married women. Another study reported that such women had 3.5 times higher risk of forced sex by their partners (Fawzi et al., 2005). Evidence from another study in South Africa has also shown that there is a strong association between IPV, forced sex, transactional sex, and HIV acquisition risk (Dunkle et al., 2007). 
After acquiring HIV, women face several additional threats to their mental and physical health. Studies from around the world have reported increased frequency of intimate partner sexual violence (IPSV), further deterioration in economic conditions, and poor adherence to antiretroviral therapy (ART) after getting HIV (Bagwell-Gray, Messing, \& Baldwin-White, 2015; Lopez, Jones, Villar-Loubet, Arheart, \& Weiss, 2010; Meade, Hansen, Kochman, \& Sikkema, 2009). These studies have also identified that such disparities in health and high HIV transmission rates among women are due to complex sociocultural factors such as traditional gender roles, reliance on male partners for income and support, gender-based power imbalance in heterosexual relationships, poor decision-making about safe sex, and the reluctance of men to use condoms to prevent STIs (Dévieux, Jean-Gilles, Rosenberg, et al., 2016; Richardson et al., 2014; Rosenberg \& Malow, 2009; Wyatt et al., 2013). This uncertainty about income, food, and structural support may promote dependence on plasaj relationships or transactional sex and reduce condom negotiation power (Dévieux, Jean-Gilles, Rosenberg, et al., 2016; Li et al., 2014; Tsai \& Weiser, 2014).

A study by Kershaw (2006) reported that the majority of women felt that they had less decision-making power than men. Approximately $86 \%$ felt that the decision to use a condom was made by their male partners; $92 \%$ reported that they felt that overall power in a relationship rested with men; and not a single female respondent believed that men had less power than they did in their relationship. These findings indicate the strong relationship between power disparities and potential vulnerabilities. 


\section{IPV and HIV Susceptibility}

Haitian women face very high rates of lifetime IPV, which ranges between $16 \%$ 54\%, and is greater than many other Caribbean nations. (Fawzi et al., 2003; Gage, 2005; Gage \& Hutchinson, 2006; C. Garcia-Moreno et al., 2006; Kishor \& Johnson, 2006; Silverman, Decker, Kapur, Gupta, \& Raj, 2007). These studies have also identified that such disparities in health and high HIV transmission rates among women are due to complex sociocultural factors such as traditional gender roles, reliance on male partners for income and support, gender-based power imbalance in heterosexual relationships, poor decision-making about safe sex, and reluctance to use condoms (Dunkle et al., 2007; Durevall \& Lindskog, 2015; Richter et al., 2014). However, very few studies conducted in Haiti studied the association between IPV, power imbalance, condom use, and HIV transmission risk (Kershaw et al., 2006).

A cross-sectional study by Kershaw (2006) in rural regions of Haiti among 200 pregnant women who attended a prenatal care clinic in their community examined the association between IPV, condom use, risky sexual behavior, HIV knowledge, imbalance of power, and demographic variables in an intimate relationship. Evidence from this study suggested that lower condom use in the past and intentions to use condoms in the future were adversely affected by decreased power in an intimate relationship. A history of IPV was also found to predict STI infection diagnosis in the sample. The researchers suggested that protective sexual behaviors, such as condom use, may be low due to violence-related anxiety about making requests to use condoms and that this fear could potentially increase during pregnancy, as violence may lead to stillbirths, miscarriage, or other pregnancy-related complications (Silverman et al., 2007). 
A similar study by Fawzi et al. (2005) investigated the correlates of forced sex among 749 pregnant women who were recruited from rural health centers in Haiti. This study reported a very high prevalence of forced sex; one in two women had experienced such events in their relationships. The likelihood of experiencing forced sex was predicted by the length of relationship suggesting that men in long-term relationships were more likely to abuse their female partners.

Research shows that traditional gender roles promoting the idea of masculine dominance often result in a higher occurence of IPV (Abrahams, Jewkes, Laubscher, \& Hoffman, 2006; Gage \& Hutchinson, 2006; Santana, Raj, Decker, La Marche, \& Silverman, 2006). Women who have experienced such dominant partners, and who are also victims of IPV, had a higher susceptibility to HIV infection and transmission (Fawzi et al., 2005). For example, among a sample of female PLWH in the U.S., $25 \%$ had experienced IPV in their adulthood and about $10 \%$ reported severe forms of IPV, such as physical abuse during pregnancy, as compared to HIV- women (Brezing, Ferrara, \& Freudenreich, 2015; Villar-Loubet et al., 2014). Women with a history of STI or STIrelated symptoms also reported a $3 \%$ higher incidence of forced sex when compared to those who did not experience forced sex in their intimate relationship. Women in abusive relationships also reported less access to healthcare services, condoms, and treatment alternatives (Fawzi et al., 2005). Thus, traditional gender norms and IPV have farreaching effects on HIV susceptibility and access to health care services.

\section{Intimate Partner Sexual Violence}

Globally, approximately $35 \%$ of women have reported that they experienced IPV and intimate partner sexual violence (IPSV) at least once in their lifetime (García- 
Moreno, 2013; Garcia-Moreno, Jansen, Ellsberg, Heise, \& Watts, 2006; WHO, 2005b). Annually, it is estimated that on average $2 \%-12 \%$ of women experience IPV globally (García-Moreno, 2013; Claudia Garcia-Moreno et al., 2006; WHO, 2005b). In the U.S., the estimated prevalence of IPV is approximately 5.9\% (Black et al., 2011; Claudia Garcia-Moreno et al., 2006; Tjaden \& Thoennes, 2006; Walters, Chen, \& Breiding, 2013; Walton-Moss, Manganello, Frye, \& Campbell, 2005). IPSV is a subset of IPV (Saltzman, Fanslow, McMahon, \& Shelley, 1999) and the prevalence ranges between 28\% - 68\%, following episodes of IPV (Eby, Campbell, Sullivan, \& Davidson, 1995; Jina \& Thomas, 2013; McFarlane et al., 2005; Ullman \& Sigurvinsdottir, 2015; Zhang et al., 2012). IPSV has been found to be correlated with higher levels of depression, anxiety and suicidal tendencies (Maddoux et al., 2014; McCall-Hosenfeld, Winter, Heeren, \& Liebschutz, 2014).

Even though IPSV is often associated with IPV, it is seldom reported in studies examining IPV and sexual violence. Studies have often included IPSV under the umbrella term IPV without isolating the specific domains and correlates of IPSV (Campbell, Dworkin, \& Cabral, 2009). This lack of specificity is also complicated by the fact that victims of sexual violence or assault do not report IPSV occurring in an intimate relationship. Thus, there is a need to explore the factors associated with IPSV in countries such as Haiti, where traditional gender-based norms and attitudes are common in the general population.

\section{IPV, History of Childhood Sexual Abuse and HIV}

Childhood sexual abuse (CSA) is, "any interaction between a child and an adult or older child in which the child is used for the sexual stimulation of the perpetrator or an 
observer. Sexual abuse often involves direct physical contact, touching, kissing, fondling, rubbing, oral sex, or penetration of the vagina or anus. Sometimes a sex offender may receive gratification just by exposing himself to a child, or by observing or filming a child removing his or her clothes. Offenders often do not use physical force, but may use play, deception, threats, or other coercive methods to engage youngsters and maintain their silence" (National Child Traumatic Stress Network (NCTSN), 2015; World Health Organization (WHO), 1999).

Recently, a survey was conducted in seven countries to study the prevalence of sexual violence against children (Sumner, Mercy, et al., 2015). This study reported that among Haitian females aged 18-24 years, $6 \%-11 \%$ of the participants reported unwanted sex before the age of 18 years. The study emphasized that victims of childhood sexual violence are at a significantly higher risk for adverse health outcomes, such as poor mental health and chronic diseases.

Several studies have demonstrated the link between CSA and negative outcomes, including mental health impacts, and IPV. For example, in a study among women who experienced abuse as a child or an adult, these individuals were 4-7 times more likely to report mood disorders and psychosis when compared to women who did not experience abuse, after adjusting for socioeconomic status, age motherhood and personality traits (Ouellet-Morin et al., 2015). In a Peruvian study among 1500 pregnant women, it was observed that childhood abuse was significantly associated with higher levels of IPV (Barrios et al., 2015). Childhood abuse was also associated with higher odds of poor health and depressive disorders. 
Among persons who have been victims of CSA, the literature shows there is a 1.5-2 times greater likelihood of becoming infected with HIV when compared to participants who do not have a history of CSA; the association is stronger among women (Jones et al., 2010; McCauley et al., 1997; O'Cleirigh, Safren, \& Mayer, 2012; Parcesepe et al., 2015; Pence et al., 2012; Sikkema et al., 2013; Whetten et al., 2006). These findings demonstrate the increased vulnerability to physical and mental sequelae among women who have experienced CSA and indicates a strong need for studies to examine these impacts, particularly in countries such as Haiti that have been understudied.

\section{Adherence to Antiretroviral Drugs and IPV}

Long-term management and good prognosis in HIV infection require at least $90 \%$ adherence to ART (Harrigan et al., 2005). Lower adherence may lead to higher viral loads and a higher risk of transmitting the infection to partners (Bangsberg et al., 2000; Berg et al., 2004; García et al., 2002; Gardner et al., 2008; Lopez et al., 2010). In societies where traditional gender norms are held, researchers have reported poor disclosure of HIV status to intimate partners and poor treatment adherence; traditional gender norms and IPV appeart to act as barriers against effectve treatment and follow-up (Arnsten et al., 2002; Berg et al., 2004; Malow et al., 2013; Tapp et al., 2011; Turner, Laine, Cosler, \& Hauck, 2003).

For example, a behavioral study conducted in Haiti about the factors and correlates of treatment non-adherence found that female participants were half as likely to report their HIV serostatus to their partners when compared to male participants; anxiety associated with physical abuse and financial implications deterred female PLWHs from disclosing their HIV positive status to the partners (Fitzgerald, Maxi, Marcelin, Johnson, 
\& Pape, 2004). Similar findings were also observed in several studies across different regions (Karamagi, Tumwine, Tylleskar, \& Heggenhougen, 2006; Kiarie et al., 2006; Urassa, Gosling, Pool, \& Reyburn, 2005). Though there are several studies on treatment adherence among Haitian women, they do not fully investigate details of gender norms and power dynamics. This gap in the literature may be filled by conducting a longitudinal study, and examining the effect of traditional gender norms and IPV on treatment adherence.

\section{Alcohol Use and IPV}

It is estimated that approximately $38 \%$ of the adult population across the globe consumed alcohol in the year 2014; alcohol was responsible for 3.3 million deaths in that year (WHO, 2015b). Apart from morbidity and mortality, alcohol consumption is responsible for many physical and mental disabilities and socioeconomic problems such as depression and low income due to alcohol related poor health conditions (Crane, Godleski, Przybyla, Schlauch, \& Testa, 2015; Devries et al., 2014; WHO, 2015b). In Haiti, the average alcohol consumption was 5.2 liters per person per year in the population over 15 years old (WHO, 2005a). Dévieux and colleagues reported that the study sample drank about $13.4(S D=16)$ ounces on an average upon last drinking experience (Dévieux et al., 2013). Another study done among Haitian PLWH have shown high levels of experimentation with alcohol use and higher levels of alcohol consumption (Dévieux et al., 2009). These studies also showed that alcohol consumption was associated with increased risky sexual behaviors, higher HIV transmission risk and higher levels of violence. (Dévieux et al., 2013; Dévieux et al., 2015; Gage \& Suzuki, 2006; Malow, Rosenberg, \& Dévieux, 2009; Malow, Stein, et al., 2009). 
In a study done by Dévieux and colleagues, HIV+ participants scored on an average $13(S D=16)$ on the Alcohol Use Disorders Identification Test (AUDIT; a total score of $\geq$ eight on the AUDIT suggests potential hazardous drinking) as well as CAGE questionnaires, indicating high prevalence of alcohol use problems in this population (Dévieux et al., 2013). A recent study conducted among 258 Haitians (females=62\%) showed that $51 \%$ of the participants lived with alcohol consumers and $67 \%$ reported that their partner consumed alcohol (Conserve, King, Dévieux, Jean-Gilles, \& Malow, 2014). Several studies have shown a strong relationship between alcohol consumption in higher quantities and IPV (Bellis et al., 2015; Choenni, Hammink, \& van de Mheen, 2015; Cunradi, Todd, \& Mair, 2015; Fromme, Katz, \& D'Amico, 1997; Jewkes, 2002; Klostermann \& Fals-Stewart, 2006; Leadley, Clark, \& Caetano, 2000; Leonard, Bromet, Parkinson, Day, \& Ryan, 1985; WHO, 2010), thus exposing women to higher risk if they are living with a partner who has unhealthy drinking behavior. Consuming alcohol by an intimate partner has also been found to be a significant predictor of IPV and HIV transmission among women in several Haitians studies (Gage, 2005; Gage \& Hutchinson, 2006; WHO, 2015b). There is limited knowledge, however, about the association between alcohol use problems and severity of IPV; several public health researchers have opined that further research is needed regarding these associations (Hoaken, Assaad, \& Pihl, 1998; Rehm et al., 2010; Topalli et al., 2014).

Most of the studies that reported an association between alcohol use problems and IPV were cross-sectional studies (de Bruijn \& de Graaf, 2016; Leonard \& Quigley, 2016; Wagman et al., 2016; Wathen, MacGregor, \& MacQuarrie, 2016). Several longitudinal studies were identified that assessed temporality, and that reported a strong association 
between alcohol use problems and subsequent IPV (Buzy et al., 2004; Chen \& White, 2004; Foshee, Benefield, Ennett, Bauman, \& Suchindran, 2004; Gilbert, El-Bassel, Chang, Wu, \& Roy, 2012; Martino, Collins, \& Ellickson, 2005; Temple, Weston, Stuart, \& Marshall, 2008; Testa, Livingston, \& Leonard, 2003). Thus, alcohol use problems adversely affect IPV and may be further complicated by its associations with GBAs.

\section{IPV and Mental and Physical Health}

IPV significantly affects mental health and the general wellbeing of women (Salom, Williams, Najman, \& Alati, 2015). IPV is associated with major depressive disorders, posttraumatic stress disorders, anxiety, substance use, personality disorders, and somatoform disorders (Salom et al., 2015). A study conducted in Rwanda (Umubyeyi, Mogren, Ntaganira, \& Krantz, 2014) showed that the prevalence of mental disorders such as depression, suicide, and PTSD was significantly different between men and women who were in a violent relationship. Female participants who experienced IPV reported prevalence levels of depression, suicide, and PTSD that was more than twice that of the level among men (Umubyeyi et al., 2014).

It has been observed that the severity of many mental disorders increases with the increasing levels of violence experienced by the victims; these effects were particularly significant for PTSD (Ferrari et al., 2016; Kamimura, Christensen, Tabler, Ashby, \& Olson, 2014). Women who experienced severe forms of IPV in the previous year reported significantly higher levels of PTSD symptoms when compared to those who had not experienced IPV (McCall-Hosenfeld et al., 2014).

A study by Alhusen, Frohman, and Purcell (2015) among 166 pregnant women in the U.S. showed that the risk for suicidal ideation was nine times higher in participants 
who experienced IPV when compared to those who did not experience IPV. Research conducted in developing countries also showed similar trends. In another study in Malawi, Stewart, Umar, Tomenson, and Creed (2014a, 2014b), showed that mental health problems were significantly associated with IPV experiences and social support variables acted as moderators in this relationship. Thus there is a strong association between experiences of IPV and adverse physical and mental health outcomes. Further studies are justified in this direction to better understand the underlying complexities in these associations.

\section{Effect of Intimate Partner Violence (IPV) on Depression in Women}

In the U.S., African-American women have consistently been shown to have higher rates of IPV as compared to other ethnicities. Sabri and colleagues (2013) in their study assessed whether types and severity of IPV was associated with presence of depression and PTSD among African-American women with IPV experiences. The results of the study showed that $34.1 \%$ of the participants reported depression symptoms. Amongst the IPV types physical and psychological violence were seen to be significantly associated with mental health problems and severity of IPV experiences was observed to be directly proportional to the risk for developing depression and PTSD (Sabri et al., 2013).

Although African American women have a high prevalence of IPV, they have a lower demonstrated risk of depression and other psychiatric disorders as compared to their white women counterparts. In a cross-sectional study, 2414 young African American, Hispanic, and white women were surveyed regarding depression, PTSD symptoms, IPV, and trauma. In the study, $29 \%$ of white women reported depression 
symptoms as compared to $23 \%$ of Hispanic and 22\% of African American women (Hirth \& Berenson, 2012).

The relationship of intimate partner violence and depression was studied in a sample of pregnant women by Kornfeld, Bair-Merritt, Frosch, and Solomon (2012). They enrolled 173 mothers to complete at least one postpartum depression and intimate partner violence screening survey. Amongst the participating mothers $26 \%$ were positively screened for postpartum depression and $7 \%$ screened positive for intimate partner violence. Overall, $60 \%$ of post-partum depression could be attributed to IPV, as $60 \%$ of mothers who screened positive for intimate partner violence also had postpartum depression symptoms (Kornfeld et al., 2012).

In a longitudinal study, more than 600 rural Bangladeshi women were followed up from the last trimester of pregnancy to 6-8 months postpartum to assess the effect of IPV on post-partum depression. Eighteen percent of women reported physical violence by their partner during pregnancy, while, majority of the women (52\%) were subjected to physical abuse within 6-8 months after childbirth. Women who reported poor relationships with their husbands were found to have five-fold more likelihood (OR: 4.95, CI: 2.55-9.62) of post -partum depressive symptoms compared to women with good spousal relationships. Women who reported physical IPV after childbirth in comparison to those who did not report physical IPV, were nearly three times more likely to manifest depressive symptoms 6-8 months after childbirth. Consistent with the findings of Sabri et al (2013) physical violence was found to be significantly associated with post-partum depression and violence by an intimate partner was not found to be of statistical significance (Kabir, Nasreen, \& Edhborg, 2014). Research also shows that IPV during 
pregnancy causes antenatal depressive symptoms that act as mediator for post-natal depression as well as mother-to-infant bonding failure (Kita, Haruna, Matsuzaki, \& Kamibeppu, 2016).

Research has also focused on the confounding factors that might overestimate the relationship of depression and IPV. Ouellet-Morin et al. (2015) in a recently concluded longitudinal study were able to show a significant association between IPV and depression in women while controlling for various confounding variables. The study results revealed that women with IPV experiences have two times more risk for developing depression even after controlling for confounders such as childhood maltreatment, socioeconomic deprivation, antisocial personality, and young motherhood. The study also showed that association between IPV and depression is long lasting, women with IPV were more likely to report new-onset depression not only in the immediate period but also up till two years later (Ouellet-Morin et al., 2015).

Although IPV is usually independently associated with depression, there are measures, along with early detection and management that can result in better outcomes. Social support is a major factor in this regard. A study evaluated the relationship between intimate partner abuse, sense of belongingness, and depressive symptoms in 71 female patients visiting primary care (Chang, Kahle, \& Hirsch, 2015). As expected, IPV was found to be associated with increased depressive symptoms. Further investigation using mediation analyses established a strong convergent support for a model in which loss of belongingness act as a mediator for the effect of IPV on depressive symptoms, and this mediation effect remained significant even after controlling for content overlap between measures of belongingness and depressive symptoms (Chang, Kahle, \& Hirsch, 2015). 


\section{Effect of Intimate Partner Violence (IPV) on Anxiety in Women}

Anxiety is commonly associated with IPV. Literature searches for studies focusing on anxiety in IPV revealed that IPV was not the sole focus of investigation in the relevant studies and was investigated along with other mental health problems such a PTSD and depression. Statistics show that anxiety is responsible for $27 \%$ of all IPV disease burden and it is only second to depression which is attributable for almost $50 \%$ of the disease burden (Dillon, Hussain, Loxton, \& Rahman, 2013).

Anxiety is usually co-morbid with depression. In a cross-sectional study, 376 pregnant women were screened for presence of domestic violence based on Hurt, Insulted, Threaten, Scream (HITS) inventory and anxiety and depression using the Hospital Anxiety and Depression Scale questionnaire (HADS). Domestic violence was experienced by $30.6 \%$ of women with $25.2 \%$ suffering from physical abuse. Findings from the study depicted that $63 \%$ of women exhibited anxiety and depression simultaneously and $11.4 \%$ had only anxiety, while depression alone was found in $10.4 \%$ of the women (Abdelhai \& Mosleh, 2015).

In congruence with these results, a household survey conducted in Tehran showed much higher rates for anxiety as compared to depression reported as $15.3 \%$ and $32.7 \%$ respectively in married women. The survey also showed that prevalence of physical and non-physical violence was $35.1 \%$ and $77.2 \%$ respectively. It was also found that the women who suffered from any form of domestic violence were 5 times more likely to present with symptoms of depression and 3 times more likely to report anxiety symptoms. (Ahmadzad-Asl, Davoudi, Zarei, Mohammad-Sadeghi, \& Rasoulian, 2016). 
A cross section study of pregnant women in Nigeria showed that more than $1 / 3 \mathrm{rd}$ $(36.7 \%)$ pregnant women reported intimate partner violence within the previous 12 months, $15.5 \%$ women had depression symptoms and $5.6 \%$ had anxiety. The proportion of anxiety and depression symptoms in this study sample is in conflict with other research which show a higher proportion of anxiety symptoms as compared to depression symptoms. Another interesting finding from the study was that women in violent intimate relationships were 10 times more likely to report being depressed and 17 times more likely to report anxiety symptoms as compared to women who were not in a violent relationship (Mapayi et al., 2013). Oliveira Fonseca and colleagues (2014) in their research cited four cross sectional studies that explored the relationship between IPV and anxiety symptoms occurring during pregnancy. These studies were done in Tanzania, Portugal, Bangladesh and South Africa. Findings from these studies revealed that anxiety symptoms were specifically associated with physical IPV in Bangladesh; psychological and sexual IPV in South Africa; physical and sexual IPV in Tanzania; and all three types of intimate violence in Portugal.

IPV victimization in women suffering from anxiety and post-traumatic stress disorder (PTSD) has also been strongly associated with substance use disorders and alcohol related problems. Jaquier, Flanagan, and Sullivan (2015) based on evidence from past research, tested the hypothesis that different types of IPV including psychological, physical, and sexual IPV are differentially related to substance abuse and alcohol problems and they explored this association through anxiety and PTSD symptom severity among 143 community women presently experiencing IPV. The study results, consistent with previous research, showed a higher prevalence for anxiety symptoms, $42 \%$, and a 
lower, $18.9 \%$, for depression. In the study sample $68.5 \%$ of women met criteria for problematic alcohol use, and $64.3 \%$ for drug use problems. Two types of IPV variables, i.e., psychological and physical variables, were found to be significantly associated with drug and alcohol misuse ( $\mathrm{p}<0.05)$; sexual IPV was not found to be associated with alcohol problem and had a weak association with substance misuse $(p<.10)$ correlated with drug problems (Jaquier et al., 2015).

Researchers presented plausible explanation for relationship of women sufferers of physical and psychological IPV, anxiety symptoms and alcohol and drug misuse, based on the tension- reduction theory, first put forward by Conger in 1956, and a more recent self -medication theory. The study postulated that the IPV victim women indulge in problematic alcohol and drug use as a way of coping and reducing tension of symptoms of anxiety and stress due to physical and psychological IPV (Jaquier et al., 2015).

Another study that found a statistically significant association between symptoms of anxiety and smoking $(p<0.012)$ in women reporting IPV supported the explanation from the aforementioned research and similarly attributed smoking and anxiety relationship to a surviving behavior of women to alleviate their anxiety symptoms (Zacarias, Macassa, Soares, Svanström, \& Antai, 2012).

As already observed with depression, social attachment and support was found to have a protective effect from anxiety symptoms in IPV victims. Women who possess a support system in form of friends and family reportedly had more self-esteem and were better equipped to cope with the stress of depressive and anxiety symptoms (Zacarias et al., 2012). 
Furthermore, research has also identified two other factors: age $(\mathrm{p}=0.01)$ and education ( $\mathrm{p}=0.001$ ) as statistically significant predictors of the score for symptoms of anxiety in women in a violent relationship. Thus, the higher the age and education level of the women, the lower are the score for symptoms of anxiety (de Oliveira FonsecaMachado, dos Santos Monteiro, Haas, de Vilhena Abrão, \& Gomes-Sponholz, 2015).

\section{Summary}

Evidence shows an increase in the prevalence of HIV, despite declining incidence, due to increasing survival rates. Data from previous studies suggest the use of socio-demographic predictors to evaluate risky sexual behaviors provides modest but inconsistent results; these results would likely be improved by including variables that reflect gender-based attitudes. The Theory of Gender and Power guides the current study, since sexual inequality, gender, and power imbalances may add to the understanding of factors important in sexual behaviors and outcomes in Haiti. Such disparities in health and high HIV transmission rates among women are due to complex sociocultural factors such as traditional gender roles, reliance on male partners for income and support, gender-based power imbalances in heterosexual relationships, poor decision-making about safe sex, and the reluctance of men to use condoms to prevent STIs. The higher prevalence of STIs among Haitian women when compared to men might be explained by differences in power, early experiences of IPV, sexual violence, early sexual debut, low condom use, and low knowledge. These factors have resulted in increased frequency of IPSV, further deterioration in economic conditions, and poor adherence to ART after getting HIV. Moreover, several studies have demonstrated the link between CSA and negative outcomes including mental health impacts and IPV; among victims of CSA, 
there is a greater likelihood of becoming infected with HIV when compared to participants who do not have a history of CSA, especially among women. Since traditional gender norms and IPV appear to act as barriers to protective behaviors, the studies that follow investigate these relationships in samples of Haitian women. 
Table 2.1. Proposed model conceptualizing the influence of the theory of gender and power on women's health

\begin{tabular}{|c|c|c|c|c|c|c|}
\hline Societal Level & $\begin{array}{c}\text { Institutional } \\
\text { Level }\end{array}$ & $\begin{array}{c}\text { Social } \\
\text { Mechanisms }\end{array}$ & Exposures & Risk Factors & $\begin{array}{c}\text { Biological } \\
\text { Factors }\end{array}$ & Disease \\
\hline $\begin{array}{l}\text { Sexual division } \\
\text { of labor }\end{array}$ & $\begin{array}{l}\text { Work site, } \\
\text { school, family }\end{array}$ & $\begin{array}{l}\text { Manifested as } \\
\text { unequal pay } \\
\text { produces } \\
\text { economic } \\
\text { inequities for } \\
\text { women }\end{array}$ & $\begin{array}{l}\text { Economic } \\
\text { Exposures }\end{array}$ & $\begin{array}{l}\text { Socioeconomic } \\
\text { risk factors }\end{array}$ & & \\
\hline $\begin{array}{l}\text { Sexual division } \\
\text { of power }\end{array}$ & $\begin{array}{l}\text { Relationships, } \\
\text { medical system, } \\
\text { media }\end{array}$ & $\begin{array}{l}\text { Manifested as } \\
\text { imbalances } \\
\text { in control } \\
\text { produce } \\
\text { inequities in } \\
\text { power for } \\
\text { women }\end{array}$ & $\begin{array}{l}\text { Physical } \\
\text { exposures }\end{array}$ & $\begin{array}{l}\text { Behavioral risk } \\
\text { factors }\end{array}$ & $\begin{array}{l}\text { Anatomical } \\
\text { features } \\
\text { Genetic } \\
\text { determination } \\
\text { Hormones }\end{array}$ & HIV \\
\hline $\begin{array}{l}\text { Cathexis: } \\
\text { social norms } \\
\text { and affective } \\
\text { attachments }\end{array}$ & $\begin{array}{l}\text { Relationships, } \\
\text { family, church }\end{array}$ & $\begin{array}{l}\text { Manifested as } \\
\text { constraints } \\
\text { in expectations } \\
\text { produce } \\
\text { disparities in } \\
\text { norms for } \\
\text { women }\end{array}$ & $\begin{array}{l}\text { Social } \\
\text { exposures }\end{array}$ & $\begin{array}{l}\text { Personal risk } \\
\text { factors }\end{array}$ & & \\
\hline
\end{tabular}

NOTE: The public health level includes exposures, risk factors, biological factors, and disease. The social/behavioral sciences level includes risk factors, biological factors, and disease. The medical level includes biological factors and disease.

The table is reproduced from Wingood et al. (Wingood, DiClemente, DiClemente, Crosby, \& Kegler, 2002) 
Table 2.2. Independent and dependent measures/variables identified from the structures of TGP

Outcome Variables

1. Major IPV

2. HIV+ status ${ }^{\mathrm{a}}$

3. Risky sexual behavior ${ }^{\mathrm{b}}$

Exposure variables

1. Social norms

1.1. gender based attitudes (WHO, 2013b) ${ }^{\mathrm{a}}$

1.2. domestic violence questionnaire (WHO, 2005b) ${ }^{\mathrm{b}}$

1.3. sexuality related measures (Davis, Yarber, \& Bauserman, 1998) ${ }^{\mathrm{b}}$

1.4. resources available for women (education, work, nursing care, etc.) ${ }^{\mathrm{a}, \mathrm{b}}$

2. Inequity of power

2.1. prevalence of physical and sexual abuse $e^{\mathrm{a}, \mathrm{b}}$

2.2. miscarriages due to abuse ${ }^{\mathrm{a}}$

2.3. social support after domestic violence ${ }^{\mathrm{a}}$

2.4. income of partner ${ }^{\mathrm{a}, \mathrm{b}}$

2.5 employment status ${ }^{\mathrm{a}, \mathrm{b}}$

2.6. partner's view on working women ${ }^{\mathrm{a}}$

2.7. controlling behavior of intimate partner ${ }^{\mathrm{a}}$

2.8. power equity related to gender in relationships (Pulerwitz, Gortmaker, \& DeJong, 2000) ${ }^{\mathrm{b}}$

3. Inequity at work

3.1. differences in income ${ }^{\mathrm{b}}$

3.2. health insurance status ${ }^{\mathrm{b}}$

3.3. education status $\mathrm{a}^{\mathrm{a}, \mathrm{b}}$

4. Substance abuse (ASI; McLellan et al., 1980) ${ }^{\mathrm{a}, \mathrm{b}}$

5. Depression and mental health, DSM-V (APA, 2013; WHO, 2005b)

6. The State-Trait Anxiety Inventory (Spielberger, 1983) ${ }^{\mathrm{b}}$

7. Alcohol use: AUDIT (Saunders, Aasland, Babor, Grant, \& others, 1993)

8. Drug and Sexual Risk Behavioral Assessment (CDC, 2013)

9. Childhood sexual abuse ${ }^{\mathrm{a}, \mathrm{b}}$

10. General Health, Mental Health, and Daily Activities ${ }^{b}$

11. Partner support ${ }^{\mathrm{b}}$

12. Demographics $\mathrm{a}, \mathrm{b}$

a: Parent study - 1; b: Parent study - 2 


\section{References}

Abdelhai, R., \& Mosleh, H. (2015). Screening for antepartum anxiety and depression and their association with domestic violence among Egyptian pregnant women. The Journal Of The Egyptian Public Health Association, 90(3), 101-108.

Abrahams, N., Jewkes, R., Laubscher, R., \& Hoffman, M. (2006). Intimate partner violence: prevalence and risk factors for men in Cape Town, South Africa. Violence and Victims, 21(2), 247-264.

Ahmadzad-Asl, M., Davoudi, F., Zarei, N., Mohammad-Sadeghi, H., \& Rasoulian, M. (2016). Domestic violence against women as a risk factor for depressive and anxiety disorders: findings from domestic violence household survey in Tehran, Iran. Archives of Women's Mental Health, 1-9.

Alhusen, J. L., Frohman, N., \& Purcell, G. (2015). Intimate partner violence and suicidal ideation in pregnant women. Archives of Women's Mental Health, 18(4), 573-578.

Allen, C. F., Edwards, P., Gennari, F., Francis, C., Caffe, S., Boisson, E., . . . Jack, N. (2013). Evidence on Delay in Sexual Initiation, Multiple Partnerships and Condom Use among Young People: Review of Caribbean HIV Behavioural Studies. West Indian Medical Journal, 62(4), 292-298.

Allman, J., Desse, G., \& Rival, A. (1985). Condom use in Haiti. Paper presented at the Center for Population and Family Health, New York.

American Psychiatric Association (APA). (2013). Diagnostic and statistical manual of mental disorders (DSM - 5). American Psychiatric Pub.

American Psychiatric Association. (APA; 2013). Diagnostic and statistical manual of mental disorders (DSM-5). American Psychiatric Pub.

Arnsten, J. H., Demas, P. A., Grant, R. W., Gourevitch, M. N., Farzadegan, H., Howard, A. A., \& Schoenbaum, E. E. (2002). Impact of Active Drug Use on Antiretroviral Therapy Adherence and Viral Suppression in HIV-infected Drug Users. Journal of General Internal Medicine, 17(5), 377-381.

Bagwell-Gray, M. E., Messing, J. T., \& Baldwin-White, A. (2015). Intimate Partner Sexual Violence: A Review of Terms, Definitions, and Prevalence. Trauma Violence Abuse, 16(3), 316-335.

Bangsberg, D. R., Hecht, F. M., Charlebois, E. D., Zolopa, A. R., Holodniy, M., Sheiner, L., . . Moss, A. (2000). Adherence to protease inhibitors, HIV-1 viral load, and development of drug resistance in an indigent population. AIDS, 14(4), 357-366. 
Barrios, Y. V., Gelaye, B., Zhong, Q., Nicolaidis, C., Rondon, M. B., Garcia, P. J., . . . Williams, M. A. (2015). Association of childhood physical and sexual abuse with intimate partner violence, poor general health and depressive symptoms among pregnant women. PloS One, 10(1), e0116609.

Bellis, M. A., Quigg, Z., Hughes, K., Ashton, K., Ferris, J., \& Winstock, A. (2015). Harms from other people's drinking: an international survey of their occurrence, impacts on feeling safe and legislation relating to their control. BMJ Open, 5(12), $\mathrm{e} 010112$.

Berg, K. M., Demas, P. A., Howard, A. A., Schoenbaum, E. E., Gourevitch, M. N., \& Arnsten, J. H. (2004). Gender differences in factors associated with adherence to antiretroviral therapy. Journal of General Internal Medicine, 19(11), 1111-1117.

Black, M. C., Basile, K. C., Breiding, M. J., Smith, S. G., Walters, M. L., Merrick, M. T., \& Stevens, M. R. (2011). National intimate partner and sexual violence survey. Atlanta, GA: Centers for Disease Control and Prevention, 75.

Boulos, M. L., Boulos, R., \& Nichols, D. J. (1991). Perceptions and practices relating to condom use among urban men in Haiti. Studies in Family Planning, 22(5), 318325.

Brezing, C., Ferrara, M., \& Freudenreich, O. (2015). The syndemic illness of HIV and trauma: implications for a trauma-informed model of care. Psychosomatics, 56(2), 107-118.

Brown, E., Brady, C., \& LeMay, V. (2013). Measuring the Total Condom Market in the Caribbean: Insights and Findings from the CARISMA programme. Retrieved from https://cnaablog.files.wordpress.com/2013/03/measuring-the-tcm-in-thecaribbean-final-report.pdf

Buzy, W. M., McDonald, R., Jouriles, E. N., Swank, P. R., Rosenfield, D., Shimek, J. S., \& Corbitt-Shindler, D. (2004). Adolescent girls' alcohol use as a risk factor for relationship violence. Journal of Research on Adolescence 14(4), 449-470.

Campbell, R., Dworkin, E., \& Cabral, G. (2009). An ecological model of the impact of sexual assault on women's mental health. Trauma Violence Abuse, 10(3), 225246.

Carver, J. W., Dévieux, J. G., Gaston, S. C., Altice, F. L., \& Niccolai, L. M. (2014). Sexual risk behaviors among adolescents in Port-au-Prince, Haiti. AIDS and Behavior, 18(8), 1595-1603.

Catania, J. A., Kegeles, S. M., \& Coates, T. J. (1990). Towards an understanding of risk behavior: An AIDS risk reduction model (ARRM). Health Education and Behavior, 17(1), 53-72. 
CDC. (2013). CDC/HRSA Intervention for Seropositive Injection Drug Users, Research \& Evaluation (INSPIRE). Retrieved from http://hab.hrsa.gov/abouthab/special/inspire.html

Chang, E. C., Kahle, E. R., \& Hirsch, J. K. (2015). Understanding How Domestic Abuse Is Associated With Greater Depressive Symptoms in a Community Sample of Female Primary Care Patients Does Loss of Belongingness Matter? Violence Against Women, 1077801215576580.

Chapais, B. (2014). Complex kinship patterns as evolutionary constructions, and the origins of sociocultural universals. Current Anthropology, 55(6), 751-783.

Chen, P. H., \& White, H. R. (2004). Gender Differences in Adolescent and Young Adult Predictors of Later Intimate Partner Violence A Prospective Study. Violence Against Women, 10(11), 1283-1301.

Choenni, V., Hammink, A., \& van de Mheen, D. (2015). Association Between Substance Use and the Perpetration of Family Violence in Industrialized Countries A Systematic Review. Trauma, Violence, \& Abuse, 1524838015589253.

Connell, R. W. (1987). Gender and power: Society, the person and sexual politics. John Wiley \& Sons.

Conserve, D. F., King, G., Dévieux, J. G., Jean-Gilles, M., \& Malow, R. M. (2014). Determinants of HIV serostatus disclosure to sexual partner among HIV-positive alcohol users in Haiti. AIDS and Behavior, 18(6), 1037-1045.

Conserve, D. F., Whembolua, G. L., \& Surkan, P. J. (2016). Attitudes Toward Intimate Partner Violence and Associations With Condom Use Among Men in Haiti: An Analysis of the Nationally Representative Demographic Health Survey. $J$ Interpers Violence, 31(6), 989-1006.

Couture, M. C., Soto, J. C., Akom, E., Joseph, G., \& Zunzunegui, M. V. (2010a). Determinants of intention to use condoms among clients of female sex workers in Haiti. AIDS Care, 22(2), 253-262.

Couture, M. C., Soto, J. C., Akom, E., Joseph, G., \& Zunzunegui, M. V. (2010b). Violence against intimate partners and associations with inconsistent condom use among clients of female sex workers in Haiti. Public Health Reports, 125(6), 896902.

Couture, M. C., Soto, J. C., Akom, E., Labbe, A. C., Joseph, G., \& Zunzunegui, M. V. (2008). Clients of female sex workers in Gonaives and St-Marc, Haiti characteristics, sexually transmitted infection prevalence and risk factors. Sexually Transmitted Diseases, 35(10), 849-855. 
Crane, C. A., Godleski, S. A., Przybyla, S. M., Schlauch, R. C., \& Testa, M. (2015). The Proximal Effects of Acute Alcohol Consumption on Male-to-Female Aggression: A Meta-Analytic Review of the Experimental Literature. Trauma Violence Abuse, 1524838015584374.

Cunradi, C. B., Todd, M., \& Mair, C. (2015). Discrepant Patterns of Heavy Drinking, Marijuana Use, and Smoking and Intimate Partner Violence Results From the California Community Health Study of Couples. Journal of Drug Education, 45(2), 73-95.

Cyrus, E., Gollub, E. L., Jean-Gilles, M., Neptune, S., Pelletier, V., \& Dévieux, J. (2016). An Exploratory Study of Acculturation and Reproductive Health Among Haitian and Haitian-American Women in Little Haiti, South Florida. J Immigr Minor Health, 18(3), 666-672.

Davis, C. M., Yarber, W. L., \& Bauserman, R. (1998). Handbook of sexuality-related measures: Sage publication.

de Bruijn, D. M., \& de Graaf, I. M. (2016). The role of substance use in same-day intimate partner violence: A review of the literature. Aggression and Violent Behavior, 27, 142-151.

de Oliveira Fonseca-Machado, M., Camargo Alves, L., Scotini Freitas, P., dos Santos Monteiro, J. C., \& Gomes-Sponholz, F. (2014). Mental health of women who suffer intimate partner violence during pregnancy. Investigación y Educación en Enfermería, 32(2), 291-305.

de Oliveira Fonseca-Machado, M., dos Santos Monteiro, J. C., Haas, V. J., de Vilhena Abrão, A. C. F., \& Gomes-Sponholz, F. (2015). Intimate partner violence and anxiety disorders in pregnancy: the importance of vocational training of the nursing staff in facing them. Revista Latino-Americana de Enfermagem, 23(5), 855 .

Desormeaux, J., Behets, F. M., Adrien, M., Coicou, G., Dallabetta, G., Cohen, M., \& Boulos, R. (1996). Introduction of partner referral and treatment for control of sexually transmitted diseases in a poor Haitian community. International Journal of STD and AIDS, 7(7), 502-506.

Dévieux, J. G., Deschamps, M. M., Malow, R. M., Jean-Gilles, M., Saint-Jean, G., SaintJean, G., . . Pape, J. W. (2009). Knowledge, attitudes, and behaviors among a sample of HIV-positive and HIV-negative females visiting an urban VCT center in Haiti. Journal of Health Care for the Poor and Underserved, 20(2), 554-568.

Dévieux, J. G., Jean-Gilles, M., Frankel, A., Attonito, J., Saxena, A., \& Rosenberg, R. (2016). Predictors of Sexual Activity in Haitian-American Adolescents. J Immigr Minor Health, 18(1), 161-172. 
Dévieux, J. G., Jean-Gilles, M., Rosenberg, R., Beck-Sague, C., Attonito, J. M., Saxena, A., \& Stein, J. A. (2016). Depression, Abuse, Relationship Power and Condom Use by Pregnant and Postpartum Women with Substance Abuse History. AIDS and Behavior, 20(2), 292-303.

Dévieux, J. G., Malow, R. M., Attonito, J. M., Jean-Gilles, M., Rosenberg, R., Gaston, S., ... Deschamps, M. M. (2013). Post-traumatic stress disorder symptomatology and alcohol use among HIV-seropositive adults in Haiti. AIDS Care, 25(10), 1210-1218.

Dévieux, J. G., Rosenberg, R., Saint-Jean, G., Bryant, V. E., \& Malow, R. M. (2015). The Continuing Challenge of Reducing HIV Risk among Haitian Youth: The Need for Intervention. J Int Assoc Provid AIDS Care, 14(3), 217-223.

Devin, R. B., \& Erickson, P. I. (1996). The influence of male care givers on child health in rural Haiti. Social Science and Medicine, 43, 479-488.

Devries, K. M., Child, J. C., Bacchus, L. J., Mak, J., Falder, G., Graham, K., . . Heise, L. (2014). Intimate partner violence victimization and alcohol consumption in women: a systematic review and meta-analysis. Addiction, 109(3), 379-391.

DiClemente, R. J., Crosby, R. A., \& Kegler, M. (2009). Emerging theories in health promotion practice and research. John Wiley \& Sons.

Dillon, G., Hussain, R., Loxton, D., \& Rahman, S. (2013). Mental and physical health and intimate partner violence against women: a review of the literature. International Journal of Family Medicine, 2013.

Dunkle, K. L., Jewkes, R. K., Brown, H. C., Gray, G. E., McIntryre, J. A., \& Harlow, S. D. (2004). Gender-based violence, relationship power, and risk of HIV infection in women attending antenatal clinics in South Africa. Lancet, 363(9419), 14151421.

Dunkle, K. L., Jewkes, R. K., Brown, H. C., Yoshihama, M., Gray, G. E., McIntyre, J. A., \& Harlow, S. D. (2004). Prevalence and patterns of gender-based violence and revictimization among women attending antenatal clinics in Soweto, South Africa. American Journal of Epidemiology, 160, 230-239.

Dunkle, K. L., Jewkes, R. K., Nduna, M., Jama, N., Levin, J., Sikweyiya, Y., \& Koss, M. P. (2007). Transactional sex with casual and main partners among young South African men in the rural Eastern Cape: prevalence, predictors, and associations with gender-based violence. Social Science \& Medicine (1982), 65, 1235-1248. 
Dunkle, K. L., Jewkes, R. K., Nduna, M., Levin, J., Jama, N., Khuzwayo, N., . . Duvvury, N. (2006). Perpetration of partner violence and HIV risk behaviour among young men in the rural Eastern Cape, South Africa. AIDS, 20(16), 21072114.

Durevall, D., \& Lindskog, A. (2015). Intimate partner violence and HIV in ten subSaharan African countries: what do the Demographic and Health Surveys tell us? The Lancet Global Health, 3(1), e34-e43.

Eby, K. K., Campbell, J. C., Sullivan, C. M., \& Davidson, W. S., 2nd. (1995). Health effects of experiences of sexual violence for women with abusive partners. Health Care for Women International, 16(6), 563-576.

Emerson, R. (1962). Power-dependence relations. American Sociological Review, 31-34.

Farmer, P. E. (1995). Culture, poverty, and the dynamics of HIV transmission in rural Haiti. In H. Ten Brummelhuis \& G. H. Herdt (Eds.), Culture and sexual risk: Anthropological perspectives on AIDS: Psychology Press.

Farmer, P. E. (1998). Culture, Poverty, and HIV Transmission Chapter in: The art of medical anthropology: Readings. Geest, S. van der \& Rienks, A., eds (pp. 215228).

Fawzi, M. C. S., Lambert, W., Singler, J. M., Koenig, S. P., Leandre, F., Nevil, P., . . Farmer, P. E. (2003). Prevalence and risk factors of STDs in rural Haiti: implications for policy and programming in resource-poor settings. International Journal of STD and AIDS, 14(12), 848-853.

Fawzi, M. C. S., Lambert, W., Singler, J. M., Tanagho, Y., Leandre, F., Nevil, P., . . Farmer, P. E. (2005). Factors associated with forced sex among women accessing health services in rural Haiti: implications for the prevention of HIV infection and other sexually transmitted diseases. Social Science and Medicine, 60(4), 679-689.

Ferrari, G., Agnew-Davies, R., Bailey, J., Howard, L., Howarth, E., Peters, T. J., . . . Feder, G. S. (2016). Domestic violence and mental health: a cross-sectional survey of women seeking help from domestic violence support services. Global Health Action, 9.

Fisher, J. D., \& Fisher, W. A. (1992). Changing AIDS-risk behavior. Psychological Bulletin, 111(3), 455.

Fitzgerald, D. W., Behets, F., Caliendo, A., Roberfroid, D., Lucet, C., Fitzgerald, J. W., \& Kuykens, L. (2000). Economic hardship and sexually transmitted diseases in Haiti's rural Artibonite Valley. The American Journal of Tropical Medicine and Hygiene, 62, 496-501. 
Fitzgerald, D. W., Maxi, A., Marcelin, A., Johnson, W. D., \& Pape, J. W. (2004). Notification of positive HIV test results in Haiti: can we better intervene at this critical crossroads in the life of HIV-infected patients in a resource-poor country? AIDS Patient Care and STDS, 18, 658-664.

Foshee, V. A., Benefield, T. S., Ennett, S. T., Bauman, K. E., \& Suchindran, C. (2004). Longitudinal predictors of serious physical and sexual dating violence victimization during adolescence. Preventive Medicine, 39(5), 1007-1016.

Fromme, K., Katz, E., \& D'Amico, E. (1997). Effects of alcohol intoxication on the perceived consequences of risk taking. Experimental and Clinical Psychopharmacology, 5(1), 14.

Gage, A. J. (2005). Women's experience of intimate partner violence in Haiti. Social Science and Medicine, 61(2), 343-364.

Gage, A. J., \& Hutchinson, P. L. (2006). Power, control, and intimate partner sexual violence in Haiti. Archives of Sexual Behavior, 35(1), 11-24.

Gage, A. J., \& Suzuki, C. (2006). Risk factors for alcohol use among male adolescents and emerging adults in Haiti. Journal of Adolescence, 29(2), 241-260.

García-Moreno, C. (2013). Global and regional estimates of violence against women: prevalence and health effects of intimate partner violence and non-partner sexual violence: World Health Organization.

Garcia-Moreno, C., Jansen, H. A., Ellsberg, M., Heise, L., Watts, C. H., Health, W. H. O. M.-c. S. o. W. s., \& Domestic Violence against Women Study, T. (2006). Prevalence of intimate partner violence: findings from the WHO multi-country study on women's health and domestic violence. Lancet, 368(9543), 1260-1269.

Garcia-Moreno, C., Jansen, H. A. F. M., Ellsberg, M., Heise, L., \& Watts, C. H. (2006). Prevalence of intimate partner violence: findings from the WHO multi-country study on women's health and domestic violence. The Lancet, 368, 1260-1269.

García, O. P., Knobel, H., Carmona, A., Guelar, A., López-Colomés, J. L., \& Caylà, J. A. (2002). Impact of adherence and highly active antiretroviral therapy on survival in HIV-infected patients. Journal of Acquired Immune Deficiency Syndromes (1999), 30(1), 105-110.

Gardella, A. (2006). Gender assessment USAID/Haiti. Washington, DC: United States Agency for International Development.

Gardner, E. M., Sharma, S., Peng, G., Hullsiek, K. H., Burman, W. J., MacArthur, R. D., ... Mannheimer, S. B. (2008). Differential adherence to combination antiretroviral therapy is associated with virological failure with resistance. AIDS, $22(1), 75$. 
Gilbert, L., El-Bassel, N., Chang, M., Wu, E., \& Roy, L. (2012). Substance use and partner violence among urban women seeking emergency care. Psychology of Addictive Behaviors, 26(2), 226.

Gilman, C. P. (2010). The Man-Made World; or, Our Androcentric Culture. Hyweb Technology Co. Ltd.

Gomez, A. M., Speizer, I. S., \& Beauvais, H. (2009). Sexual violence and reproductive health among youth in Port-au-Prince, Haiti. Journal of Adolescent Health, 44(5), 508-510.

Greer, L., \& Bendersky, C. (2013). Power and status in conflict and negotiation research: Introduction to the special issue. Negotiation and Conflict Management Research, 6(4), 239-252.

Gupta, J., Small, M. J., \& Kershaw, T. S. (2009). Gender and HIV/AIDS in Haiti: women's lack of power as an overarching vulnerability. Gender and HIV/AIDS: critical perspectives from the developing world. Surry: Ashgate Publishing Limited.

Haberland, N. A. (2015). The case for addressing gender and power in sexuality and HIV education: a comprehensive review of evaluation studies. Int Perspect Sex Reprod Health, 41(1), 31-42.

Harrigan, P. R., Hogg, R. S., Dong, W. W., Yip, B., Wynhoven, B., Woodward, J., . . Alexander, C. S. (2005). Predictors of HIV drug-resistance mutations in a large antiretroviral-naive cohort initiating triple antiretroviral therapy. Journal of Infectious Diseases, 191(3), 339-347.

Harvey, S. M. (2000). New kinds of data new options for HIV prevention among women: a public health challenge. Health Education and Behavior, 27(5), 566-569.

Hempstone, H., Diop-Sidibe, N., A., K. S., Lauredent, E., \& Heerey, M. (2004). HIV/AIDS in Haiti: A literature review. Washington, DC.

Hirth, J. M., \& Berenson, A. B. (2012). Racial/ethnic differences in depressive symptoms among young women: The role of intimate partner violence, trauma, and posttraumatic stress disorder. Journal of Women's Health, 21(9), 966-974.

Hoaken, P., Assaad, J.-M., \& Pihl, R. O. (1998). Cognitive functioning and the inhibition of alcohol-induced aggression. Journal of Studies on Alcohol, 59(5), 599-607.

Holschneider, S. O. M., \& Alexander, C. S. (2003). Social and psychological influences on HIV preventive behaviors of youth in Haiti. Journal of Adolescent Health, 33, 31-40. 
Hunter, L. M., Reid-Hresko, J., \& Dickinson, T. W. (2011). Environmental Change, Risky Sexual Behavior, and the HIV/AIDS Pandemic: Linkages Through Livelihoods in Rural Haiti. Population Research and Policy Review, 30(5), 729750 .

Husnu, S., \& Mertan, B. E. (2015). The roles of traditional gender myths and beliefs about beating on self-reported partner violence. Journal of Interpersonal Violence, 0886260515600879.

Jaquier, V., Flanagan, J. C., \& Sullivan, T. P. (2015). Anxiety and posttraumatic stress symptom pathways to substance use problems among community women experiencing intimate partner violence. Anxiety, Stress, \& Coping, 28(4), 445455 .

Jewkes, R. (2002). Intimate partner violence: causes and prevention. Lancet, 359(9315), 1423-1429.

Jina, R., \& Thomas, L. S. (2013). Health consequences of sexual violence against women. Best Practice \& Research: Clinical Obstetrics \& Gynaecology, 27(1), $15-26$.

Jones, D. J., Runyan, D. K., Lewis, T., Litrownik, A. J., Black, M. M., Wiley, T., . . . Nagin, D. S. (2010). Trajectories of childhood sexual abuse and early adolescent HIV/AIDS risk behaviors: The role of other maltreatment, witnessed violence, and child gender. Journal of Clinical Child and Adolescent Psychology, 39(5), 667-680.

Kabir, Z. N., Nasreen, H.-E., \& Edhborg, M. (2014). Intimate partner violence and its association with maternal depressive symptoms 6-8 months after childbirth in rural Bangladesh. Global Health Action, 7.

Kamimura, A., Christensen, N., Tabler, J., Ashby, J., \& Olson, L. M. (2014). Prevalence of intimate partner violence and its impact on health: female and male patients using a free clinic. Journal of Health Care for the Poor and Underserved, 25(2), 731-745.

Karamagi, C. A. S., Tumwine, J. K., Tylleskar, T., \& Heggenhougen, K. (2006). Intimate partner violence against women in eastern Uganda: implications for HIV prevention. BMC Public Health, 6, 1.

Kershaw, T. S. (2006). Power Dynamics and Decision-making among 200 Pregnant Women in Rural Haiti. Unpublished data.

Kershaw, T. S., Small, M., Joseph, G., Theodore, M., Bateau, R., \& Frederic, R. (2006). The influence of power on HIV risk among pregnant women in rural Haiti. AIDS and Behavior, 10, 309-318. 
Kiarie, J. N., Farquhar, C., Richardson, B. A., Kabura, M. N., John, F. N., Nduati, R. W., \& John-Stewart, G. C. (2006). Domestic violence and prevention of mother-tochild transmission of HIV-1. AIDS, 20, 1763.

Kishor, S., \& Johnson, K. (2006). Reproductive health and domestic violence: are the poorest women uniquely disadvantaged? Demography, 43, 293-307.

Kita, S., Haruna, M., Matsuzaki, M., \& Kamibeppu, K. (2016). Associations between intimate partner violence (IPV) during pregnancy, mother-to-infant bonding failure, and postnatal depressive symptoms. Archives of Women's Mental Health, $1-12$.

Klostermann, K. C., \& Fals-Stewart, W. (2006). Intimate partner violence and alcohol use: Exploring the role of drinking in partner violence and its implications for intervention. Aggression and Violent Behavior, 11(6), 587-597.

Kornfeld, B. D., Bair-Merritt, M. H., Frosch, E., \& Solomon, B. S. (2012). Postpartum depression and intimate partner violence in urban mothers: co-occurrence and child healthcare utilization. The Journal of Pediatrics, 161(2), 348-353. e342.

Landry, M. D., O'Connell, C., Tardif, G., \& Burns, A. (2010). Post-earthquake Haiti: the critical role for rehabilitation services following a humanitarian crisis. Disability and Rehabilitation, 32(19), 1616-1618.

Leadley, K., Clark, C. L., \& Caetano, R. (2000). Couples' drinking patterns, intimate partner violence, and alcohol-related partnership problems. Journal of Substance Abuse, 11(3), 253-263.

Leonard, K. E., Bromet, E. J., Parkinson, D. K., Day, N. L., \& Ryan, C. M. (1985). Patterns of alcohol use and physically aggressive behavior in men. Journal of Studies on Alcohol, 46(4), 279-282.

Leonard, K. E., \& Quigley, B. M. (2016). Thirty years of research show alcohol to be a cause of intimate partner violence: Future research needs to identify who to treat and how to treat them. Drug and Alcohol Review, 36(1), 7-9.

Li, Y., Marshall, C. M., Rees, H. C., Nunez, A., Ezeanolue, E. E., \& Ehiri, J. E. (2014). Intimate partner violence and HIV infection among women: a systematic review and meta-analysis. Journal of the International AIDS Society, 17, 18845.

Lopez, E. J., Jones, D. L., Villar-Loubet, O. M., Arheart, K. L., \& Weiss, S. M. (2010). Violence, coping, and consistent medication adherence in HIV-positive couples. AIDS Education and Prevention, 22(1), 61.

Lundgren, R., \& Amin, A. (2015). Addressing intimate partner violence and sexual violence among adolescents: emerging evidence of effectiveness. Journal of Adolescent Health, 56(1), S42-S50. 
Maartens, G., Celum, C., \& Lewin, S. R. (2014). HIV infection: epidemiology, pathogenesis, treatment, and prevention. Lancet, 384(9939), 258-271.

Maddoux, J., Symes, L., McFarlane, J., Koci, A., Gilroy, H., \& Fredland, N. (2014). Problem-solving and mental health outcomes of women and children in the wake of intimate partner violence. Journal of Environmental and Public Health, 2014.

Magee, E. M., Small, M., Frederic, R., Joseph, G., \& Kershaw, T. (2006). Determinants of HIV/AIDS risk behaviors in expectant fathers in Haiti. Journal of Urban Health, 83, 625-636.

Maharaj, P., Neema, S., Cleland, J., Busza, J., \& Shah, I. (2012). Condom use within marriage: an assessment of changes in South Africa and Uganda. AIDS Care, 24(4), 444-450.

Malow, R. M., Dévieux, J. G., Stein, J. A., Rosenberg, R., Jean-Gilles, M., Attonito, J., . . . Pape, J. W. (2013). Depression, substance abuse and other contextual predictors of adherence to antiretroviral therapy (ART) among Haitians. AIDS and Behavior, 17(4), 1221-1230.

Malow, R. M., Rosenberg, R., \& Dévieux, J. G. (2009). Cognitive-behavioral stress management interventions for ethnic-minority HIV-positive alcohol/drug abusers in resource limited and culturally diverse communities. American Journal of Infectious Diseases, 5(1), 48-59.

Malow, R. M., Stein, J. A., McMahon, R. C., Dévieux, J. G., Rosenberg, R., \& JeanGilles, M. (2009). Effects of a culturally adapted HIV prevention intervention in Haitian youth. Journal of the Association of Nurses in AIDS Care, 20(2), 110-121.

Mapayi, B., Makanjuola, R., Mosaku, S., Adewuya, O., Afolabi, O., Aloba, O., \& Akinsulore, A. (2013). Impact of intimate partner violence on anxiety and depression amongst women in Ile-Ife, Nigeria. Archives of Women's Mental Health, 16(1), 11-18.

Martino, S. C., Collins, R. L., \& Ellickson, P. L. (2005). Cross-lagged relationships between substance use and intimate partner violence among a sample of young adult women. Journal of Studies on Alcohol, 66(1), 139-148.

Maynard-Tucker, G. (1996). Haiti: Unions, fertility and the quest for survival. Social Science and Medicine, 43, 1379-1387.

McCall-Hosenfeld, J. S., Winter, M., Heeren, T., \& Liebschutz, J. M. (2014). The association of interpersonal trauma with somatic symptom severity in a primary care population with chronic pain: exploring the role of gender and the mental health sequelae of trauma. Journal of Psychosomatic Research, 77(3), 196-204. 
McCauley, J., Kern, D. E., Kolodner, K., Dill, L., Schroeder, A. F., DeChant, H. K., .. . Bass, E. B. (1997). Clinical characteristics of women with a history of childhood abuse: unhealed wounds. JAMA, 277(17), 1362-1368.

McDermott, R. C., \& Lopez, F. G. (2013). College men's intimate partner violence attitudes: Contributions of adult attachment and gender role stress. Journal of Counseling Psychology, 60(1), 127.

McFarlane, J., Malecha, A., Watson, K., Gist, J., Batten, E., Hall, I., \& Smith, S. (2005). Intimate partner sexual assault against women: frequency, health consequences, and treatment outcomes. Obstetrics and Gynecology, 105(1), 99-108.

McLellan, A. T., Luborsky, L., Woody, G. E., \& O'brien, C. P. (1980). An improved diagnostic evaluation instrument for substance abuse patients: the Addiction Severity Index. The Journal of nervous and mental disease, 168(1), 26-33.

Meade, C. S., Hansen, N. B., Kochman, A., \& Sikkema, K. J. (2009). Utilization of medical treatments and adherence to antiretroviral therapy among HIV-positive adults with histories of childhood sexual abuse. AIDS Patient Care and STDS, 23(4), 259-266.

Moore, M. P. (2015). Sexual Behavior and HIV Risk in Black College Women: The Influence of Gender, Peer, and Relationship Beliefs.

Mugweni, E., Pearson, S., \& Omar, M. (2012). Traditional gender roles, forced sex and HIV in Zimbabwean marriages. Culture, Health \& Sexuality, 14(5), 577-590.

Mulrenan, C., Colombini, M., Howard, N., Kikuvi, J., Mayhew, S. H., \& Integra, I. (2015). Exploring risk of experiencing intimate partner violence after HIV infection: a qualitative study among women with HIV attending postnatal services in Swaziland. BMJ Open, 5(5), e006907.

National Child Traumatic Stress Network (NCTSN). (2015). Sexual Abuse. Retrieved from http://www.nctsn.org/trauma-types/sexual-abuse

National Institute on Drug Abuse (NIDA; 2013). Alcohol and Substance Abuse Measurement. Retrieved from https://www.drugabuse.gov/nidamed-medicalhealth-professionals/tool-resources-your-practice/screening-assessment-drugtesting-resources/chart-evidence-based-screening-tools-adults

O'Cleirigh, C., Safren, S. A., \& Mayer, K. H. (2012). The pervasive effects of childhood sexual abuse: Challenges for improving HIV prevention and treatment interventions. Journal of Acquired Immune Deficiency Syndromes, 59(4), 331.

Osinde, M. O., Kaye, D. K., \& Kakaire, O. (2011). Intimate partner violence among women with HIV infection in rural Uganda: critical implications for policy and practice. BMC Women's Health, 11, 50. 
Ouellet-Morin, I., Fisher, H. L., York-Smith, M., Fincham-Campbell, S., Moffitt, T. E., \& Arseneault, L. (2015). Intimate partner violence and new-onset depression: a longitudinal study of women's childhood and adult histories of abuse. Depression and Anxiety, 32(5), 316-324.

Padilla, M. B., Guilamo-Ramos, V., Bouris, A., \& Reyes, A. M. (2010). HIV/AIDS and tourism in the Caribbean: an ecological systems perspective. American Journal of Public Health, 100(1), 70-77.

Parcesepe, A. M., Toivgoo, A., Chang, M., Riedel, M., Carlson, C., DiBennardo, R., \& Witte, S. S. (2015). Physical and sexual violence, childhood sexual abuse and HIV/STI risk behaviour among alcohol-using women engaged in sex work in Mongolia. Glob Public Health, 10(1), 88-102.

Peasant, C., Sullivan, T. P., Weiss, N. H., Martinez, I., \& Meyer, J. P. (2016). Beyond the syndemic: condom negotiation and use among women experiencing partner violence. AIDS Care, 1-8.

Pence, B. W., Mugavero, M. J., Carter, T. J., Leserman, J., Thielman, N. M., Raper, J. L., ... Whetten, K. (2012). Childhood trauma and health outcomes in HIV-infected patients: an exploration of causal pathways. Journal of Acquired Immune Deficiency Syndromes, 59(4), 409.

PSI. (2015). Condom social marketing programme wraps up. Retrieved from http://www.psi.org/condom-social-marketing-programme-wraps-up/

Pulerwitz, J., Gortmaker, S. L., \& DeJong, W. (2000). Measuring sexual relationship power in HIV/STD research. Sex Roles, 42(7-8), 637-660.

Purcell, E. (2012). Poverty, Inequality and Power Dynamics: Women and their Role in the Haitian AIDS Epidemic. Paper 38.

Ragins, B. R., \& Winkel, D. E. (2011). Gender, emotion and power in work relationships. Human Resource Management Review, 21(4), 377-393.

Raiford, J. L., Seth, P., \& DiClemente, R. J. (2013). What girls won't do for love: human immunodeficiency virus/sexually transmitted infections risk among young African-American women driven by a relationship imperative. Journal of Adolescent Health, 52(5), 566-571.

Reed, E. (1975). Woman's evolution: from matriarchal clan to patriarchal family.

Rehm, J., Baliunas, D., Borges, G. L., Graham, K., Irving, H., Kehoe, T., . . Poznyak, V. (2010). The relation between different dimensions of alcohol consumption and burden of disease: an overview. Addiction, 105(5), 817-843. 
Republique d'Haiti Ministère de La Santé Publique et de La Population (MSPP). (2012). Enquete Mortalité et Utilisation des Services EMMUS-V Haiti 2012. Retrieved from https://mspp.gouv.ht/site/downloads/EMMUS\%20V\%20document\%20final.pdf

Richardson, E. T., Collins, S. E., Kung, T., Jones, J. H., Hoan Tram, K., Boggiano, V. L., ... Zolopa, A. R. (2014). Gender inequality and HIV transmission: a global analysis. Journal of the International AIDS Society, 17, 19035.

Richter, L., Komarek, A., Desmond, C., Celentano, D., Morin, S., Sweat, M., . . Coates, T. (2014). Reported physical and sexual abuse in childhood and adult HIV risk behaviour in three African countries: findings from Project Accept (HPTN-043). AIDS and Behavior, 18(2), 381-389.

Robillard, A. (2012). Music videos and sexual risk in African American adolescent girls: Gender, power and the need for media literacy. American Journal of Health Education, 43(2), 93-103.

Rosenberg, R., \& Malow, R. M. (2009). The hard science of hard risks in women's HIV prevention: Making biology part of the context. In C. Pope, R. White, \& R. Malow (Eds.), HIV/AIDS: Global frontiers in prevention/intervention (pp. 73-81). Routledge, New York.

Rubens, M., McCoy, H. V., \& Shehadeh, N. (2014). Proficiency in condom use among migrant workers. Journal of the Association of Nurses in AIDS Care, 25(3), 233242.

Sabri, B., Bolyard, R., McFadgion, A. L., Stockman, J. K., Lucea, M. B., Callwood, G. B., . . Campbell, J. C. (2013). Intimate partner violence, depression, PTSD, and use of mental health resources among ethnically diverse Black women. Social Work in Health Care, 52(4), 351-369.

Salom, C. L., Williams, G. M., Najman, J. M., \& Alati, R. (2015). Substance use and mental health disorders are linked to different forms of intimate partner violence victimisation. Drug and Alcohol Dependence, 151, 121-127.

Saltzman, L. E., Fanslow, J. L., McMahon, P. M., \& Shelley, G. A. (1999). Intimate partner violence surveillance: Uniform definitions and recommended data elements, version 1.0. Atlanta, GA: National Center for Injury Prevention and Control, Centers for Disease Control and Prevention.

Salud, M. C., Marshak, H. H., Natto, Z. S., \& Montgomery, S. (2014). Exploring HIVtesting intentions in young Asian/Pacific Islander (API) women as it relates to acculturation, theory of gender and power (TGP), and the AIDS risk reduction model (ARRM). AIDS Care, 26(5), 642-647. 
Santana, M. C., Raj, A., Decker, M. R., La Marche, A., \& Silverman, J. G. (2006). Masculine gender roles associated with increased sexual risk and intimate partner violence perpetration among young adult men. Journal of Urban Health, 83, 575585 .

Saunders, J. B., Aasland, O. G., Babor, T. F., Grant, M., \& others. (1993). Development of the alcohol use disorders identification test (AUDIT): WHO collaborative project on early detection of persons with harmful alcohol consumption-II. Addiction, 88, 791-804.

Shen, A. C.-T., Chiu, M. Y.-L., \& Gao, J. (2012). Predictors of dating violence among Chinese adolescents: The role of gender-role beliefs and justification of violence. Journal of Interpersonal Violence, 0886260511424497.

Sikkema, K. J., Ranby, K. W., Meade, C. S., Hansen, N. B., Wilson, P. A., \& Kochman, A. (2013). Reductions in traumatic stress following a coping intervention were mediated by decreases in avoidant coping for people living with HIV/AIDS and childhood sexual abuse. Journal of Consulting and Clinical Psychology, 81(2), 274.

Silverman, J. G., Decker, M. R., Kapur, N. A., Gupta, J., \& Raj, A. (2007). Violence against wives, sexual risk and sexually transmitted infection among Bangladeshi men. Sexually Transmitted Infections, 83, 211-215.

Speizer, I. S., Beauvais, H., Gomez, A. M., Outlaw, T. F., \& Roussel, B. (2009). Using Multiple Sampling Approaches to Measure Sexual Risk-taking Among Young People in Haiti: Programmatic Implications. Studies in Family Planning, 40(4), $277-288$.

Spielberger, C., Gorsuch, R., \& Lushene, R. (1970). Manual for the state-trait anxiety inventory. Palo Alto, CA: Consulting Psychologists Press.

Stewart, R. C., Umar, E., Tomenson, B., \& Creed, F. (2014a). A cross-sectional study of antenatal depression and associated factors in Malawi. Archives of Women's Mental Health, 17(2), 145-154.

Stewart, R. C., Umar, E., Tomenson, B., \& Creed, F. (2014b). Validation of the multidimensional scale of perceived social support (MSPSS) and the relationship between social support, intimate partner violence and antenatal depression in Malawi. BMC Psychiatry, 14(1), 1.

Sumner, S. A., Marcelin, L. H., Cela, T., Mercy, J. A., Lea, V., Kress, H., \& Hillis, S. D. (2015). Sentinel events predicting later unwanted sex among girls: A national survey in Haiti, 2012. Child Abuse and Neglect, 50, 49-55. 
Sumner, S. A., Mercy, A. A., Saul, J., Motsa-Nzuza, N., Kwesigabo, G., Buluma, R., . . . Hillis, S. D. (2015). Prevalence of sexual violence against children and use of social services - seven countries, 2007-2013. MMWR: Morbidity and Mortality Weekly Report, 64(21), 565-569.

Swan, H., \& O'Connell, D. J. (2012). The impact of intimate partner violence on women's condom negotiation efficacy. Journal of Interpersonal Violence, 27, 775-792.

Tanser, F., Barnighausen, T., Grapsa, E., Zaidi, J., \& Newell, M. L. (2013). High coverage of ART associated with decline in risk of HIV acquisition in rural KwaZulu-Natal, South Africa. Science, 339(6122), 966-971.

Tapp, C., Milloy, M., Kerr, T., Zhang, R., Guillemi, S., Hogg, R. S., . . Wood, E. (2011). Female gender predicts lower access and adherence to antiretroviral therapy in a setting of free healthcare. BMC Infectious Diseases, 11(1), 1.

Temple, J. R., Weston, R., Stuart, G. L., \& Marshall, L. L. (2008). The longitudinal association between alcohol use and intimate partner violence among ethnically diverse community women. Addictive Behaviors, 33(9), 1244-1248.

Testa, M., Livingston, J. A., \& Leonard, K. E. (2003). Women's substance use and experiences of intimate partner violence: A longitudinal investigation among a community sample. Addictive Behaviors, 28(9), 1649-1664.

Tjaden, P. G., \& Thoennes, N. (2006). Extent, nature, and consequences of rape victimization: Findings from the National Violence Against Women Survey: US Department of Justice, Office of Justice Programs, National Institute of Justice Washington, DC.

Topalli, V., Giancola, P. R., Tarter, R. E., Swahn, M., Martel, M. M., Godlaski, A. J., \& Mccoun, K. T. (2014). The Persistence of Neighborhood Disadvantage An Experimental Investigation of Alcohol and Later Physical Aggression. Criminal Justice and Behavior, 41(4), 400-416.

Tsai, A. C., \& Weiser, S. D. (2014). Population-based study of food insecurity and HIV transmission risk behaviors and symptoms of sexually transmitted infections among linked couples in Nepal. AIDS and Behavior, 18(11), 2187-2197.

Turner, B. J., Laine, C., Cosler, L., \& Hauck, W. W. (2003). Relationship of gender, depression, and health care delivery with antiretroviral adherence in HIV-infected drug users. Journal of General Internal Medicine, 18(4), 248-257.

Ullman, S. E., \& Sigurvinsdottir, R. (2015). Intimate Partner Violence and Drinking among Victims of Adult Sexual Assault. J Aggress Maltreat T, 24(2), 117-130. 
Umubyeyi, A., Mogren, I., Ntaganira, J., \& Krantz, G. (2014). Intimate partner violence and its contribution to mental disorders in men and women in the post genocide Rwanda: findings from a population based study. BMC Psychiatry, 14(1), 1.

UNAIDS. (2015). HIV and AIDS estimates in Haiti, 2015. Retrieved from http://www.unaids.org/en/regionscountries/countries/haiti/

UNFPA. (2008). Donor Support for Contraceptives and Condoms for STI/HIV Prevention, 2008. Retrieved from http://www.unfpa.org/sites/default/files/pubpdf/2008_donor_support_report.pdf

United Nations Population Fund (UNFPA). (2011). One Year after the Earthquake, Haiti's Recovery Proceeds Slowly. Retrieved from http://www.unfpa.org/news/one-year-after-earthquake-haiti\%E2\%80\%99srecovery-proceeds-slowly\#sthash.KIR2tIWJ.dpuf

Urassa, P., Gosling, R., Pool, R., \& Reyburn, H. (2005). Attitudes to voluntary counselling and testing prior to the offer of nevirapine to prevent vertical transmission of HIV in northern Tanzania. AIDS Care, 17, 842-852.

Villar-Loubet, O. M., Illa, L., Echenique, M., Cook, R., Messick, B., Duthely, L. M., . . . Potter, J. (2014). Prenatal and mental health care among trauma-exposed, HIVinfected, pregnant women in the United States. Journal of the Association of Nurses in AIDS Care, 25(1), S50-S61.

Wagman, J. A., Donta, B., Ritter, J., Naik, D., Nair, S., Saggurti, N., . . Silverman, J. G. (2016). Husband's Alcohol Use, Intimate Partner Violence, and Family Maltreatment of Low-Income Postpartum Women in Mumbai, India. Journal of Interpersonal Violence, 0886260515624235.

Walters, M. L., Chen, J., \& Breiding, M. J. (2013). The National Intimate Partner and Sexual Violence Survey (NISVS): 2010 findings on victimization by sexual orientation. Atlanta, GA: National Center for Injury Prevention and Control, Centers for Disease Control and Prevention, 648(73), 6.

Walton-Moss, B. J., Manganello, J., Frye, V., \& Campbell, J. C. (2005). Risk factors for intimate partner violence and associated injury among urban women. Journal of Community Health, 30(5), 377-389.

Wathen, C. N., MacGregor, J. C., \& MacQuarrie, B. J. (2016). Relationships among intimate partner violence, work, and health. Journal of Interpersonal Violence, 0886260515624236.

Wechsberg, W. M., Myers, B., Reed, E., Carney, T., Emanuel, A. N., \& Browne, F. A. (2013). Substance use, gender inequity, violence and sexual risk among couples in Cape Town. Cult Health Sex, 15(10), 1221-1236. 
Whetten, K., Leserman, J., Lowe, K., Stangl, D., Thielman, N., Swartz, M., . . Van Scoyoc, L. (2006). Prevalence of childhood sexual abuse and physical trauma in an HIV-positive sample from the deep south. American Journal of Public Health, 96(6), 1028-1030.

World Health Organization (WHO). (2005a). Haiti: Statistics summary (2002 - present). Global Health Observatory country views. Retrieved from http://apps.who.int/gho/data/node.country.country-HTI

WHO. (2005b). WHO multi country study on women's health and life events. Gender, equity and human rights. Retrieved from http://www.who.int/reproductivehealth/publications/violence/9241593512/en/

WHO. (1999). Report of the Consultation on Child Abuse Prevention. Retrieved from http://www.who.int/mip2001/files/2017/childabuse.pdf

WHO. (2010). WHO Facts on Intimate Partner Violence and Alcohol. Retrieved from http://www.who.int/violence_injury_prevention/violence/world_report/factsheets/ fs_intimate.pdf

WHO. (2013a). Risk factors data by country: Haiti. Retrieved from http://apps.who.int/gho/data/view.main.SEX1760

WHO. (2013b). WHO: Gender Based Violence. Retrieved from http://www.who.int/gender/violence/gbv/en/

WHO. (2015a). Gender inequalities and HIV. Retrieved from http://apps.who.int/gender/hiv_aids/en/

WHO. (2015b). Global status report on alcohol and health, 2014. Geneva, Switzerland: World Health Organization. Retrieved from http://www.who.int/substance_abuse/publications/global_alcohol_report/en/

WHO. (2015c). Global summary of the AIDS epidemic, 2015. Retrieved from http://www.who.int/hiv/data/en

Williams, C. L., Muller, C., \& Kilanski, K. (2012). Gendered organizations in the new economy. Gender \& Society, 26(4), 549-573.

Wilson, K., Senay, I., Durantini, M., Sánchez, F., Hennessy, M., Spring, B., \& Albarracín, D. (2015). When it comes to lifestyle recommendations, more is sometimes less: A meta-analysis of theoretical assumptions underlying the effectiveness of interventions promoting multiple behavior domain change. Psychological Bulletin, 141(2), 474. 
Wingood, G. M., DiClemente, R., DiClemente, R. J., Crosby, R. A., \& Kegler, M. C. (2002). The theory of gender and power. Emerging theories in health promotion practice and research: Strategies for improving public health. San Francisco: Jossey-Bass, 313-345.

Wingood, G. M., \& DiClemente, R. J. (2000). Application of the Theory of Gender and Power to Examine HIV-Related Exposures, Risk Factors, and Effective Interventions for Women. Health Education and Behavior, 27, 539-565.

Wyatt, G. E., Gomez, C. A., Hamilton, A. B., Valencia-Garcia, D., Gant, L. M., \& Graham, C. E. (2013). The intersection of gender and ethnicity in HIV risk, interventions, and prevention: new frontiers for psychology. American Psychologist, 68(4), 247-260.

Xiao, Z., Palmgreen, P., Zimmerman, R., \& Noar, S. (2010). Adapting and applying a multiple domain model of condom use to Chinese college students. AIDS Care, 22(3), 332-338.

Zacarias, A. E., Macassa, G., Soares, J. J., Svanström, L., \& Antai, D. (2012). Symptoms of depression, anxiety, and somatization in female victims and perpetrators of intimate partner violence in Maputo City, Mozambique. International journal of women's health, 4, 491.

Zhang, C., Li, X. M., Hong, Y., Chen, Y. Y., Liu, W., \& Zhou, Y. J. (2012). Partner Violence and HIV Risk Among Female Sex Workers in China. AIDS and Behavior, 16(4), 1020-1030.

Zierler, S., \& Krieger, N. (1997). Reframing women's risk: social inequalities and HIV infection. Annual Review of Public Health, 18, 401-436. 


\title{
CHAPTER III: Factors Associated with Intimate Partner Violence (IPV) in a Sample of Haitian Women
}

\begin{abstract}
Intimate partner violence (IPV) represents a growing public health concern in Haiti. IPV has been associated with a number of psychological, psychosomatic, and reproductive health sequelae. Though a number of studies have been conducted, the factors initiating and perpetuating IPV are understudied in Haiti. A sub-sample of 231 HIV- women who had experienced IPV and who attended the GHESKIO Centers in Haiti was selected. Participants were placed into two groups based on whether they had suffered major or minor exposure to IPV. A number of measures were administered to assess partner violence, childhood sexual abuse (CSA), and attitudes towards gender roles. Logistic regressions were conducted to determine predictors of IPV. IPV was negatively correlated with age $(\mathrm{p}<0.05)$ and history of mental health $(\mathrm{p}<0.05)$, and positively correlated with lack of family support $(\mathrm{p}<0.01)$. Generalized linear mixed modeling showed that lack of family support $(\beta=0.28, \mathrm{p}<0.05)$, history of $\operatorname{CSA}(\beta=$ $0.66, \mathrm{p}<0.05)$, and traditional gender-based attitudes $(\beta=0.10, \mathrm{p}<0.001)$ predicted major IPV. These findings suggest the need to examine the context in which IPV occurs and may be important to future researchers who seek to develop interventions to prevent or ameliorate the impact of IPV among Haitian women.
\end{abstract}

\section{Introduction}

Intimate partner violence (IPV) has been a growing social issue in many developing nations (Bourey, Williams, Bernstein, \& Stephenson, 2015). The 2012 Haiti Mortality, Morbidity, and Service Utilization Survey (EMMUS-V) reported an increase 
in IPV from approximately $25 \%$ to $29 \%$ over a period of two years (Republique d'Haiti Ministère de La Santé Publique et de La Population (MSPP), 2012). In the Latin American region, a nationally representative sample of Colombian women revealed that $41 \%$ had experienced physical violence and $34 \%$ experienced sexual violence in the past year (Gómez-Camargo et al., 2014; Profamilia, 2000). Similarly, a Peruvian study using Demographic and Health Survey (DHS) data showed that $48 \%$ of the women were disrespected by their dominant male partners, $27 \%$ reported being labelled as useless, $25 \%$ were threatened to be abandoned and $21 \%$ were threatened to be separated from their children if they disclosed their abusive relationship (Gomez, 2015). In a crosssectional study conducted in Africa, 25\% of the women reported lifetime prevalence of IPV, of which $10 \%$ occurred within the past year (Coovadia, Jewkes, Barron, Sanders, \& McIntyre, 2009).

The adverse effects of IPV in terms of mental, physical and reproductive health have been documented in a number of studies. IPV has been associated with posttraumatic stress disorder, suicidal ideation, anxiety and depressive disorders, and other psychological sequelae (Hellmuth, Jaquier, Overstreet, Swan, \& Sullivan, 2014; Mitchell, Wight, Van Heerden, \& Rochat, 2016; Schechter, Moser, McCaw, \& Myers, 2014). A number of psychosomatic and reproductive adverse events have also been implicated in IPV (Iverson et al., 2015). These include some that may be somatization disorders such as chronic pain syndrome, dysmenorrhea, dysphagia, dyspareunia, pruritus and torticollis, and affective disorders such as panic attack, obsessive compulsion disorders, conversion disorders, and pathological anxiety (Iverson et al., 2015; Lövestad, Löve, Vaez, \& Krantz, 2016; McLeod, Horwood, \& Fergusson, 2016). A number of other behavioral 
consequences such as fear of requesting their male partner to use condoms, use of birth control measures, abortions and safe sex practices, and enquiring about sexually transmitted infections (STIs) before coital acts are also adversely affected by IPV (García-Moreno, 2013; Hall, Chappell, Parnell, Seed, \& Bewley, 2014; McCloskey, 2016). Some studies have also associated sexual violence with alcohol use and substance use, both among abusers and victims, thereby limiting their judgment for safe sex practices (Fehringer \& Hindin, 2014; Lipsky, Kernic, Qiu, Wright, \& Hasin, 2014; Overup, Dibello, Brunson, Acitelli, \& Neighbors, 2014). Many studies have also reported significant associations between sexual violence and HIV/STI transmission rates (Kalokhe et al., 2016; Mittal, Senn, \& Carey, 2013; Prowse, Logue, Fantasia, \& Sutherland, 2014). Given the adverse associations between IPV and disease transmission as well as many psychological and socio-behavioral components, it is imperative that the determinants associated with IPV in any given population is understood.

Although there is considerable evidence of IPV in many developing nations, the determinants and factors affecting it are varied across different geographical settings. Much of the existing research is modelled on the studies conducted in United States with categorization such as sexual, physical and emotional violence, and less on patterns associated with socio-demographic and ethno-linguistic factors (Abramsky et al., 2014). Though studies abound on the relationship between IPV and factors such as gender inequality, cultural values perpetuating aggression on women, and patriarchal societal values, many studies have not considered it important to include these additional factors along with conventional factors like income, employement, education, household wealth and urban residence (Ali \& Naylor, 2013; Scarduzio, Carlyle, Harris, \& Savage, 2016). 
Similarly, many studies seem to have focused on individual characteristics such as criminality and victimization and may have overlooked the complex roles played by income, education, childhood sexual abuse, family and social support, gender roles, socio-cultural norms, linguistic determinants, family characteristics, and living conditions (Barrios et al., 2015; Stewart, Umar, Tomenson, \& Creed, 2014; Wright, 2016).

Haiti is the poorest nation in the Western Hemisphere. The per capita gross domestic product was $\$ 1,800$ in the year 2015 , ranking it as $211^{\text {th }}$ among 229 countries in the world (CIA, 2016). Over 70\% of the population live below internationally determined poverty levels. Life expectancy is less than 57 years; more than half of the population are illiterate and unemployed; and about $40 \%$ experience food insecurity. Complicating these factors, only one-fourth of the population have access to community health services. The population is also growing at levels far above replacement (200,000 live births per year; World Bank, 2016). In the context of these adverse conditions and continued civil unrest, IPV and sexual violence are prevalent in Haiti (Fawzi et al., 2005). About 54\% of the women reported some form of physical or sexual IPV in their lifetime, in contrast to IPV reporting in the WHO Americas region (29.8\%) and Southeast Asia, which has the highest regional IPV reports (37.7\%; Fawzi et al., 2005; Republique d'Haiti Ministère de La Santé Publique et de La Population [MSPP], 2012). However, the factors initiating and perpetuating IPV are not well documented. Hence, the current study is intended to assess the determinants associated with IPV in a sample of Haitian women. 


\section{Methods}

\section{Participants and Setting}

From January to December 2013, a cohort of men and women attending GHESKIO and its partner clinics in Port-au-Prince, Haiti, were enrolled in a crosssectional study to examine gender-based roles/attitudes and prevalence of intimate partner violence. From a group of women that had experienced IPV $(\mathrm{N}=513)$, a subsample of HIV negative women with complete demographic information $(n=231)$ was selected for the current study. Participants were divided into two groups based on their history of IPV exposure-minor IPV $(n=104)$ and major IPV $(n=127$; see Measures for major and minopr IPV categorization). In the original study, these women were asked several questions related to their general health condition in the past 4 weeks and 12 months, recent intimate partner violence history, and questions related to their family/community.

\section{Measures}

Demographic information: Age (18 - 75 years), education attainment (None, Primary, and Secondary and above), marital status (Married/living as married and Single/living as single), income (None, $\leq 25,000$, and $>25,000 \mathrm{HTG}$ ), number of children, length of stay in the community (in years), alcohol use, smoking history, and age of sexual debut (in years) were collected.

Partner violence: A culturally adapted questionnaire from the multi-country study conducted by the World Health Organization (WHO) was used to measure partner violence (WHO, 2005). The questionnaire contained four domains to measure different types of partner violence. Partner's controlling behavior - Controlling behavior of an 
intimate partner was assessed by asking participants seven questions: (1) Tries to keep you from seeing your friends; (2) Tries to restrict contact with your family of birth; (3) Insists on knowing where you are at all times; (4) Ignores you and treats you indifferently; (5) Gets angry if you speak with another man; (6) Is often suspicious that you are unfaithful; and (7) Expects you to ask his permission before seeking health care for yourself. Responses to these questions were 'Yes (=1)' and 'No (=0)'. Cronbach's alpha for the seven questions was 0.66. Psychological violence - History of varying levels of lifetime psychological violence was asked by four items: (1) Insulted you or made you feel bad about yourself; (2) Belittled or humiliated you in front of other people; (3) Did things to scare you on purpose; and (4) Threatened to hurt you or someone you care about. The degree of psychological violence increased from first to fourth question. Responses to these questions were 'Yes $(=1)$ ' and 'No $(=0)$ '. Cronbach's alpha for the four questions was 0.71 . Physical violence - History of lifetime physical violence by an intimate partner was reported through six items: (1) Slapped you or thrown something at you that could hurt you; (2) Pushed you or shoved you; (3) Hit you with his fist or with something else that could hurt you; (4) Kicked you, dragged you or beaten you up; (5) Choked or burnt you on purpose; and (6) Threatened to use or actually used a gun, knife or other weapon against you. Severity of physical violence increased from the first to sixth question. Responses to these questions were 'Yes (=1)' and 'No (=0)'. Physical violence was divided into minor (Questions $1-4$ ) and major (Questions 5 and 6) physical violence categories. Cronbach's alpha for the four questions was 0.78. Sexual violence - History of an intimate partner's sexual violence towards a participant was recorded by asking three questions: (1) Physically forced you to have sexual intercourse 
when you did not want to; (2) Did you ever have sexual intercourse you did not want because you were afraid of what he might do; and (3) Did he ever force you to do something sexual that you found degrading or humiliating. Responses to these questions were 'Yes $(=1)$ ' and 'No $(=0)$ '. Cronbach's alpha for the three items was 0.41 , and it was lowest among all types of violence items.

Childhood sexual abuse (CSA): CSA was measured by asking the participants "before the age of 15 years, do you remember if anyone in your family ever touched you sexually, or made you do something sexual that you didn't want to?" Responses to these questions were 'Yes (=1)' and 'No (=0)'.

Attitudes towards gender roles: A culturally adapted questionnaire from the multicountry study conducted by the WHO was used to measure attitude towards gender roles (WHO, 2005). Five questions were asked to measure traditional or non-traditional attitudes towards gender roles. These were (1) A good wife obeys her husband even if she disagrees; (2) It is important for a man to show his wife/partner who is the boss; (3) A woman should be able to choose her own friends even if her husband disapproves; (4) It's a wife's obligation to have sex with her husband even if she doesn't feel like it; and (5) If a man mistreats his wife, others outside of the family should intervene. Responses to these questions included 'Agree,' 'Disagree,' and 'Don't know.' Since 'Don't know' responses did not provide information about attitudes, it was excluded from the analysis.

\section{Statistical Analysis}

Statistical analyses were performed using SAS software version 9.4. Descriptive statistics for continuous variables were reported as means and standard deviations $(S D)$. For categorical and nominal variables, frequencies and percentages were reported. 
Descriptive statistics were used to analyze types of partner control, psychological violence, physical violence, and sexual violence. This analysis was followed by correlation analysis among variables included in the regression model. Univariate statistics were reported and compared between the two groups. Finally, generalized linear mixed modelling analysis with binary distribution and logit link function was used to find the predictors of major IPV. Multivariable adjusted estimates, standardized estimates, and respective $p$-values were reported. For all analyses, statistical tests were performed with an alpha level of 0.05 .

\section{Results}

\section{Demographics}

The mean $(S D)$ age of the participants was 25.5 (5.4) years (Table 3.1). Approximately $68.4 \%$ had some secondary education and only $0.9 \%$ had a college or professional degree. Approximately $31.2 \%$ of participants did not report any income. The majority of participants (82.2\%) had a partner, but did not live with him. Approximately $41.7 \%$ and $77.1 \%$ of participants reported not taking alcohol and not smoking, respectively.

\section{History of IPV}

Approximately $83.1 \%$ of participants reported that their partners got angry if they spoke to another man, and $81 \%$ reported that their partners were suspicious that they may be unfaithful (Table 3.2). Approximately $97.4 \%$ reported that they were slapped by their partners, and $95.7 \%$ reported that they were pushed or shoved by their partners. Approximately $83.5 \%$ of the participants reported that they were physically forced to have sexual intercourse when they did not want to. 


\section{Attitude Towards Gender Roles}

Table 3.3 shows the comparison of attitudes towards gender roles between participants with minor and major IPV. A significantly higher number of participants with a history of major IPV reported that a good wife should obey her husband even if she disagrees (Table 3.3). Similarly, participants with major IPV reported that it is important for a man to show his wife who is the boss and if a man mistreats his wife, someone from outside the family should not intervene.

\section{Correlation between Demographics, IPV, CSA, and Traditional Gender Based}

\section{Attitudes (TGBA)}

IPV was negatively correlated with age $(\mathrm{p}<0.05)$ and history of mental health $(\mathrm{p}$ $<0.05$ ), and positively correlated with lack of family support ( $\mathrm{p}<0.01$; see Table 3.4 for

correlations). CSA was positively correlated with history of IPV $(\mathrm{p}<0.05)$ and negatively correlated with age at sexual debut $(\mathrm{p}<0.01)$. TGBAs were positively correlated with history of IPV $(\mathrm{p}<0.01)$.

\section{Predictors of Major IPV}

Generalized linear mixed modelling analysis showed that lack of family support $(\beta=0.28, \mathrm{p}<0.05)$, history of CSA $(\beta=0.66, \mathrm{p}<0.05)$, and TGBA $(\beta=0.10, \mathrm{p}<0.001)$ predicted major IPV. Table 3.5 shows unstandardized estimates, standard errors, and pvalues.

\section{Discussion}

This is one of the few studies that examined the predictors of IPV in a representative sample of poor women in Haiti. In this study, history of IPV was significantly associated with traditional gender-based attitudes, history of childhood 
sexual abuse, and lack of family support. More than half of the participants reported history of male dominance, psychological, physical and sexual violence.

\section{Gender-based Attitudes}

Similar to the observations in the current study, a country-wide survey conducted on behalf of the Haitian government reported that IPV increased from approximately $25 \%$ to $29 \%$ over a period of two years (Republique d'Haiti Ministère de La Santé Publique et de La Population (MSPP), 2012). This survey also reported that among Haitian women who experienced physical or sexual violence, approximately $65 \%$ did not seek help, and about $43 \%$ did not tell anyone about IPV. In a study demonstrating the negative sequelae of these experiences, another researcher reported that sexual violence, poverty, and gender inequality were critical to Haitian women's vulnerability to HIV/AIDS (Marchand, 2011). Given that more than half of the women in the current study reported a history of male dominance and violence, the findings in the literature suggest that the women in the sample have been placed in a positon of greater vulnerability to sexually transmitted infections and other potentially negative effects of this violence.

Gender-based attitudes as a concept includes a wide continuum of behaviors and attributes that fall between traditional and egalitarian extremes (Reyes, Foshee, Niolon, Reidy, \& Hall, 2016). Traditional attitudes include behaviors based on stereotypical gender-based characteristics, whereas egalitarian attitudes include individual perceptions independent of the cultural rules associated with gender (Reyes et al., 2016). Studies have shown that when compared to egalitarian attitudes, traditional gender attitudes were more likely to be associated with a negative outlook towards women which included 
objectification and tacit approval of rape myths (Angelone, Mitchell, \& Grossi, 2014; Reyes et al., 2016).

Gender-based attitudes are significantly associated with higher approval of physical, psychological and sexual violence against women, lower levels of perceived seriousness for acts of interpersonal violence, initiation and perpetration of violence against women, and tacit acceptance of coercive marriages (Field, Kimuna, \& Lang, 2015; Reyes et al., 2016; Scarduzio et al., 2016; Umana, Fawole, \& Adeoye, 2014). Individuals with traditional gender roles were also more likely to blame the victims in cases of IPV, instead of the perpetrators, and were generally callous towards the adverse psychosocial consequences of domestic violence (Tenkorang, Owusu, Yeboah, \& Bannerman, 2013). The literature support the findings of the current study, reflecting an association between traditional gender-based attitudes and higher IPV prevalence. The findings suggest that to reduce IPV prevalence, focused action and education about cultural attitudes will need to be undertaken. Researchers may also need to consider interventions with males, not only with females, in order to begin to address this issue.

Traditional gender-based attitudes are also associated with adverse mental health outcomes in victimized female partners. Many victimization studies have shown that the emotional, social, and psychological consequences of IPV are tacitly endured by women due to their social upbringing in traditional gender-based societies. For example, in a study comparing the consequences of IPV among male and female victims, women experienced greater levels of insecurity and psychological distress when compared to men due to their economic dependence and male-dominated social settings (Golden, Perreira, \& Durrance, 2013). In studies analyzing the nature of altercations between 
heterosexual couples experiencing IPV, it was observed that females experienced higher levels of anxiety and physiological distress than their male spouses and that such anxiety and psychological distress led women to choose a pessimistic and fatalistic approach towards the violence, dominated and subdued by the fear of retaliation or abandonment by their spouses, and thus leading to significantly lower rates of reporting (Kosia et al., 2016; Mapayi et al., 2013). Women have also reported higher rates of depression and vulnerability due to the gender-based norms of subservience to their male partners instilled in them during their childhood (Lövestad et al., 2016). Although psychological variables were not specifically assessed as part of this study, it may be inferred that the existence of IPV, coupled with lack of family support and history of child abuse found among many women in the sample will almost certainly have psychological impacts. The predictors of IPV observed in the current study, therefore, may help future researchers to identify the factors that could be modified to initiate appropriate social and legal empowerment strategies, help women overcome traditional beliefs about gender roles, and adopt a more egalitarian outlook.

\section{Childhood Sexual Abuse}

The current study revealed significant associations between IPV and history of childhood sexual abuse. These findings are similar to previous studies on the adverse psychosocial effects of childhood sexual abuse and the increased likelihood of enduring victimization by partners during adulthood (CDC, 2013; Zhan, Shaboltas, Skochilov, Krasnoselskikh, \& Abdala, 2013; Regan \& Durvasula, 2015; Zhan et al., 2013). Childhood abuse may also be responsible for lower self-esteem, insecurity, anxiety and post-traumatic symptoms that continue in adult life and decrease a woman's interest in 
sex, emotional and sexual well-being (Sperry \& Widom, 2013). This lack of interest may be one of the triggers for their dominant partners who consider their lack of interest in sex as a sign of unfaithfulness, resulting in marital discord and IPV (Walton \& Chou, 2015).

Among most cultures, childhood abuse is rarely discussed. It is therefore important for interventionists to determine history of childhood abuse, as well as past experience with IPV, since these factors may reflect hidden factors that could potentially reduce the effectiveness of interventions to reduce the incidence of IPV. Many studies have shown that positive therapeutic interventions and counseling could positively restructure the adverse effects of childhood sexual abuse and produce significant changes in their perception of physical and sexual relationships (e.g., Walton \& Chou, 2015). Therefore, the current study which determined an association between childhood abuse and IPV in this group of Haitian women may indicate the need for further advocacy and empowerment programs as well as for cognitive behavioral therapy, thereby enhancing women's well-being.

\section{Family Support}

This study found significant associations between IPV and lack of family support. Empirical studies have shown that seeking family support by women in an abusive relationship constitutes one of the most significant steps in the stages of coping model

(Lee, Pomeroy, \& Bohman, 2007; Sylaska \& Edwards, 2014). Women locked in abusive relationships go through numerous stages of change which include disclosing their abusive relationship to acquaintances they trust, identifying and externalizing their problems, deciding to seek help, and choosing their source of support such as public authorities, the police, community organizations and assisting and preventing agencies. 
They could also alternatively seek support from family and friends (Sylaska \& Edwards, 2014). In this sample, the fact that lack of family support was significantly associated with IPV suggests a potentially important intervention component for these women that may have been overlooked in the Haitian context.

In a study by Dixon and Graham-Kevan (2011), it was postulated that patriarchal families with their traditional gender roles tend to be less supportive of their abused female victims in spite of their awareness about IPV. On the contrary, families with more egalitarian gender roles are more supportive towards their female victims (Roh, Burnette, Lee, Lee, \& Easton, 2016). Thus, the patriarchal nature of the family itself acts as a deterrent against prompt reporting and redressal of IPV. In the current study, greater family support was associated with lower incidence of IPV. Given that the Haitian culture is very patriarchal, there may be resistance to support of victims of IPV, however, the literature suggests that prevalence of IPV could be decreased if women received greater family support. Nevertheless, the hypothesis needs to be retested with larger studies where variables associated with family characteristics and their role in empowering victims have been collected. Only then will it be possible to understand the role of family support in preventing or decreasing IPV.

\section{Summary and Limitations}

In summary, this study sought to understand some of the predictors of IPV in a sample of Haitian women. Within the limited scope, the analyses found several of the determinants responsible for IPV in this population. Further large scale studies should be planned in the future as extensions of this study to better understand the associations observed here. 
There are some limitations that need to be acknowledged. This study involved cross-sectional analyses of data collected for a parent study. Because of the crosssectional analyses, only associations could be observed; causality and ordering of events could not be established with certainty. Data used for the current study were collected for the specific aims of the parent study and therefore variables may not have been specifically relevant to the aims of the current study. This limitation may be responsible for some surrogate information biases in the current study. 
Table 3.1. Demographics characteristics of the participants $(n=231)$

\begin{tabular}{|c|c|}
\hline Characteristics & Total \\
\hline Age in years, Mean $(S D)$ & $25.5(5.4)$ \\
\hline \multicolumn{2}{|l|}{ Education, $\mathrm{n}(\%)$} \\
\hline None & $9(3.9 \%)$ \\
\hline Primary & $62(26.8 \%)$ \\
\hline Secondary & $158(68.4 \%)$ \\
\hline College or professional & $2(0.9 \%)$ \\
\hline \multicolumn{2}{|l|}{ Yearly income in USD, $\mathrm{n}(\%)$} \\
\hline None & $72(31.2 \%)$ \\
\hline$\leq \$ 360$ & $53(22.9 \%)$ \\
\hline$>\$ 360$ & $106(45.9 \%)$ \\
\hline \multicolumn{2}{|l|}{ Marital status, n (\%) } \\
\hline Currently married & $0(0 \%)$ \\
\hline Living with a man but not married & $23(10.0 \%)$ \\
\hline Have partner, but not living together & $196(82.2 \%)$ \\
\hline $\begin{array}{r}\text { Not currently married or living with a } \\
\text { man }\end{array}$ & $11(4.8 \%)$ \\
\hline Number of children, Mean $(S D)$ & $1.7(1.1)$ \\
\hline $\begin{array}{l}\text { Length of stay in the community in } \\
\text { years, Mean }(S D)\end{array}$ & $7.5(6.2)$ \\
\hline \multicolumn{2}{|l|}{ Alcohol, n $(\%)$} \\
\hline Every day or nearly everyday & $30(13.0 \%)$ \\
\hline Once or twice a week & $53(23.0 \%)$ \\
\hline 1-3 times a month & $16(7.0 \%)$ \\
\hline Less than once a month & $35(15.2 \%)$ \\
\hline Never & $96(41.7 \%)$ \\
\hline \multicolumn{2}{|l|}{ Smoking, n (\%) } \\
\hline Daily & $32(13.9 \%)$ \\
\hline Occasionally & $21(9.1 \%)$ \\
\hline Not at all & $178(77.1 \%)$ \\
\hline Age of sexual debut, Mean $(S D)$ & $15.6(2.3)$ \\
\hline
\end{tabular}


Table 3.2. History of partner control, psychological violence, and physical violence among participants $(n=231)$

\section{Type of Partner Control}

Tries to keep you from seeing your friends

Tries to restrict contact with your family of birth

$112(48.5 \%)$

Insists on knowing where you are at all times

$176(76.2 \%)$

Ignores you and treats you indifferently

$183(79.2 \%)$

Gets angry if you speak with another man

$192(83.1 \%)$

Is often suspicious that you are unfaithful

$187(81.0 \%)$

Expects you to ask his permission before seeking health care for yourself

$126(54.5 \%)$

\section{Type of Psychological Violence}

Insulted you or made you feel bad about yourself

$201(87.0 \%)$

Belittled or humiliated you in front of other people

$193(83.5 \%)$

Did things to scare you on purpose

$168(72.7 \%)$

Threatened to hurt you or someone you care about

$178(77.1 \%)$

\section{Type of Physical Violence}

Slapped you or thrown something at you that could hurt you

Pushed you or shoved you

$221(95.7 \%)$

Hit you with his fist or with something else that could hurt you

$217(93.9 \%)$

Kicked you, dragged you or beaten you up

$190(82.3 \%)$

Choked or burnt you on purpose

$128(55.4 \%)$

Threatened to use or actually used a gun, knife or other weapon against you

$100(43.3 \%)$

\section{Type of Sexual Violence}

Physically forced you to have sexual intercourse when you did not want to

Did you ever have sexual intercourse you did not want because you were afraid of what he might do 
Table 3.3. Comparison of attitudes towards gender roles between participants with minor and major IPV $(n=231)$

\begin{tabular}{|c|c|c|c|}
\hline Questions & $\begin{array}{l}\text { Minor IPV } \\
104(45.0 \%)\end{array}$ & $\begin{array}{l}\text { Major IPV } \\
127(55.0 \%)\end{array}$ & $p$-value \\
\hline A good wife obeys her husband even if she disagrees & $76(73.1 \%)$ & $107(84.3 \%)$ & 0.03 \\
\hline Family problems should only be discussed with people in the family & $91(87.5 \%)$ & $116(91.3 \%)$ & 0.25 \\
\hline It is important for a man to show his wife/partner who is the boss & $85(81.7 \%)$ & $118(92.9 \%)$ & 0.01 \\
\hline $\begin{array}{l}\text { A woman should be able to choose her own friends even if her husband } \\
\text { disapproves }\end{array}$ & $30(28.8 \%)$ & $52(40.9 \%)$ & 0.03 \\
\hline $\begin{array}{l}\text { It's a wife's obligation to have sex with her husband even if she doesn't feel like } \\
\text { it }\end{array}$ & $22(21.2 \%)$ & $25(19.7 \%)$ & 0.64 \\
\hline If a man mistreats his wife, others outside of the family should intervene & $54(51.9 \%)$ & $45(35.4 \%)$ & 0.04 \\
\hline $\begin{array}{l}\text { Does a man have a good reason to hit his wife if she does not complete her } \\
\text { household work to his satisfaction }\end{array}$ & $6(5.8 \%)$ & $18(14.2 \%)$ & 0.03 \\
\hline Does a man have a good reason to hit his wife if she disobeys him & $7(6.7 \%)$ & $14(11.0 \%)$ & 0.37 \\
\hline $\begin{array}{l}\text { Does a man have a good reason to hit his wife if she refuses to have sexual } \\
\text { relations with him }\end{array}$ & $4(3.8 \%)$ & $3(2.4 \%)$ & 0.24 \\
\hline $\begin{array}{l}\text { Does a man have a good reason to hit his wife if she asks him whether he has } \\
\text { other girlfriends }\end{array}$ & $3(2.9 \%)$ & $2(1.6 \%)$ & 0.23 \\
\hline $\begin{array}{l}\text { Does a man have a good reason to hit his wife if he suspects that she is } \\
\text { unfaithful }\end{array}$ & $28(26.9 \%)$ & $54(42.5 \%)$ & 0.03 \\
\hline $\begin{array}{l}\text { Does a man have a good reason to hit his wife if he finds out she has been } \\
\text { unfaithful }\end{array}$ & $30(28.8 \%)$ & $55(43.3 \%)$ & 0.05 \\
\hline $\begin{array}{l}\text { Can a married woman refuse to have sex with her husband if she doesn't want } \\
\text { to }\end{array}$ & $46(44.2 \%)$ & $46(36.2 \%)$ & 0.45 \\
\hline Can a married woman refuse to have sex with her husband if he is drunk & $60(57.7 \%)$ & $62(48.8 \%)$ & 0.40 \\
\hline Can a married woman refuse to have sex with her husband if she is sick & $78(75.0 \%)$ & $79(62.2 \%)$ & 0.07 \\
\hline Can a married woman refuse to have sex with her husband if he mistreats her & $78(75.0 \%)$ & $77(60.6 \%)$ & 0.04 \\
\hline
\end{tabular}


Table 3.4. Correlation between demographic characteristics, age at sexual debut, partner alcohol, family support, mental health, IPV, CSA, and TGBA $(n=231)$

\begin{tabular}{|c|c|c|c|c|c|c|c|c|c|c|c|}
\hline & 1 & 2 & 3 & 4 & 5 & 6 & 7 & 8 & 9 & 10 & 11 \\
\hline 1. Age & --- & --- & --- & --- & --- & --- & --- & --- & --- & --- & --- \\
\hline 2. Income & -.077 & --- & --- & --- & --- & --- & --- & --- & --- & --- & --- \\
\hline 3. Marital status & $.258 * *$ & -.100 & --- & --- & --- & --- & --- & --- & --- & --- & --- \\
\hline 4. Education & .005 & .002 & -.117 & --- & --- & --- & --- & --- & --- & --- & --- \\
\hline 5. Age at sexual debut & $.298 * *$ & -.093 & .007 & $.181 * *$ & --- & --- & --- & --- & --- & --- & --- \\
\hline 6. Partner alcohol & $.174 *$ & $-.146^{*}$ & .033 & .029 & .072 & --- & --- & --- & --- & --- & --- \\
\hline 7. No family support & -.059 & -.017 & .057 & $-.218 * *$ & .044 & -.104 & --- & --- & --- & --- & --- \\
\hline 8. Mental health & .081 & -.075 & -.070 & $.275 * *$ & .012 & $.216^{* *}$ & $-.242 * *$ & --- & --- & --- & --- \\
\hline 9. CSA & -.067 & -.078 & $.199 * *$ & -.062 & $-.278 * *$ & -.099 & -.096 & -.041 & --- & --- & --- \\
\hline 10. TGBA & -.106 & .097 & .051 & -.012 & -.056 & .009 & -.012 & -.091 & $.277 * *$ & --- & --- \\
\hline 11. IPV & $-.159 *$ & -.051 & .029 & -.059 & -.038 & -.033 & $.176 * *$ & $-.131 *$ & $.156^{*}$ & .018 & --- \\
\hline
\end{tabular}
$* p<.05 ; * * p<.01 ; * * * p<.001$ 
Table 3.5. Generalized linear mixed modeling predicting Major IPV $(n=231)$

\begin{tabular}{|c|c|c|c|}
\hline Independent variables & Estimate (95\% CI) & SE & $p$-value \\
\hline Age & $-0.03(-0.06,0.01)$ & 0.02 & 0.1337 \\
\hline Lack of family support & $0.28(0.10,0.48)$ & 0.10 & 0.0048 \\
\hline \multicolumn{4}{|l|}{ Childhood sexual abuse } \\
\hline No & $-0.66(-1.28,-0.04)$ & 0.32 & 0.0383 \\
\hline Yes & Ref. & & \\
\hline Mental health score & $-0.03(-0.07,0)$ & 0.02 & 0.0852 \\
\hline \multicolumn{4}{|l|}{ Income } \\
\hline None & $0.36(-0.03,0.75)$ & 0.20 & 0.0705 \\
\hline$\leq \$ 360$ & $0.21(-0.25,0.67)$ & 0.23 & 0.3752 \\
\hline$>\$ 360$ & Ref. & & \\
\hline Education & $0.01(-0.05,0.07)$ & 0.03 & 0.6808 \\
\hline \multicolumn{4}{|l|}{ Marital status } \\
\hline Living with a man but not married & $-0.25(-1.06,0.56)$ & 0.41 & 0.5447 \\
\hline Have partner, but not living together & $-0.21(-1.12,0.69)$ & 0.46 & 0.6441 \\
\hline \multicolumn{4}{|l|}{$\begin{array}{l}\text { Not currently married or living with a man } \\
\text { Alcohol use by partner }\end{array}$} \\
\hline No & $0.29(-0.06,0.65)$ & 0.18 & 0.1045 \\
\hline Yes & Ref. & & \\
\hline Age of sexual debut & $0.01(-0.07,0.09)$ & 0.04 & 0.803 \\
\hline Traditional gender based attitudes & $0.1(0.04,0.17)$ & 0.03 & 0.0021 \\
\hline
\end{tabular}




\section{References}

Abramsky, T., Devries, K., Kiss, L., Nakuti, J., Kyegombe, N., Starmann, E., . . . Musuya, T. (2014). Findings from the SASA! Study: a cluster randomized controlled trial to assess the impact of a community mobilization intervention to prevent violence against women and reduce HIV risk in Kampala, Uganda. BMC Medicine, 12(1), 1.

Ali, P. A., \& Naylor, P. B. (2013). Intimate partner violence: A narrative review of the feminist, social and ecological explanations for its causation. Aggression and Violent Behavior, 18(6), 611-619.

Angelone, D. J., Mitchell, D., \& Grossi, L. (2014). Men's Perceptions of an Acquaintance Rape The Role of Relationship Length, Victim Resistance, and Gender Role Attitudes. Journal of Interpersonal Violence, 0886260514552448.

Barrios, Y. V., Gelaye, B., Zhong, Q., Nicolaidis, C., Rondon, M. B., Garcia, P. J., . . . Williams, M. A. (2015). Association of childhood physical and sexual abuse with intimate partner violence, poor general health and depressive symptoms among pregnant women. PloS One, 10(1), e0116609.

Bourey, C., Williams, W., Bernstein, E. E., \& Stephenson, R. (2015). Systematic review of structural interventions for intimate partner violence in low- and middleincome countries: organizing evidence for prevention. BMC Public Health, 15, 1165 .

CDC. (2013). Violence, crime, and abuse exposure in a national sample of children and youth: an update. JAMA Pediatrics, 167(7), 614-621.

CIA. (2016). Central America and Caribbean : HAITI. Retrieved from https://www.cia.gov/library/publications/the-world-factbook/geos/ha.html

Coovadia, H., Jewkes, R., Barron, P., Sanders, D., \& McIntyre, D. (2009). The health and health system of South Africa: historical roots of current public health challenges. Lancet, 374(9692), 817-834.

Dixon, L., \& Graham-Kevan, N. (2011). Understanding the nature and etiology of intimate partner violence and implications for practice and policy. Clinical Psychology Review, 31(7), 1145-1155.

Fawzi, M. S., Lambert, W., Singler, J., Tanagho, Y., Leandre, F., Nevil, P., . . Louissaint, M. (2005). Factors associated with forced sex among women accessing health services in rural Haiti: implications for the prevention of HIV infection and other sexually transmitted diseases. Social Science \& Medicine, 60(4), 679-689. 
Fehringer, J. A., \& Hindin, M. J. (2014). "I Get Angry If He's Always Drinking and We Have No Money": Exploring Motivations for Male and Female Perpetrated Intimate Partner Violence in the Philippines. Health Care for Women International, 35(4), 476-491.

Field, C. J., Kimuna, S. R., \& Lang, M. N. (2015). The relation of interracial relationships to intimate partner violence by college students. Journal of Black Studies, 46(4), 384-403.

García-Moreno, C. (2013). Global and regional estimates of violence against women: prevalence and health effects of intimate partner violence and non-partner sexual violence: World Health Organization.

Golden, S. D., Perreira, K. M., \& Durrance, C. P. (2013). Troubled times, troubled relationships: How economic resources, gender beliefs, and neighborhood disadvantage influence intimate partner violence. Journal of Interpersonal Violence, 0886260512471083.

Gómez-Camargo, D. E., Ochoa-Diaz, M. M., Canchila-Barrios, C. A., Ramos-Clason, E. C., Salguedo-Madrid, G. I., \& Malambo-García, D. I. (2014). Sexual and reproductive health in university students at an institution of higher learning in Colombia. Revista de Salud Pública, 16(5), 660-672.

Gomez, J. T. (2015). Instituto Nacional de Estadística e Informática. Retrieved from https://www.inei.gob.pe/media/MenuRecursivo/investigaciones/07-los-efectosde-la-crisis-migracion-de-jovenes-en-el-peru.pdf

Hall, M., Chappell, L. C., Parnell, B. L., Seed, P. T., \& Bewley, S. (2014). Associations between intimate partner violence and termination of pregnancy: a systematic review and meta-analysis. PLoS Med, 11(1), e1001581.

Hellmuth, J. C., Jaquier, V., Overstreet, N., Swan, S. C., \& Sullivan, T. P. (2014). The mediating role of avoidance coping between IPV victimization, mental health, and substance abuse among women experiencing bidirectional IPV. Psychiatry Research, 220, 391.

Iverson, K. M., Vogt, D., Dichter, M. E., Carpenter, S. L., Kimerling, R., Street, A. E., \& Gerber, M. R. (2015). Intimate partner violence and current mental health needs among female veterans. The Journal of the American Board of Family Medicine, 28(6), 772-776.

Kalokhe, A., del Rio, C., Dunkle, K., Stephenson, R., Metheny, N., Paranjape, A., \& Sahay, S. (2016). Domestic Violence Against Women in India: a systematic review of a decade of quantitative studies. Global Public Health, 1-16.

Kosia, A., Frumence, G., Likindikoki, S., Semakafu, A., Kakoko, D., \& Nyamhanga, T. (2016). 432 Role of government of Tanzania in addressing intimate partner violence: a case from Singida, Tanzania. Injury Prevention, 22(Suppl 2), A157A158. 
Lee, J., Pomeroy, E. C., \& Bohman, T. M. (2007). Intimate partner violence and psychological health in a sample of Asian and Caucasian women: The roles of social support and coping. Journal of Family Violence, 22(8), 709-720.

Lipsky, S., Kernic, M. A., Qiu, Q., Wright, C., \& Hasin, D. S. (2014). A Two-Way Street for Alcohol Use and Partner Violence: Who's Driving It? Journal of Family Violence, 29(8), 815-828.

Lövestad, S., Löve, J., Vaez, M., \& Krantz, G. (2016). Intimate partner violence and its association with depression: a population-based study in Sweden. The European Journal of Public Health, 26(suppl 1), ckw166. 048.

Mapayi, B., Makanjuola, R., Mosaku, S., Adewuya, O., Afolabi, O., Aloba, O., \& Akinsulore, A. (2013). Impact of intimate partner violence on anxiety and depression amongst women in Ile-Ife, Nigeria. Archives of Women's Mental Health, 16(1), 11-18.

Marchand, H. (2011). Violence, Inégalités de Genre et Vulnérabilité des Femmes au VIH/SIDA en Haïti. Mémoire présenté à la Faculté des Études supérieures de l'Université Laval dans le cadre du programme de maîtrise en santé communautaire pour l'obtention du grade de maître ès Sciences (M.Sc.). Retrieved from https://www.theses.ulaval.ca\%2F2011\%2F28299\%2F28299.pdf

McCloskey, L. A. (2016). Focus: Sex and Gender Health: The Effects of Gender-based Violence on Women's Unwanted Pregnancy and Abortion. The Yale Journal of Biology and Medicine, 89(2), 153.

McLeod, G., Horwood, L., \& Fergusson, D. (2016). Adolescent depression, adult mental health and psychosocial outcomes at 30 and 35 years. Psychological Medicine, 46(7), 1401.

Mitchell, J., Wight, M., Van Heerden, A., \& Rochat, T. J. (2016). Intimate partner violence, HIV, and mental health: a triple epidemic of global proportions. International Review of Psychiatry, 28(5), 452-463.

Mittal, M., Senn, T. E., \& Carey, M. P. (2013). Fear of violent consequences and condom use among women attending an STD clinic. Women \& health, 53(8), 795-807.

Overup, C. S., Dibello, A. M., Brunson, J. A., Acitelli, L. K., \& Neighbors, C. (2014). Drowning the pain: intimate partner violence and drinking to cope prospectively predict problem drinking. Addictive Behaviors, 41, 152-161.

Profamilia. (2000). Salud sexual y reproductiva en Colombia Resultados encuesta nacional de demografía y salud: Profamilia.

Prowse, K. M., Logue, C. E., Fantasia, H. C., \& Sutherland, M. A. (2014). Intimate Partner Violence and the CDC's Best-Evidence HIV Risk Reduction Interventions. Public Health Nursing, 31(3), 215-233. 
Regan, P. C., \& Durvasula, R. S. (2015). A Brief Review of Intimate Partner Violence in the United States: Nature, Correlates, and Proposed Preventative Measures. Interpersona, 9(2), 127.

Republique d'Haiti Ministère de La Santé Publique et de La Population (MSPP). (2012). Enquete Mortalité et Utilisation des Services EMMUS-V Haiti 2012. Retrieved from https://mspp.gouv.ht/site/downloads/EMMUS\%20V\%20document\%20final.pdf

Reyes, H. L. M., Foshee, V. A., Niolon, P. H., Reidy, D. E., \& Hall, J. E. (2016). Gender role attitudes and male adolescent dating violence perpetration: Normative beliefs as moderators. Journal of Youth and Adolescence, 45(2), 350-360.

Roh, S., Burnette, C. E., Lee, K. H., Lee, Y.-S., \& Easton, S. D. (2016). Risk and Protective Factors for Depressive Symptoms Among Indigenous Older Adults: Intimate Partner Violence (IPV) and Social Support. Journal of Gerontological Social Work, 59(4), 316-331.

Scarduzio, J. A., Carlyle, K. E., Harris, K. L., \& Savage, M. W. (2016). "Maybe She Was Provoked" Exploring Gender Stereotypes About Male and Female Perpetrators of Intimate Partner Violence. Violence Against Women, 1077801216636240.

Schechter, D. S., Moser, D. A., McCaw, J. E., \& Myers, M. M. (2014). Autonomic functioning in mothers with interpersonal violence-related posttraumatic stress disorder in response to separation-reunion. Developmental Psychobiology, 56(4), 748-760.

Sperry, D. M., \& Widom, C. S. (2013). Child abuse and neglect, social support, and psychopathology in adulthood: A prospective investigation. Child Abuse \& Neglect, 37(6), 415-425.

Stewart, R. C., Umar, E., Tomenson, B., \& Creed, F. (2014). Validation of the multidimensional scale of perceived social support (MSPSS) and the relationship between social support, intimate partner violence and antenatal depression in Malawi. BMC Psychiatry, 14(1), 1.

Sylaska, K. M., \& Edwards, K. M. (2014). Disclosure of Intimate Partner Violence to Informal Social Support Network Members A Review of the Literature. Trauma, Violence, \& Abuse, 15(1), 3-21.

Tenkorang, E. Y., Owusu, A. Y., Yeboah, E. H., \& Bannerman, R. (2013). Factors influencing domestic and marital violence against women in Ghana. Journal of Family Violence, 28(8), 771-781.

The World Bank. (2016). Haiti: The Challenges of Poverty Reduction. Retrieved from http://web.worldbank.org/WBSITE/EXTERNAL/TOPICS/EXTPOVERTY/EXT PA/0, contentMDK:20207590 menuPK:435735 pagePK:148956 piPK:216618 theSitePK:430367,00.html 
Umana, J. E., Fawole, O. I., \& Adeoye, I. A. (2014). Prevalence and correlates of intimate partner violence towards female students of the University of Ibadan, Nigeria. BMC Women's Health, 14(1), 1.

Walton, J. S., \& Chou, S. (2015). The Effectiveness of Psychological Treatment for Reducing Recidivism in Child Molesters A Systematic Review of Randomized and Nonrandomized Studies. Trauma, Violence, \& Abuse, 16(4), 401-417.

WHO. (2005). WHO multi country study on women's health and life events. Gender, Equity and Human Rights.

Wright, E. (2016). Less social support for women in disadvantaged neighborhoods means that they are more likely to be the victims of intimate partner violence. USAppAmerican Politics and Policy Blog.

Zhan, W., Shaboltas, A. V., Skochilov, R. V., Krasnoselskikh, T. V., \& Abdala, N. (2013). History of childhood abuse, sensation seeking, and intimate partner violence under/not under the influence of a substance: A cross-sectional study in Russia. PloS One, 8(7), e68027. 


\title{
CHAPTER IV: Association between Intimate Partner Violence and HIV Status among Haitian Women
}

\begin{abstract}
The prevalence of IPV among women in Haiti has reportedly increased from $25 \%$ to $29 \%$. A number of studies have associated higher levels of STD/HIV transmission with IPV among women, in part due to forced sexual activity and microscopic vaginal and anal tears that increase viral contact in raw wounds. This study examined the associations and contributory factors relating IPV and HIV status. The sample included HIV+ women ( $\mathrm{n}=55)$ attending the GHESKIO clinics who had experienced HIV. A sample of HIVwomen $(n=110)$, matched on demographic and mental health variables, were used as the controls. Mental and physical well-being, attitudes towards gender roles, and partner violence were assessed. Logistic regressions were utilized for calculating multivariable adjusted odds ratios. HIV+ participants reported poorer general and mental health. Both groups reported very high partner control, however HIV+ women were more likely to report more severe forms of violence $(\mathrm{p}<0.0001)$. Women who experienced severe forms of intimate partner violence were 3.5 times more likely to have an HIV positive status compared to those who did not experience severe IPV $(\beta=1.248, p<0.0001)$. This study points to the significant association between IPV and HIV status, indicating an important area for future studies and interventions.
\end{abstract}

\section{Introduction}

Intimate partner violence (IPV) has become a significant public health problem globally (Devries et al., 2013; WHO, 2005). IPV is described as either physical, psychological or sexual assault of a spouse or partner, either during cohabitation or 
sexual encounters (Wagman et al., 2015). Women in Haiti have reported an increase in the incidence of IPV from 25\% to 29\% (Republique d'Haiti Ministère de La Santé Publique et de La Population (MSPP), 2012). This statistic represents approximately one in three Haitian women. Globally, women have reported 25-30\% lifetime prevalence and 8-14\% past year prevalence for different types of IPV (Devries et al., 2013). However, the actual prevalence is uncertain because of the stigma associated with IPV, as well as the fear of backlash and permanent loss of relationship and economic sustenance in resource poor settings (Overstreet \& Quinn, 2013). Many studies have associated IPV with detrimental mental and physical health consequences, leading to irreparable damage (Iverson et al., 2015; McLeod, Horwood, \& Fergusson, 2016). In addition, IPV has also been associated with increased rates of sexually transmitted infections (STIs; Stockman, Lucea, \& Campbell, 2013).

A number of studies have associated higher levels of STI/HIV transmission with IPV among women (Decker et al., 2013; Kouyoumdjian et al., 2013; Stockman et al., 2013). For example, of the 2.5 million PLWH in India, $39 \%$ constitute women aged between 15-49 years. A majority of these women experience IPV, though prevalence is low (physical and sexual IPV reported by $7.68 \%$ and physical IPV in the absence of sexual violence reported by $27.80 \%$ of female PLWH) because of lower levels of reporting and negligence by the authorities (Silverman, Decker, Saggurti, Balaiah, \& Raj, 2008). In a study done among 1,366 South African women attending antenatal health care centers, HIV positive women reported $1.48(95 \%$ CI 1.15-1.89) times higher odds of experiencing IPV when compared to non-HIV infected women. Similarly, HIV positive women reported $1.52(95 \%$ CI 1·13-2.04) times higher odds of being dominated by their 
male partners (Dunkle et al., 2004). A Rwandan study conducted among married women showed that women experiencing different forms of IPV showed 3.46 times higher risk for acquiring HIV and 4.11 times higher risk for other STIs (Dude, 2011). In a randomized controlled study among 1,590 African American and Hispanic women in New York, 1 in 5 women reported IPV in the past month. This study also found that there were higher rates of HIV and other STIs in women who reported IPV in either of the two time intervals (Wu, El-Bassel, Witte, Gilbert, \& Chang, 2003). Thus, there is considerable evidence for the association between IPV experienced by women and higher risk for HIV/STI transmission.

A number of risk factors have been associated with IPV that increase the likelihood of acquiring and transmitting HIV infections. These factors include forced sexual activity, accessory injuries to vagina or other body parts, microscopic lacerations and tears to the anal and buccal mucosa as well as nail injuries to skin and other sensitive areas thereby increasing viral contact to the raw wounds and increasing transmission rates (Gilbert et al., 2016). In addition, women experiencing IPV are often subjected to nonconsensual sexual activities without any open communication about risk factors such as promiscuity, extramarital affairs, or commercial sex worker contact (Stockman et al., 2013). Women who are HIV infected also avoid testing and disclosure of their serostatus to their partners due to fear of exacerbation of IPV, loss of economic support and banishment from the family and community (Nasrullah, Oraka, Breiding, \& Chavez, 2013).

In view of this evidence, researchers decided to further explore these associations among Haitian women living in impoverished and marginalized settings. Primary aims 
were to: 1) to describe the demographic factors and the prevalence of different types of IPV in a sample of women recruited in Haiti; and 2) to understand whether there were associations between IPV and HIV status and the contributory factors that exacerbated or alleviated these relationships.

\section{Methods}

\section{Participants and Setting}

From January to December 2013, a cohort of men and women attending GHESKIO (Haitian Group for the Study of Kaposi's Sarcoma and Opportunistic Infections) and its partner clinics in Port-au-Prince, Haiti, were enrolled in a crosssectional study to examine gender-based roles/attitudes and prevalence of intimate partner violence. A sub-sample of HIV positive women with complete demographics information $(n=55)$ was selected from a group of women who had experienced IPV $(\mathrm{N}=$ 513). From the same study, an age, physical, and mental health score adjusted random sample was drawn to form a pool of potential matches. A 1:2 optimized matching was performed to get a control group with 110 HIV negative participants with history of IPV since the number of participants with HIV+ serostatus was relatively small. This method would increase the statistical power of finding an association between our outcome and independent variables. From the pool of HIV-participants, one 'optimal' choice of matched pair was selected on the basis of \pm 2 age in years, mental and physical well being composite scores. In the original study, these women were asked several questions related to their general health condition in the past 4 weeks and 12 months, recent intimate partner violence history, and questions related to their family/community. 


\section{Measures}

Demographic Information: Age (18 - 75 years), education attainment (None, Primary, and Secondary and above), marital status (Married/living as married and Single/living as single), income (None, $\leq 25,000$, and $>25,000$ Haitian Gourdes [approx. US\$370]), number of children, length of stay in the community (in years), alcohol use, smoking history, and age of sexual debut (in years) were collected.

WHO Self-reported Questionnaire-20 (SRQ-20): A culturally adapted questionnaire from the multi-country study conducted by the World Health Organization (WHO) was used to measure mental and physical well-being among participants (WHO, 2005). This 20-item questionnaire asked participants about their general health, mental health, and if they felt easily tired when performing daily activities. Responses to these questions were 'Yes $(=1)$ ' and 'No $(=0)$ '. All questions were added to compute a composite score that ranged from 0 to 20 with higher scores depicting higher symptoms of adverse general and mental health conditions. Questions were also divided into four domains of decreased energy, somatic symptoms, depressive mood, and depressive thoughts. Composite scores for each domain were also calculated. Cronbach's alpha for the SRQ was 0.83 .

Attitudes Towards Gender Roles: A culturally adapted questionnaire from the multicountry study conducted by the WHO was used to measure attitude towards gender roles (WHO, 2005). Five questions were asked to measure traditional or non-traditional attitudes towards gender roles. These were (1) A good wife obeys her husband even if she disagrees; (2) It is important for a man to show his wife/partner who is the boss; (3) A woman should not be able to choose her own friends even if her husband disapproves; (4) It's a wife's obligation to have sex with her husband even if she doesn't feel like it; and (5) 
If a man mistreats his wife, others outside of the family should not intervene. Responses to these questions included 'Agree,' 'Disagree,' and 'Don't know.' Since 'Don't know' responses did not provide information about attitudes, it was excluded from the analysis. Partner violence: A culturally adapted questionnaire from the multi-country study conducted by the WHO was used to measure partner violence (WHO, 2005). The questionnaire contained four domains to measure different types of partner violence. Partner's controlling behavior - Controlling behavior of an intimate partner was assessed by asking participants seven questions: (1) Tries to keep you from seeing your friends; (2) Tries to restrict contact with your family of birth; (3) Insists on knowing where you are at all times; (4) Ignores you and treats you indifferently; (5) Gets angry if you speak with another man; (6) Is often suspicious that you are unfaithful; and (7) Expects you to ask his permission before seeking health care for yourself. Responses to these questions were 'Yes (=1)' and 'No (=0)'. Cronbach's alpha for the seven questions was 0.66. Psychological violence - History of varying levels of lifetime psychological violence was asked by four items: (1) Insulted you or made you feel bad about yourself; (2) Belittled or humiliated you in front of other people; (3) Did things to scare you on purpose; and (4) Threatened to hurt you or someone you care about. Degree of psychological violence increased from first to fourth question. Responses to these questions were 'Yes $(=1)$ ' and 'No $(=0)$ '. Cronbach's alpha for the four questions was 0.71. Physical violence - History of lifetime physical violence by an intimate partner was reported through six items: (1) Slapped you or thrown something at you that could hurt you; (2) Pushed you or shoved you; (3) Hit you with his fist or with something else that could hurt you; (4) Kicked you, dragged you or beaten you up; (5) Choked or burnt you 
on purpose; and (6) Threatened to use or actually used a gun, knife or other weapon against you. Severity of physical violence increased from the first to sixth question. Responses to these questions were 'Yes $(=1)$ ' and 'No $(=0)$ '. Cronbach's alpha for the four questions was 0.78 . Sexual violence - History of an intimate partner's sexual violence towards a participant was recorded by asking three questions: (1) Physically forced you to have sexual intercourse when you did not want to; (2) Did you ever have sexual intercourse you did not want because you were afraid of what he might do; and (3) Did he ever force you to do something sexual that you found degrading or humiliating. Responses to these questions were 'Yes $(=1)$ ' and 'No $(=0)$ '. Cronbach's alpha for the three items was 0.41 , and it was lowest among all types of violence items.

\section{Statistical Analysis}

Statistical analyses were performed using SAS software version 9.4. Descriptive statistics for continuous variables were reported as means and standard deviations $(S D)$. For categorical or nominal variables, frequencies and percentages were reported. Differences in means were calculated using independent sample t-Tests, and differences in proportions were calculated using Chi-square tests. For all analyses, statistical tests were performed with an alpha level of 0.05 . Univariate statistics were reported and compared between the two groups. Logistic regression analysis with HIV seropositive status as dependent variable was used for calculating bivariate odds ratios, multivariable adjusted odds ratios (AOR), and 95\% confidence intervals (CI). HIV status was recoded as a binary dependent variable with a value of ' 1 ' representing HIV positive status and '0' HIV negative status. Variables with a minimum significance of 0.10 in the bivariate analyses were included in the final logistic regression model. 


\section{Results}

\section{Demographic Characteristics}

The mean $(S D)$ age for HIV positive and negative participants was $28.8(5.7)$ and 26.5 (5.5) years respectively (Table 4.1). On average, HIV positive women were two years older than the HIV negative control group $(\mathrm{p}<0.01)$. Secondary education was reported to be about $17 \%$ higher in the control group (HIV negative) as compared to women who were HIV+ $(\mathrm{p}<0.05)$. Approximately $47 \%$ of the HIV+ women did not report any source of income, compared to only $28 \%$ women in the control group (p < 0.05). Compared to the HIV+ women, 1.5 times more HIV negative participants reported earning higher than 25,000 Haitian Gourdes (HTG; 1 HTG = \$68 USD) last year (p < 0.05). The majority of women in the case and control groups were either single or living without a partner. However, HIV positive cases were more likely to be married or living with a partner than women in the control group. Mean (SD) number of children among HIV+ women was significantly higher than among HIV- women $(\mathrm{p}<0.5)$. Women in the HIV+ group also reported an average of $8.3(7.2)$ years living in the same community as compared to 6.6 (5.1) years in the control group. However, the difference was not significant $(\mathrm{p}>0.20)$. Frequency of drinking alcoholic beverages was about 3.8 times ( $p$ $<0.02)$ and smoking was 2.4 times higher $(\mathrm{p}<0.01)$ among HIV+ women. The mean age of sexual debut was slightly lower among HIV+ women, 15.8 years, compared to 16 years among the control group, but the difference between the two groups was not significant $(\mathrm{p}>0.05)$. 


\section{General Health, Mental Health, and Daily Activities}

On average, HIV positive participants reported poorer general and mental health. The total composite mean score for SRQ-20 was significantly higher among HIV positive participants $(\mathrm{p}<0.05)$. As explained in the methods section, higher SRQ reflects poorer general and mental health. These participants also reported higher suicidal thinking, anxiety symptoms, and tiredness when compared to the control group (Table 4.2).

\section{Attitudes Towards Gender Roles}

HIV positive participants showed non-traditional gender-based attitudes in general (Table 4.3). However, a majority (69\%) reported that if a man mistreats his wife, others outside of the family should not intervene. This finding was significantly higher than the control group, in which only $46 \%$ participants said this. In response to questions about whether a good wife should obey her husband even if she disagrees, and whether a woman should be able to choose her own friends even if her husband disapproves, a majority of HIV negative participants responded yes with $66 \%$ and $73 \%$ respectively. As compared to this, only $49 \%$ and $56 \% \mathrm{HIV}+$ participants responded yes. In questions about whether it is important for a man to show his wife/partner who is the boss and it being a wife's obligation to have sex with her husband even if she doesn't feel like it, there were no differences between the two groups. Approximately $80 \%$ of participants in both groups responded that it is important for a man to show his wife/partner who is the boss.

\section{Partner Violence}

In general, the majority of participants in both groups showed higher partner control by answering yes to majority of (six out of seven) questions. HIV positive 
participants reported higher control by intimate partners with respect to two questions that asked if a partner tried to keep them from seeing their friends and restricted their contact with their family of birth (Table 4.4). Among questions about types of psychological violence, the percentage of HIV positive participants who said yes to questions that asked if a respondent was belittled or humiliated in front of other people by an intimate partner and if any intimate partner did things to scare a respondent on purpose was higher compared to HIV negative participants. On the questions that enquired about any history of severe physical violence among respondents, $69 \%$ of HIV positive participants reported that they were choked or burnt on purpose and $71 \%$ said that their partner had threatened to use or actually used a gun, knife or other weapon against them. This severe form of violence was significantly higher among HIV+ participants as compared to HIV negative women $(\mathrm{p}<0.0001)$. Prevalence of sexual violence was similar across the two groups with the exception of 'Physically forced you to have sexual intercourse when you did not want to' question, where HIV negative participants reported significantly higher prevalence.

\section{Relationship Between IPV and HIV Status}

Results from logistic regression analysis show that participants with incomes of $\leq 25,000$ HTG (approximately US\$370) were 0.24 as likely to have an HIV positive status compared to participants with no income (Table 4.5). Age at sexual debut was inversely proportional to HIV positive status indicating that early age of sexual debut was associated with HIV positive status. Participants with later age of sexual debut were $25 \%$ less likely to have an HIV positive status. The composite score for history of severe forms of violence was positively associated with HIV positive status and showed that 
participants who experienced severe forms of intimate partner violence were 3.5 times more likely to have an HIV positive status compared to those who did not experience severe IPV. Low education attainment, married or living as married status, psychiatric disturbance, and psychological violence were positively associated with HIV positive status, however, these were not statistically significant. HIV positive participants reported less sexual violence, and although the composite score for sexual violence was negatively associated with their status, it was not significant.

\section{Discussion}

This is one of the few studies that has examined the relationship between IPV and HIV in a representative sample of women from Haiti. In this study, it was found that history of IPV was significantly associated with HIV seropositive status. The analyses also determined that participants who reported earlier age of first sexual debut were significantly more likely to be HIV positive when compared to those who reported later age of sexual debut. In addition, women who had an income were less likely to be HIV+ compared to women with no income.

The findings of this study represent extensions of similar work relating IPV and HIV in other resource poor settings. A number of studies have shown that pediatric sexual assault, sexual coercion and adult sexual assault were associated with greater risk for HIV transmission (Decker et al., 2016; Engstrom, Winham, \& Gilbert, 2016). For example, in a study among PLWH in India, physical violence and sexual violence were associated with higher prevalence of HIV infection among married women (Silverman et al., 2008). However, this Indian study showed that such incidences were associated with increased sexual risk behaviors and not directly associated with HIV seroconversion. In 
addition, the Indian study also found associations between IPV and high risk behaviors such as multiple partners, non-primary partners, transactional sex and substance use, which could not be measured in this study. Though a few studies have reported that sexual transmission occurred bidirectionally between men and women (Boily et al., 2009; Ruzagira et al., 2011), and that dominant men were not solely responsible for transmitting HIV to their submissive female partners, the prevalence of HIV among young female partners was around $90 \%$ higher than among males (Chomba et al., 2008). Although the mechanism of action was not determined in this study, that is, whether transmission occurred through contact with an infected partner, or via risky behaviors on the part of the women, this question is an important one, and should be determined in order to allow for more targeted interventions in the future.

In this study, participants with early initiation of sexual activity reported higher rates of HIV disease. This finding is also supported by other studies in resource limited settings. In a study conducted by Pettifor et al. among sexually active adult women, there were significant associations between early age of coital debut and risk for acquiring HIV infection (relative hazard - 1.30; 95\% CI: 1.13-1.50), after controlling for age and duration of sexual activity (Pettifor, Van Der Straten, Dunbar, Shiboski, \& Padian, 2004). However, unlike the current study, the Pettifor study reported that the relationship between coital debut and risk for HIV infection diminished and became non-significant after controlling for number of sexual partners, thus emphasizing the greater role of sexual promiscuity in HIV transmission compared to coital debut. In another study, age at first sexual intercourse was directly associated with prevalence of chlamydial infection, gonorrhea, and trichomoniasis (Kaestle, Halpern, Miller, \& Ford, 2005). These STIs are 
known risk factors for HIV disease transmission (Kalichman, Pellowski, \& Turner, 2011; Lissouba, Van de Perre, \& Auvert, 2013; Ward \& Rönn, 2010). The current study was not able to distinguish among the factors mentioned above since the parent study did not collect data that allowed these analyses, thereby limiting understanding of the characteristics associated with HIV. However, it would be important for future researchers in Haiti to assess these characteristics in an effort to determine if they are relevant in the Haitian population.

The relationship between poverty and HIV disease prevalence observed in this study is a well-established association. Even during the early years of the epidemic, Stillwagon (2000) showed that HIV disease prevalence was highly correlated with poverty and associated risk factors such as inadequate caloric intake, non-nutritious foods, and other STIs. Several other studies have also acknowledged poverty as one of the greatest risk factors for HIV disease transmission and was associated with disease severity and mortality (Bärnighausen, Hosegood, Timaeus, \& Newell, 2007; Chapoto \& Jayne, 2005; Chapoto, Kirimi, \& Kadiyala, 2012). Thus, it is not surprising that poverty and its associated factors, such as illiteracy and poor living conditions in Haiti, would be associated with increased prevalence of HIV in this sample, irrespective of incidence of IPV. The current study also postulates that poverty transmigrated from many macro factors, such as inadequate nutrition, lower education, poor living conditions, and limited accessibility to care, to individual factors, such as weakened immune recuperation, uncontrolled viral load, and suboptimal compliance to antiretroviral therapy.

The findings of this study are very relevant for HIV prevention and care. It would be valuable for clinicians to enquire about IPV incidence among patients in HIV/STI 
clinics. Detailed inquiry may also help to address appropriate wound care strategies for injuries incurred during IPV to prevent transmission of HIV through raw wounds and infected surfaces and identify HIV negative women at highest risk of infection. Better HIV testing and education services could be implemented in areas reporting higher rates of domestic violence and IPV in Haiti. This strategy would empower victims experiencing IPV to be cautious about injuries and promote increased reporting of violence.

It is very important to identify, educate and empower victims experiencing IPV. Community-based programs should improve awareness among women experiencing and surviving IPV. This approach would lead to increased awareness about such incidents and promote immediate reporting and improved care. Clinical programs should further investigate the number of cases and transmission rates ascribed directly to IPV. This plan would enable researchers to devise appropriate strategies such as risk prevention, early intervention, and access to health care resources to reduce HIV transmission rates.

There are several limitations that should be acknowledged. Because this study involved cross-sectional analyses of data collected for the parent study, only associations could be observed; causality and ordering of events could not be established. Data used for the current study were collected for the specific aims of the parent study and therefore variables that would have allowed further in-depth assessment of the initial findings were not available, since they were not a part of the specific aims of the parent study. This fact may be responsible for some surrogate information bias in the current study. A number of other unaccounted for factors affecting the outcome variables in the present study were not collected by the parent study, thus limiting the results of this study. For example, 
variables such as sexual risk behavior, childhood sexual abuse, length of time in relationship involving IPV, other STIs, and substance use could not be ascertained because data were already collected for the parent study.

The data is self-reported and recall and social desirability biases may have affected the findings of this study. The study participants were recruited from the GHESKIO centers, which provide comprehensive health care services, free of charge, to socioeconomically underprivileged communities in Haiti. Participants in this study may therefore differ significantly from individuals who have limited access to the GHESKO centers due to structural barriers. Thus, the results of this study cannot be generalized to the entire Haitian population.

In this study, only female participants were observed for the associations between IPV and HIV prevalence. Male partners and their STI transmission risk factors were not assessed as part of this study. 
Table 4.1. Demographics characteristics of the participants $(n=165)$

\begin{tabular}{|c|c|c|c|}
\hline Characteristics & $\begin{array}{c}\text { HIV positive } \\
(\mathrm{n}=55,33.3 \%)\end{array}$ & $\begin{array}{c}\text { HIV negative } \\
(n=110,66.6 \%)\end{array}$ & $p$-value \\
\hline Age in years, mean (SD) & $28.8(5.7)$ & $26.5(5.5)$ & 0.01 \\
\hline \multicolumn{4}{|l|}{ Education, $\mathrm{n}(\%)$} \\
\hline None & $9(16.4 \%)$ & $7(6.4 \%)$ & 0.04 \\
\hline Primary & $15(27.3 \%)$ & $22(20.0 \%)$ & \\
\hline Secondary and above & $31(56.4 \%)$ & $81(73.6 \%)$ & \\
\hline \multicolumn{4}{|l|}{ Income in Haitian gourde, $\mathrm{n}(\%)$} \\
\hline None & $26(47.3 \%)$ & $31(28.2 \%)$ & 0.04 \\
\hline$\leq 25,000$ & $14(25.5 \%)$ & $33(30.0 \%)$ & \\
\hline$>25,000$ & $15(27.3 \%)$ & $46(41.8 \%)$ & \\
\hline \multicolumn{4}{|l|}{ Marital status, n (\%) } \\
\hline Married/ living as married & $17(30.9 \%)$ & $19(17.3 \%)$ & 0.04 \\
\hline Single/living as single & $38(69.1 \%)$ & $91(82.7 \%)$ & \\
\hline Number of children, mean (SD) & $1.5(1.4)$ & $1.1(1.1)$ & 0.03 \\
\hline $\begin{array}{l}\text { Length of stay in the community in } \\
\text { years, mean (SD) }\end{array}$ & $8.3(7.2)$ & $6.6(5.1)$ & 0.20 \\
\hline \multicolumn{4}{|l|}{ Alcohol, n (\%) } \\
\hline Every day or nearly everyday & $13(24.1 \%)$ & $7(6.4 \%)$ & 0.02 \\
\hline Once or twice a week & $8(14.8 \%)$ & $24(21.8 \%)$ & \\
\hline 1-3 times a month & $3(5.6 \%)$ & $10(9.1 \%)$ & \\
\hline Less than once a month & $8(14.8 \%)$ & $21(19.1)$ & \\
\hline Never & $22(40.7 \%)$ & $48(43.6 \%)$ & \\
\hline \multicolumn{4}{|l|}{ Smoking, n (\%) } \\
\hline Daily & $12(21.8 \%)$ & $10(9.1 \%)$ & 0.01 \\
\hline Occasionally & $9(16.4 \%)$ & $8(7.3 \%)$ & \\
\hline Not at all & $34(61.8 \%)$ & $92(83.6 \%)$ & \\
\hline Age of sexual debut, mean (SD) & $15.8(2.8)$ & $16.0(2.5)$ & 0.70 \\
\hline
\end{tabular}


Table 4.2. WHO Self-Reported questionnaire-20 score by HIV status ( $n=165)$

\begin{tabular}{llll}
\hline & HIV positive & HIV negative & \\
Self-reported Questionnaire-20 & $(\mathbf{n = 5 5 , 3 3 . 3 \% )}$ & $(\mathbf{n = 1 1 0 , 6 6 . 6 \%})$ & $\boldsymbol{p}$-value \\
\hline Decreased energy, mean $(S D)$ & $4.0(1.4)$ & $3.6(1.7)$ & 0.21 \\
Somatic symptoms, mean $(S D)$ & $2.5(1.1)$ & $2.3(1.2)$ & 0.25 \\
Depressive mood, mean $(S D)$ & $2.2(0.8)$ & $2.1(0.9)$ & 0.27 \\
Depressive thoughts, mean $(S D)$ & $2.6(1.1)$ & $2.3(1.4)$ & 0.14 \\
Total, mean $(\boldsymbol{S D})$ & $13.2(3.8)$ & $11.8(4.9)$ & 0.04 \\
\hline
\end{tabular}


Table 4.3. Attitudes towards gender roles among HIV positive and negative participants $(n=165)$

\begin{tabular}{lllc}
\hline \multicolumn{1}{c}{ Attitudes Towards Gender Roles } & $\begin{array}{c}\text { HIV positive } \\
(\mathbf{n = 5 5 , 3 3 . 3 \%})\end{array}$ & $\begin{array}{c}\text { HIV negative } \\
(\mathbf{n = 1 1 0 , 6 6 . 6 \%})\end{array}$ & $\begin{array}{c}\boldsymbol{p} \text { - } \\
\text { value }\end{array}$ \\
\hline $\begin{array}{l}\text { A good wife obeys her husband even if } \\
\text { she disagrees }\end{array}$ & $27(49.1 \%)$ & $73(66.4 \%)$ & 0.03 \\
$\begin{array}{l}\text { It is important for a man to show his } \\
\text { wife/partner who is the boss }\end{array}$ & $44(80 \%)$ & $90(84.1 \%)$ & 0.51 \\
$\begin{array}{l}\text { A woman should be able to choose her } \\
\text { own friends even if her husband } \\
\text { disapproves }\end{array}$ & $31(56.4 \%)$ & $78(72.9 \%)$ & 0.03 \\
$\begin{array}{l}\text { It's a wife's obligation to have sex with } \\
\text { her husband even if she doesn't feel like } \\
\text { it }\end{array}$ & $13(23.6 \%)$ & $25(22.7 \%)$ & 0.90 \\
$\begin{array}{l}\text { If a man mistreats his wife, others } \\
\text { outside of the family should not } \\
\text { intervene }\end{array}$ & $38(69.1 \%)$ & $50(45.9 \%)$ & 0.01 \\
\hline
\end{tabular}


Table 4.4. Partner violence among HIV positive and negative participants $(n=165)$

\begin{tabular}{|c|c|c|c|}
\hline & $\begin{array}{c}\text { HIV positive } \\
(\mathrm{n}=\mathbf{5 5}, \mathbf{3 3 . 3 \%})\end{array}$ & $\begin{array}{c}\text { HIV negative } \\
(\mathrm{n}=110,66.6 \%)\end{array}$ & $p$-value \\
\hline \multicolumn{4}{|l|}{ Type of Control } \\
\hline Tries to keep you from seeing your friends & $39(70.9 \%)$ & $53(48.2 \%)$ & 0.006 \\
\hline Tries to restrict contact with your family of birth & $35(63.6 \%)$ & $28(25.5 \%)$ & $<0.0001$ \\
\hline Insists on knowing where you are at all times & $37(67.3 \%)$ & $68(61.8 \%)$ & 0.50 \\
\hline Ignores you and treats you indifferently & $35(63.6 \%)$ & $73(66.4 \%)$ & 0.73 \\
\hline Gets angry if you speak with another man & $42(76.4 \%)$ & $81(73.6 \%)$ & 0.71 \\
\hline Is often suspicious that you are unfaithful & $39(70.9 \%)$ & $68(61.8 \%)$ & 0.25 \\
\hline $\begin{array}{l}\text { Expects you to ask his permission before seeking health care for yourself } \\
\text { Type of Psychological Violence }\end{array}$ & $25(45.5 \%)$ & $41(37.3 \%)$ & 0.31 \\
\hline Insulted you or made you feel bad about yourself & $39(70.9 \%)$ & $69(62.7 \%)$ & 0.30 \\
\hline Belittled or humiliated you in front of other people & $39(70.9 \%)$ & $61(55.5 \%)$ & 0.04 \\
\hline Did things to scare you on purpose & $35(63.6 \%)$ & $47(42.7 \%)$ & 0.01 \\
\hline Threatened to hurt you or someone you care about & $30(54.5 \%)$ & $44(40.0 \%)$ & 0.07 \\
\hline \multicolumn{4}{|l|}{ Type of Physical Violence } \\
\hline Slapped you or thrown something at you that could hurt you & $13(23.6 \%)$ & $74(67.3 \%)$ & $<0.0001$ \\
\hline Pushed you or shoved you & $16(29.1 \%)$ & $71(64.5 \%)$ & $<0.0001$ \\
\hline Hit you with his fist or with something else that could hurt you & $20(36.4 \%)$ & $67(60.9 \%)$ & 0.003 \\
\hline Kicked you, dragged you or beaten you up & $15(27.3 \%)$ & $47(42.7 \%)$ & 0.05 \\
\hline Choked or burnt you on purpose & $38(69.1 \%)$ & $18(16.4)$ & $<0.0001$ \\
\hline $\begin{array}{l}\text { Threatened to use or actually used a gun, knife or other weapon against you } \\
\text { Type of Sexual Violence }\end{array}$ & $39(71.0 \%)$ & $8(7.3 \%)$ & $<0.0001$ \\
\hline Physically forced you to have sexual intercourse when you did not want to & $16(29.1 \%)$ & $54(49.1 \%)$ & 0.01 \\
\hline $\begin{array}{l}\text { Did you ever have sexual intercourse you did not want because you were afraid } \\
\text { of what he might do }\end{array}$ & $17(30.9 \%)$ & $32(29.1 \%)$ & 0.81 \\
\hline $\begin{array}{l}\text { Did he ever force you to do something sexual that you found degrading or } \\
\text { humiliating }\end{array}$ & $22(40.0 \%)$ & $89(35.5 \%)$ & 0.60 \\
\hline
\end{tabular}


Table 4.5. Logistic regression analysis showing association between IPV and HIV+ status $(n=165)$

\begin{tabular}{lcccccc}
\hline \multicolumn{1}{c}{ Variables } & Beta & $\begin{array}{c}\text { Standard } \\
\text { error }\end{array}$ & $\boldsymbol{p}$-value & AOR & Lower & Upper \\
\hline Age & 0.027 & 0.051 & 0.601 & 1.027 & 0.930 & 1.134 \\
Education & & & & & & \\
$\quad$ None & & & 0.101 & & & \\
$\quad$ Primary & -0.264 & 0.825 & 0.749 & 0.768 & 0.152 & 3.867 \\
$\quad$ Secondary and above & -1.405 & 0.820 & 0.086 & 0.245 & 0.049 & 1.223 \\
Income & & & & & & \\
$\quad$ None & & & 0.081 & & & \\
S25,000 & -1.430 & 0.695 & 0.040 & 0.239 & 0.061 & 0.935 \\
>25,000 & -0.991 & 0.613 & 0.106 & 0.371 & 0.112 & 1.234 \\
Marital status & & & & & & \\
$\quad$ Single/living as single & & & & & & \\
Married/living as married & 0.687 & 0.710 & 0.333 & 1.988 & 0.494 & 7.996 \\
Age at sexual debut & -0.295 & 0.123 & 0.016 & 0.745 & 0.585 & 0.948 \\
Psychiatric disturbance & 0.029 & 0.061 & 0.636 & 1.029 & 0.914 & 1.159 \\
Physical violence & 1.248 & 0.208 & $<0.0001$ & 3.482 & 2.316 & 5.235 \\
Psychological violence & 0.377 & 0.202 & 0.062 & 1.457 & 0.981 & 2.165 \\
Sexual violence & -1.037 & 0.575 & 0.071 & 0.354 & 0.115 & 1.095 \\
\hline
\end{tabular}




\section{References}

Bärnighausen, T., Hosegood, V., Timaeus, I. M., \& Newell, M.-L. (2007). The socioeconomic determinants of HIV incidence: evidence from a longitudinal, population-based study in rural South Africa. AIDS, 21(Suppl 7), S29.

Boily, M.-C., Baggaley, R. F., Wang, L., Masse, B., White, R. G., Hayes, R. J., \& Alary, M. (2009). Heterosexual risk of HIV-1 infection per sexual act: systematic review and meta-analysis of observational studies. The Lancet Infectious Diseases, 9(2), 118-129.

Chapoto, A., \& Jayne, T. S. (2005). Characteristics of individuals afflicted by aidsrelated mortality in Zambia. Retrieved from https://ideas.repec.org/p/ags/midcwp/54472.html

Chapoto, A., Kirimi, L., \& Kadiyala, S. (2012). Poverty and Prime-Age Mortality in Eastern and Southern Africa: Evidence from Zambia and Kenya. World Development, 40(9), 1839-1853.

Chomba, E., Allen, S., Kanweka, W., Tichacek, A., Cox, G., Shutes, E., . . Stephenson, R. (2008). Evolution of couples' voluntary counseling and testing for HIV in Lusaka, Zambia. Journal of Acquired Immune Deficiency Syndromes, 47(1), 108115.

Decker, M. R., Benning, L., Weber, K. M., Sherman, S. G., Adedimeji, A., Wilson, T. E., ... Golub, E. T. (2016). Physical and Sexual Violence Predictors: 20 Years of the Women's Interagency HIV Study Cohort. American Journal of Preventive Medicine, 51(5), 731-742.

Decker, M. R., Miller, E., McCauley, H. L., Tancredi, D. J., Anderson, H., Levenson, R. R., \& Silverman, J. G. (2013). Recent partner violence and sexual and drugrelated STI/HIV risk among adolescent and young adult women attending family planning clinics. Sexually Transmitted Infections, 051288.

Devries, K. M., Mak, J. Y., García-Moreno, C., Petzold, M., Child, J. C., Falder, G., . . . Rosenfeld, L. (2013). The global prevalence of intimate partner violence against women. Science, 340(6140), 1527-1528.

Dude, A. M. (2011). Spousal intimate partner violence is associated with HIV and other STIs among married Rwandan women. AIDS and Behavior, 15(1), 142-152.

Dunkle, K. L., Jewkes, R. K., Brown, H. C., Gray, G. E., McIntryre, J. A., \& Harlow, S. D. (2004). Gender-based violence, relationship power, and risk of HIV infection in women attending antenatal clinics in South Africa. The Lancet, 363(9419), 1415-1421. 
Engstrom, M., Winham, K., \& Gilbert, L. (2016). Types and characteristics of childhood sexual abuse: how do they matter in HIV sexual risk behaviors among women in methadone treatment in New York City? Substance Use \& Misuse, 51(3), 277294.

Gilbert, L., Goddard-Eckrich, D., Hunt, T., Ma, X., Chang, M., Rowe, J., . . Almonte, M. (2016). Efficacy of a computerized intervention on HIV and intimate partner violence among substance-using women in community corrections: a randomized controlled trial. American Journal of Public Health, 106(7), 1278-1286.

Iverson, K. M., Vogt, D., Dichter, M. E., Carpenter, S. L., Kimerling, R., Street, A. E., \& Gerber, M. R. (2015). Intimate partner violence and current mental health needs among female veterans. The Journal of the American Board of Family Medicine, 28(6), 772-776.

Kaestle, C. E., Halpern, C. T., Miller, W. C., \& Ford, C. A. (2005). Young age at first sexual intercourse and sexually transmitted infections in adolescents and young adults. American Journal of Epidemiology, 161(8), 774-780.

Kalichman, S. C., Pellowski, J., \& Turner, C. (2011). Prevalence of sexually transmitted co-infections in people living with HIV/AIDS: systematic review with implications for using HIV treatments for prevention. Sexually Transmitted Infections, 87(3), 183-190.

Kouyoumdjian, F. G., Calzavara, L. M., Bondy, S. J., O'campo, P., Serwadda, D., Nalugoda, F., . . Gray, R. (2013). Intimate partner violence is associated with incident HIV infection in women in Uganda. AIDS, 27(8), 1331-1338.

Lissouba, P., Van de Perre, P., \& Auvert, B. (2013). Association of genital human papillomavirus infection with HIV acquisition: a systematic review and metaanalysis. Sexually Transmitted Infections, 050346.

McLeod, G., Horwood, L., \& Fergusson, D. (2016). Adolescent depression, adult mental health and psychosocial outcomes at 30 and 35 years. Psychological Medicine, 46(7), 1401.

Nasrullah, M., Oraka, E., Breiding, M. J., \& Chavez, P. R. (2013). HIV testing and intimate partner violence among non-pregnant women in 15 US states/territories: findings from behavioral risk factor surveillance system survey data. AIDS and Behavior, 17(7), 2521-2527.

Overstreet, N. M., \& Quinn, D. M. (2013). The intimate partner violence stigmatization model and barriers to help seeking. Basic and Applied Social Psychology, 35(1), 109-122.

Pettifor, A. E., Van Der Straten, A., Dunbar, M. S., Shiboski, S. C., \& Padian, N. S. (2004). Early age of first sex: a risk factor for HIV infection among women in Zimbabwe. AIDS, 18(10), 1435-1442. 
Republique d'Haiti Ministère de La Santé Publique et de La Population (MSPP). (2012). Enquete Mortalité et Utilisation des Services EMMUS-V Haiti 2012. Retrieved from https://mspp.gouv.ht/site/downloads/EMMUS\%20V\%20document\%20final.pdf

Ruzagira, E., Wandiembe, S., Abaasa, A., Bwanika, A. N., Bahemuka, U., Amornkul, P., ... Kamali, A. (2011). HIV incidence and risk factors for acquisition in HIV discordant couples in Masaka, Uganda: an HIV vaccine preparedness study. PLoS One, 6(8), e24037.

Silverman, J. G., Decker, M. R., Saggurti, N., Balaiah, D., \& Raj, A. (2008). Intimate partner violence and HIV infection among married Indian women. JAMA, 300(6), 703-710.

Stillwaggon, E. (2000). HIV transmission in Latin America: Comparison with Africa and policy implications. South African Journal of Economics, 68(5), 444-454.

Stockman, J. K., Lucea, M. B., \& Campbell, J. C. (2013). Forced sexual initiation, sexual intimate partner violence and HIV risk in women: a global review of the literature. AIDS and Behavior, 17(3), 832-847.

Wagman, J. A., Gray, R. H., Campbell, J. C., Thoma, M., Ndyanabo, A., Ssekasanvu, J., . .. Serwadda, D. (2015). Effectiveness of an integrated intimate partner violence and HIV prevention intervention in Rakai, Uganda: analysis of an intervention in an existing cluster randomised cohort. The Lancet Global Health, 3(1), e23-e33.

Ward, H., \& Rönn, M. (2010). The contribution of STIs to the sexual transmission of HIV. Current Opinion in HIV and AIDS, 5(4), 305.

WHO. (2005). WHO multi country study on women's health and life events. Gender, Equity and Human Rights.

Wu, E., El-Bassel, N., Witte, S. S., Gilbert, L., \& Chang, M. (2003). Intimate partner violence and HIV risk among urban minority women in primary health care settings. AIDS and Behavior, 7(3), 291-301. 


\title{
CHAPTER V: Effect of Relationship Control on Sexual Risk Behavior
}

\author{
Abstract \\ Haiti has the second highest HIV prevalence in the Caribbean; the rate among \\ women is higher than among men. This disparity is partially attributed to Haiti's cultural \\ traditions which allow male partners to dominate decision-making about sexual \\ behaviors. This study investigated associations among sexual relationship power, mental \\ health, gender role, and sexual risk behaviors in a sample of HIV+ Haitian women ( $\mathrm{n}=$ \\ 173) who were participants in an intervention program designed to reduce sexual and \\ substance risk behaviors. Alcohol use, partner support, sexual relationship power, \\ depression, anxiety, and sexual risk behaviors were assessed. Linear mixed models were \\ used to determine changes in the strength of associations between independent variables \\ and sexual risk behaviors over time. Linear mixed modelling analysis showed that \\ decreased relationship control $(\beta=-0.26, \mathrm{p}<0.05)$ and alcohol use problems $(\beta=0.18, \mathrm{p}$ \\ $<0.05)$ were significantly associated with high levels of sexual risk behavior. These \\ findings suggest factors that could potentially be a focus of interventions to reduce \\ engagement in risky behaviors among women in Haiti.
}

\section{Introduction}

Haiti has the highest HIV prevalence, second only to the Bahamas, and the highest number of people living with HIV (PLWH) in the Caribbean, the second most HIV-affected area in the world. According to UNAIDS estimates, in 2013 150,000 people were living with HIV, average prevalence was $2.2 \%$, and there were 7,500 AIDSrelated deaths (UNAIDS, 2015). Given these alarming statistics, Haiti constitutes one of the best locations for HIV/sexually transmitted infections (STI) prevention programs. 
A number of cultural, sociodemographic and psychosocial factors have contributed to the high prevalence rates of HIV in Haiti. For example, many studies have shown that condom use skills and sociodemographic characteristics such as age, income, education and relationship status have significant associations with HIV disease transmission (Maurya et al., 2016; Raymond et al., 2014). In addition, psychosocial factors such as attitudes, knowledge, perceived partner support, and self-efficacy play an important role in negotiating and implementing safe sex practices (Lang, Salazar, DiClemente, \& Markosyan, 2013; Wang, 2013).

Haiti is one of the poorest nations in the Caribbean (CIA, 2016). The country's economic growth has been relatively stagnant in the past decade, partially as a result of natural disasters. Greater than $70 \%$ of the population live below international poverty limits and two-thirds of the population do not have access to health care resources and government services (World Bank, 2016). Although Haiti has implemented a number of sustainable development programs, widespread corruption and political unrest have worsened the living standards for a majority of the people. Approximately seven of ten Haitian women reported some form of violence, and about one-third of them were victims of sexual violence such as rape, aggression and trafficking (Kang, 2011; Marcelin, 2015). These social and economic factors have contributed to a systemic and pervasive level of domestic violence co-existing with unsuccessful reforms such as the Convention on the Elimination of All Forms of Discrimination Against Women (CEDAW), all of which contribute directly to the impact of HIV on Haitian women. The prevalence of HIV among Haitian women is relatively higher when compared to men ( $0.9 \%$ vs. $0.6 \%$ among $15-24$ year olds), and the majority of these transmissions 
are due to unprotected heterosexual acts (UNICEF, 2013). This disparity is partially attributed to Haiti's cultural traditions which allows male partners to dominate decisionmaking about sexual behaviors (Conroy et al., 2016a). As a result of this reality, many HIV/STI prevention programs promote the right of Haitian women to negotiate safe sex practices (Atteraya, Kimm, \& Song, 2014; Lotfi, Tehrani, Khoei, Yaghmaei, \& Dworkin, 2013; Mugweni, Omar, \& Pearson, 2015).

A number of sociological and psychological theories have postulated the importance of gender roles and power gaps in safe sex practices. For example, researchers studying self-efficacy and condom use have theorized that gender-based power imbalances deter women's ability to negotiate and use safe sex practices (Nehl, Elifson, DePadilla, \& Sterk, 2015). Power-based imbalances also negatively affect women's control over interpersonal decisions associated with risky sexual behaviors. For example, dominant male partners generally exercise greater control, in sexual initiation and risky methods, over their subordinate female partners (Fiebert, 2014). Power imbalances also prevent women from successfully negotiating condom use.

These power imbalances are evident among persons of Caribbean and Latin American heritage. For example, in a study of 480 sexually active Latino adults, researchers found that power imbalances in relationships constituted one of the greatest barriers in successfully implementing condom use (Stokes, Harvey, \& Warren, 2016). Inconsistent condom use was found among men when they had higher relationship control and power compared to their female partners. Power imbalance complicates sexual refusal or negotiation due to suspicions of infidelity and spousal discord, thereby increasing sexual risk behaviors (Conroy, 2013). In many developing countries, men 
consider it prestigious to have multiple sexual partners, whereas women are expected to be faithful and unquestioning of their dominant male partners' behaviors (Van der Geugten, Van Meijel, Den Uyl, \& De Vries, 2016). This situation leads indirectly to sexual risks due to tacit acceptance of infidelity in male partners, which allows for transmission of HIV and other STIs to subordinate females.

Though quite a few studies have been conducted on the relationship between power inequality, gender roles and condom use worldwide, there are relatively few of these types of studies in the Haitian population. Given these adverse social conditions, along with the significant influence of domestic violence and male dominance in Haitian society, it is imperative that an understanding of power dynamics and their effects on sexual risk behaviors is gained. For the purposes of this study, the association among demographic characteristics, sexual relationship power in an intimate relationship, mental health, gender role, and sexual risk behaviors were analyzed in a sample of HIV+ Haitian women.

\section{Methods}

\section{Study Design and Population}

Data for the current study were collected between September 2009 and November 2013 from a National Institutes of Health (NIH)-funded parent study, "Intervening with Haitian HIV positive Alcohol Users: An Environmental Psychosocial Framework." The primary aim of the parent study was to evaluate the effectiveness of an adapted Cognitive Behavioral Stress Management (CBSM-A) intervention in reducing sexual and substance risk behaviors, and improving adherence to antiretroviral treatment (ART) and mental health outcomes among a sample of HIV-positive alcohol-using men and women in Haiti. 
Participants were recruited from the GHESKIO (Groupe Haitien d'Etude du Sarcome de Kaposi et des Infections Opportunistes) Centers in Port-au-Prince, Haiti in cohorts of sixteen. Once a single sex cohort of 16 males or 16 females had been consented, participants completed baseline assessments then were randomized in equal numbers to either the experimental group or the wait-list control group. Participants in a given cohort followed the same assessment schedule in both conditions; they were interviewed at baseline, then within a week post-intervention, and at 3,6, and 12-months post-intervention. While the group assigned to the experimental condition participated in the small group CBSM-A intervention within a week of completing their baseline assessment, those randomized to the wait-list control group received the intervention after the 6-month assessment point. The parent study used a prospective, randomized by cohort, two-group, intent-to-treat design with repeated measures over time.

Participants were provided information about HIV transmission and treatment, negative effects of non-adherence to ART, alcohol and drug use, and the impact of risky sexual behavior on the immune system and health status. Participants were taught how to reduce anxiety through muscle relaxation, relaxing imagery, modifying maladaptive cognitive appraisals, enhancing interpersonal conflict resolution, anger management, coping responses, and building and utilizing social support networks.

The inclusion criteria for the parent study were: individuals between 18 and 60 years; fluent in spoken Haitian Creole; documented HIV seropositivity; at least one episode of unprotected anal or vaginal sex in the past three months; recent alcohol consumption; not cognitively impaired at the time of recruitment; and absence of 
symptoms for any major psychiatric disorder. The current study included subjects who participated in baseline assessments, and 3- and 6-month follow-ups.

\section{Measures}

\section{Alcohol Use Disorders Identification Test (AUDIT): The 10-item AUDIT}

questionnaire (Saunders et al., 1993) has excellent psychometric properties, and this measure has been validated in several clinical trials in various countries. This scale has a high intraclass correlation (.95), and has high sensitivity (range $=0.70$ to 0.97 ) and specificity (range $=0.88-0.98$; Dybek et al., 2006; Gache et al., 2005). The questions assess alcohol consumption, alcohol dependence, and alcohol-related problems. Original WHO algorithms suggested the use of an AUDIT score of eight for men and seven for women to identify unhealthy alcohol use (WHO, 2001).

Partner Support: This was measured using a 10-item questionnaire that assessed whether the participant's partner provides financial and emotional support (Ethier et al., 2002). Questions related to verbal and physical abuse were also asked. A typical item was "How often does your partner throw things or hit things when he/she is upset?" and "How often does your partner verbally or emotionally abuse you when upset? (yell at you or call you names)?" Responses were on a 5-point Likert scale ( $0=$ 'not at all' to $4=$ 'always'). These questions were summed to get a composite score that ranged from 0 to 40.

Sexual Relationship Power Scale (SRPS): A sexual relationship power scale that consists of 23 items was used to measure power equity related to gender in relationships (Pulerwitz, Gortmaker, \& DeJong, 2000). Scores for the Relationship Control and Decision-Making Dominance subscales were calculated separately and then combined 
into the Sexual Relationship Power Scale. A typical item was: "If I asked my partner to use a condom, he would get angry." Each item was assessed on a 4-point Likert scale. For the analysis, high scores represent high sexual relationship power. For the items that were worded such that a higher score reflected low relationship power, these were reverse-scored so that for all items a high score represents high relationship power. Centers for Epidemiological Studies Depression Scale (CES-D): Depression was measured using this 20 -item questionnaire that assesses symptoms of depression over the past seven days (Radloff \& Locke, 1986). Because the somatic depression items in the CES-D overlap with HIV-related symptoms (Kalichman, Rompa, \& Cage, 2000), the parent study administered only 15 questions that measured cognitive and affective symptoms of depression in order to limit confounding between somatic depression variables and HIV disease-related symptoms. Somatic depression questions, such as restless sleep, anorexia, lack of energy, fatigue, and poor concentration, were not included in the parent study. The resulting 15-item questionnaire measures mood-related and attitudinal aspects of depression. Because the questionnaire was truncated to only 15 items, the original scale could not be applied to the parent study or current study and the scale was re-categorized based on mean and standard deviation (SD). Subjects were categorized as affectively depressed if they scored greater than one SD above the mean of total scores on mood-related and attitudinal aspects of depression. The Cronbach's alpha for the instrument was 0.749 .

State-Trait Anxiety Inventory (STAI): State anxiety was assessed using Form Y-1 (Spielberger, 1983). The STAI has two sections - Form Y-1 and Form Y-2. The first section of the inventory (Form Y-1) includes 20 questions that measure transitory state 
anxiety levels in terms of a 4-point Likert scale $(1=$ not at all; $2=$ somewhat; $3=$ moderately so; and, 4 = very much so). The total state anxiety scores are obtained by adding the scores for each of the 20 questions and range between 20 and 80 . Higher scores signify greater levels of state anxiety. A threshold score of 39-40 has been suggested to indicate clinically significant symptoms for the state anxiety scale (Addolorato et al., 1999; Knight, Waal-Manning, \& Spears, 1983). The second section of the inventory (Form Y-2) also includes 20 questions that measure long term trait anxiety. However, trait anxiety levels change over extremely long periods of time and cannot be used for relatively short studies (Julian, 2011). The parent study did not measure trait anxiety levels due to this reason. The Cronbach's alpha of the instrument was 0.744 . Sexual Risk Behavioral Assessment (CDC, 2013): The Vaginal Episode Equivalent index (VEE; Rubens, McCoy, \& Shehadeh, 2014; Susser, Desvarieux, \& Wittkowski, 1998) was utelized to assess risky sexual behavior. This index represented the weighted sum of participants' unsafe sexual encounters without condoms. These included unprotected oral, anal, and vaginal sexual encounters. The score calculated using this index reflects a subject's overall sexual risk-taking behavior. Instead of individually reporting number of unsafe oral, vaginal, and anal sexual acts, this score accounts for the fact that some sexual behaviors are riskier than others. Each sex act is weighted based on its differential risk following the formula:

$\mathrm{VEE}=(1 \times \#$ of unprotected vaginal sex acts $)+(2 \times \#$ of unprotected anal sex acts $)+$ $(0.01 \times \#$ of unprotected oral sex acts $)$ 


\section{Statistical Analysis}

Statistical analyses were performed using SAS software Version 9.4 (Cary, NC., 2013). Descriptive statistics for continuous variables were reported as means and standard deviations $(S D)$. For categorical or nominal variables, frequencies and percentages were reported. Differences in means were calculated using independent samples $t$-Tests, and differences in proportions were calculated using Chi-square tests. For all analyses, statistical tests were performed with an alpha level of 0.05. Differences in alcohol use problems, partner support, mental health, and sexual risk behaviors among participants were reported over time. Generalized linear mixed models were used to determine the changes in the strength of associations between independent variables and sexual risk behaviors over time.

\section{Results}

\section{Demographics}

One hundred and seventy-three HIV+ Haitian women were included in this study. The mean $(S D)$ age of participant was 35.01 (7.8) years (Table 5.1). Approximately $62.3 \%$ had less than a sixth grade education. Approximately $56.7 \%$ were married or living as married. Only a quarter of participants reported more than US\$1000 in income while $34.9 \%$ reported less than $\$ 150$ per annum. Only $3.9 \%$ were working full time compared to $62.7 \%$ unemployed.

\section{Sexual Relationship Power}

The mean $(S D)$ total sexual relationship power score calculated at baseline was 49.13 (5.7). The maximum potential score is 88 . The mean $(S D)$ relationship control 
subscale score was 33.26 (4.3) while the mean decision-making dominant subscale score was $15.90(3.4$; Table 5.2).

\section{Alcohol Use Problem, Partner Support, Mental Health, and Sexual Risk Behavior}

The AUDIT score declined significantly from baseline to 3-month follow-up and increased at 6-month follow-up (Table 5.3). Partner support reduced significantly from baseline to 3-month follow-up and to 6-month follow-up. Similarly, depression also decreased from baseline to 3-month and 6-month follow-up periods (Table 5.3). VEE scores were significantly lower at the 6-month follow-up compared to baseline (Figure

\section{1).}

\section{Predictors of Risky Sexual Behaviors}

Linear mixed modelling analysis showed that decreased relationship control subscale scores $(\beta=-0.26, \mathrm{p}<0.05)$ and alcohol use problems $(\beta=0.18, \mathrm{p}<0.05)$ were significantly associated with high levels of sexual risk behavior. Table 5.4 shows estimates, p-values, log Likelihood, Akaike Information Criterion (AIC) and Bayesian Information Criterion (BIC) values.

\section{Discussion}

This is one of the few studies that examined the association between relationship power and sexual risk behavior in a representative sample of Haitian women. In this study, the relationship control subscale of SRPS and alcohol use problems were significantly associated with VEE. However, there were no associations between the decision-making dominance subscale of SRPS or the global SRPS score and VEE.

Similar to the findings in this study, many other studies have documented that relationship control exerts profound effects on sexual risk behaviors, thereby increasing 
the risk for disease transmission (Weiss, Whelan, \& Gupta, 2000; Wingood et al., 2013). In a South African study, women who reported limited sexual decision making power were more likely to be engaged in risky sexual practices which in turn increased their risk for HIV transmission (Pettifor, Measham, Rees, \& Padian, 2004). Similarly, another study done among American women showed that individuals with greater levels of sexual decision-making power were five times more likely to report consistent condom use (Conserve et al., 2016). The findings of the current study suggest that, among this Haitian sample, where there is less relationship control, women may be more likely to engage in risky sexual behaviors. In this sample of women, risky sex may take the form of unprotected sex, sex with a partner who is known to have multiple partners, or in some cases, transactional sex for goods or money (Conserve et al., 2016; Dévieux, Jean-Gilles, Frankel et al., 2016).

In the current study, participants experiencing higher levels of domination from their partners were less likely to opt for condom use and other safe sex practices. These findings were similar to a study conducted among drug-using women that found that participants with higher decision-making abilities, as measured through the SRPS, were less likely to be involved in risky sexual behaviors (Campbell et al., 2009). Thus, the results of the current study are similar to a number of other studies that suggest greater levels of sexual decision making powers are associated with safer sex practices among women (Conroy et al., 2016b; Nkosi, Rich, \& Morojele, 2014; Zembe, Townsend, Thorson, Silberschmidt, \& Ekstrom, 2015).

In a study conducted among adolescents, negative relationship qualities were associated with suboptimal condom use after controlling for age at sexual initiation and 
duration of the relationship (Manning, Flanigan, Giordano, \& Longmore, 2009). The same study also reported that teenagers with congenial and positive relationships were also less likely to use condoms due to feelings of mutual trust and contentment with the relationship. Thus, both positive and negative relationship characteristics were associated with suboptimal condom use. In the current study, though positive relationship characteristics were not directly analyzed, an association between greater levels of independence and consistent condom use was observed among the women in the sample who ranged in age from 18 to 75 years. This finding suggests that there are certain critical variables, including relationship control, that may have a direct bearing on women's engagement in risky behaviors, and that there may be confounding variables, such as trust or relationship satisfaction, that may have unexpected impacts on behaviors. This finding is important for those developing interventions for Haitian women.

In the current study, only one of the two constructs measured by SRPS, that is, relationship control, was significantly associated with VEE. Many other studies have also reported such relationships, where sexual risk behaviors were associated with only one of the two constructs measured by SRPS (Kaufman, Shefer, Crawford, Simbayi, \& Kalichman, 2008; Parrado, Flippen, \& McQuiston, 2005). As a result of this findings, some researchers have suggested that global SRPS scores may measure two entirely different domains of sexual dominance, therefore, studies reporting inconsistent findings with global SRPS scores should consider controlling for variables affecting these two constructs (Amaro et al., 2007; Conroy et al., 2016a). The lack of association between the decision-making dominance subscale and VEE in this study may be explained by the influence of unmeasured variables associated with this subscale. However, the parent 
study and its objectives were significantly different from the current study and therefore incorporating additional variables was not an option.

Studies have shown that in addition to gender role and dominance, economic dependence also significantly contributes to increased risky sexual behaviors. For example, in a study conducted by Rosenbaum et al., women who were economically dependent on their dominant male partners were exposed to relatively higher levels of unprotected sex (Rosenbaum, Zenilman, Rose, Wingood, \& DiClemente, 2016). Similarly, another study showed both decision-making abilities and economic independence among women were associated with consistent condom use (Greig \& Koopman, 2003). These findings are in contrast to the current study where income did not have an association with condom use. It is possible that income may be seen as a proxy for relationship control, but that a simple measure of income may not be sufficient to establish an association. Perhaps a measure of relative income in comparison to their male partner, or information about who has control over the woman's money may yield a significant association with risky behaviors.

In this study, alcohol use was associated with VEE. In a number of other settings, alcohol use has been increasingly recognized as one of the most important factors affecting sexual risk behaviors, thereby indirectly affecting HIV/STI transmission. Several cross-sectional studies have consistently reported that alcohol use is associated with higher HIV transmission rates (Hendershot, Stoner, George, \& Norris, 2007; Malow, Dévieux, Rosenberg, Samuels, \& Jean-Gilles, 2006). Many other studies have also shown that alcohol use increases the risk for other STIs and risky sexual behaviors such as inconsistent condom use, multiple sexual partners, indiscriminate sex and risky sexual 
methods (Bruce, Kahana, Harper, Fernández, \& ATN, 2013; Talley, Hughes, Aranda, Birkett, \& Marshal, 2014). Several studies, however, have failed to show a definitive association between alcohol use and risky sexual behaviors (Brown, Gause, \& Northern, 2016; Walsh, Fielder, Carey, \& Carey, 2014).

To address these contrasting findings, two different models have been proposed to explain the relationship between alcohol use and risky sexual behaviors - the impairment model and the expectancy model. The impairment model proposes that alcohol acts as a pharmacological drug and impairs individual's perception and cognitive abilities (Masters et al., 2014; Murphy, Monahan, \& Miller, 1998). This impairment leads to compromised abstract thinking and decision-making faculties. Alcohol decreases the attention towards accessory stimuli and only salient features are registered and processed by the brain. In addition, alcohol also produces affective changes such as elation and euphoria (Maisto, Carey, Carey, Gordon, \& Schum, 2004). This affective changes leads to alcoholic inattention and cognitive myopia and increased risk-seeking behaviors. This behavior may be responsible for difficulty in negotiating condom use and seeking sexual pleasures at the cost of long-term adverse effects (Davis, Hendershot, George, Norris, \& Heiman, 2007).

The expectancy model emphasizes that an individual's beliefs about alcohol consumption, rather than alcohol's pharmacological effects, impair their decision-making faculties (Hendershot, Stoner, George, \& Norris, 2007). Typically, alcohol consumption is believed to impair decision-making strategies. This impairment leads to placebo effects such as unwise decisions and risky behaviors even with minimal effects of alcohol itself. For example, in a study conducted by Murphy et al., placebo-treated women (who were 
told they were getting alcohol) also reported risk-seeking behaviors such as falling for attractive men without acknowledging their sexual risk, when compared to women who were not administered placebo (sober women). Thus, this study confirms the finding that beliefs about alcohol consumption itself impairs decision-making skills and may lead to risky sexual behaviors (Murphy et al., 1998).

In the current study, it is not clear which of these two models may provide the best explanation of the impact of alcohol. Given that both relationship control and alcohol use were associated with VEE, it is possible that there may be some interaction between these and other variables, for example, lack of control in the relationship may lead to feelings of hopelessness, which individuals may mistakenly try to improve with alcohol. Future studies may attempt to determine the mechanism by which these variables exert their action on risky behaviors.

In summary, this study tried to determine the association between relationship control, alcohol use problems and sexual risk behaviors in a convenience sample of Haitian women. Within the limited scope, a few associations and their progress over time were monitored. Further large-scale studies should be planned as extensions to this study to better understand the associations observed here.

Irrespective of the findings in this study, some limitations need to be acknowledged. Data used for the current study were collected for the specific aims of the parent study and were not necessarily specific enough to meet the specific aims of the current study, potentially leading to surrogate information biases. The current study analyzed self-reported data, therefore social desirability bias could have affected the findings of this study. The study participants were recruited from the GHESKIO centers, 
which provide comprehensive health care services, free of charge, to socioeconomically underprivileged communities in Haiti. Participants in this study may be significantly different from individuals who have limited access to the GHESKO centers due to structural or other barriers. Thus, the results of this study may not be able to be generalized to the entire Haitian population. Finally, the study was of short duration and, therefore, long-term associations could not be studied. 
Table 5.1. Demographic characteristics $(n=173)$

\begin{tabular}{|c|c|}
\hline Characteristics & $n(\%)$ \\
\hline Age, Mean $(S D)$ & $35.01(7.8)$ \\
\hline \multicolumn{2}{|l|}{ Education } \\
\hline $6^{\text {th }}$ grade or less & $104(62.3 \%)$ \\
\hline $7^{\text {th }}$ grade or above & $63(37.7 \%)$ \\
\hline \multicolumn{2}{|l|}{ Marital } \\
\hline Single/living as single & $74(43.3 \%)$ \\
\hline Married/living as married & $97(56.7 \%)$ \\
\hline \multicolumn{2}{|l|}{ Income } \\
\hline$<\$ 150$ & $22(34.9 \%)$ \\
\hline$\$ 151-1,000$ & $55(39.7 \%)$ \\
\hline$>\$ 1,000$ & $16(25.4 \%)$ \\
\hline \multicolumn{2}{|l|}{ Employment } \\
\hline Full time job & $4(3.9 \%)$ \\
\hline Seasonal job & $19(18.6 \%)$ \\
\hline Unemployed & $64(62.7 \%)$ \\
\hline Incapacitated & $2(2.0 \%)$ \\
\hline Other & $13(12.7 \%)$ \\
\hline
\end{tabular}


Table 5.2. Sexual relationship power and subscale scores of the participants at baseline, Mean and SE of Mean $(n=173)$

Subscale Baseline

Relationship control subscale $33.26 \pm 4.3$

Decision making dominance subscale

$15.90 \pm 3.4$

Sexual relationship power scale

$49.13 \pm 5.7$


Table 5.3. Alcohol use problem, partner support, mental health, and risky sexual behavior among participants over time, Mean and SE of Mean $(n=173)$

\begin{tabular}{llll}
\hline Measures & \multicolumn{1}{c}{ Baseline } & \multicolumn{1}{c}{$\begin{array}{c}\text { 3-month } \\
\text { follow-up }\end{array}$} & $\begin{array}{c}\text { 6-month } \\
\text { follow-up }\end{array}$ \\
\hline AUDIT & $11.20 \pm 7.6^{\text {ab }}$ & $7.51 \pm 7.2$ & $7.67 \pm 7.2$ \\
Partner support & $11.14 \pm 5.1^{\text {ab }}$ & $9.80 \pm 4.9$ & $9.70 \pm 5.3$ \\
Depression & $35.80 \pm 9.7^{\text {ab }}$ & $31.38 \pm 11.1$ & $31.22 \pm 11.2$ \\
State anxiety & $25.93 \pm 4.7$ & $26.35 \pm 5.0$ & $26.44 \pm 4.9$ \\
VEE & $16.29 \pm 25.9^{\text {ab }}$ & $1.72 \pm 9.8$ & $1.21 \pm 5.1$ \\
\hline
\end{tabular}

${ }^{a}$ Significant difference between baseline and 3-month follow-up

${ }^{\mathrm{b}}$ Significant difference between baseline and 6-month follow-up

${ }^{\mathrm{c} S i g n i f i c a n t}$ difference between 3-month follow-up and 6-month follow-up 
Table 5.4. Generalized Linear Mixed Modelling analysis predicting risky sexual behavior $(n=173)$

\begin{tabular}{|c|c|}
\hline Independent variables & Estimate \\
\hline Intercept & $32.274 * * *$ \\
\hline Time & -2.989 \\
\hline Intervention $($ Control $=0$, Experiment $=1)$ & -1.469 \\
\hline Time $*$ Intervention & -0.500 \\
\hline Age & -0.132 \\
\hline \multicolumn{2}{|l|}{ Education } \\
\hline $6^{\text {th }}$ grade or less & 0.890 \\
\hline $7^{\text {th }}$ grade or above & Ref. \\
\hline \multicolumn{2}{|l|}{ Marital status } \\
\hline Single/living as single & 0.802 \\
\hline Married/living as married & Ref. \\
\hline Depression & 0.011 \\
\hline State anxiety & -0.049 \\
\hline Partner support & -0.091 \\
\hline AUDIT & $0.190 *$ \\
\hline Relationship control subscale & $-0.261 *$ \\
\hline \multicolumn{2}{|l|}{$* p<.05 ; * * p<.01 ; * * * p<.001$} \\
\hline \multicolumn{2}{|l|}{-2 Res Log Likelihood = 3115.4} \\
\hline \multicolumn{2}{|l|}{ AIC $($ Smaller is Better $)=3151.4$} \\
\hline \multicolumn{2}{|l|}{$\mathrm{BIC}($ Smaller is Better $)=3207.2$} \\
\hline
\end{tabular}


Figure 5.1. Vaginal Episode Equivalent by time

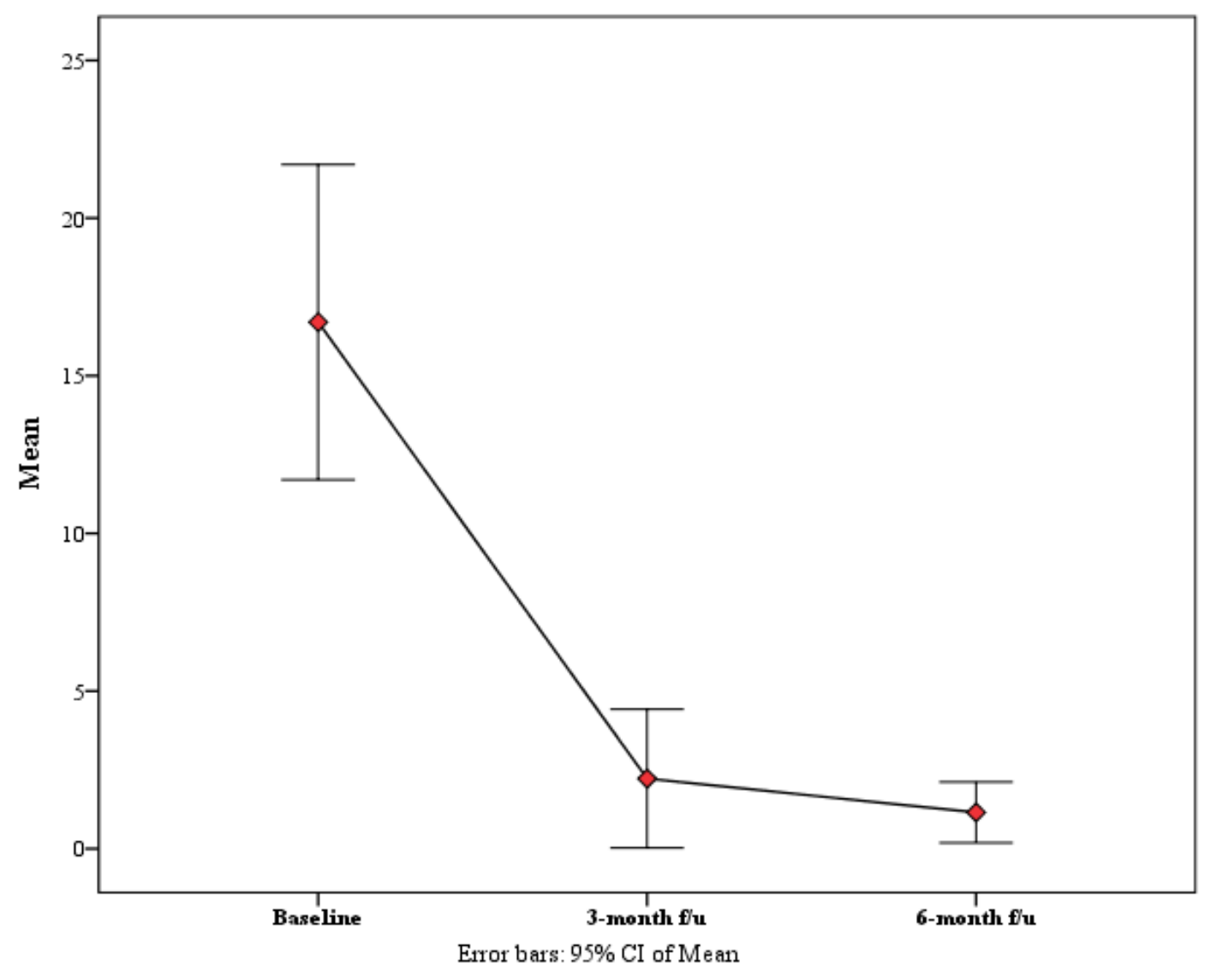




\section{References}

Addolorato, G., Ancona, C., Capristo, E., Graziosetto, R., Di Rienzo, L., Maurizi, M., \& Gasbarrini, G. (1999). State and trait anxiety in women affected by allergic and vasomotor rhinitis. Journal of Psychosomatic Research, 46(3), 283-289.

Amaro, H., Larson, M. J., Zhang, A., Acevedo, A., Dai, J., \& Matsumoto, A. (2007). Effects of trauma intervention on HIV sexual risk behaviors among women with co-occurring disorders in substance abuse treatment. Journal of Community Psychology, 35(7), 895-908.

Atteraya, M. S., Kimm, H., \& Song, I. H. (2014). Women's autonomy in negotiating safer sex to prevent HIV: findings from the 2011 Nepal Demographic and Health Survey. AIDS Education and Prevention, 26(1), 1.

Brown, J. L., Gause, N. K., \& Northern, N. (2016). The Association Between Alcohol and Sexual Risk Behaviors Among College Students: a Review. Current Addiction Reports, 3(4), 349-355.

Bruce, D., Kahana, S., Harper, G. W., Fernández, M. I., \& ATN, t. (2013). Alcohol use predicts sexual risk behavior with HIV-negative or partners of unknown status among young HIV-positive men who have sex with men. AIDS care, 25(5), 559565 .

Campbell, A. N., Tross, S., Dworkin, S. L., Hu, M.-C., Manuel, J., Pavlicova, M., \& Nunes, E. V. (2009). Relationship power and sexual risk among women in community-based substance abuse treatment. Journal of Urban Health, 86(6), 951-964.

CDC. (2013). CDC/HRSA Intervention for Seropositive Injection Drug Users, Research \& Evaluation (INSPIRE). Retrieved from http://hab.hrsa.gov/abouthab/special/inspire.html

Conroy, A. A. (2013). Gender, power, and intimate partner violence: A study on couples from rural Malawi. Journal of Interpersonal Violence, 0886260513505907.

Conroy, A. A., Tsai, A. C., Clark, G. M., Boum, Y., Hatcher, A. M., Kawuma, A., . . Weiser, S. D. (2016a). Relationship Power and Sexual Violence Among HIVPositive Women in Rural Uganda. AIDS and Behavior, 1-9.

Conroy, A. A., Tsai, A. C., Clark, G. M., Boum, Y., Hatcher, A. M., Kawuma, A., . . Weiser, S. D. (2016b). Relationship Power and Sexual Violence Among HIVPositive Women in Rural Uganda. AIDS and Behavior, 20(9), 2045-2053.

Davis, K. C., Hendershot, C. S., George, W. H., Norris, J., \& Heiman, J. R. (2007). Alcohol's effects on sexual decision making: an integration of alcohol myopia and individual differences. Journal of Studies on Alcohol and Drugs, 68(6), 843-851. 
Dybek, I., Bischof, G., Grothues, J., Reinhardt, S., Meyer, C., Hapke, U., . . Rumpf, H.J. (2006). The reliability and validity of the Alcohol Use Disorders Identification Test (AUDIT) in a German general practice population sample. Journal of Studies on Alcohol, 67(3), 473-481.

Fiebert, M. S. (2014). References examining assaults by women on their spouses or male partners: An updated annotated bibliography. Sexuality \& Culture, 18(2), 405467.

Gache, P., Michaud, P., Landry, U., Accietto, C., Arfaoui, S., Wenger, O., \& Daeppen, J. B. (2005). The Alcohol Use Disorders Identification Test (AUDIT) as a screening tool for excessive drinking in primary care: reliability and validity of a French version. Alcoholism: Clinical and Experimental Research, 29(11), 2001-2007.

Greig, F. E., \& Koopman, C. (2003). Multilevel analysis of women's empowerment and HIV prevention: quantitative survey results from a preliminary study in Botswana. AIDS and Behavior, 7(2), 195-208.

Hendershot, C. S., Stoner, S. A., George, W. H., \& Norris, J. (2007). Alcohol use, expectancies, and sexual sensation seeking as correlates of HIV risk behavior in heterosexual young adults. Psychology of Addictive Behaviors, 21(3), 365.

Hendershot, C. S., Stoner, S. A., George, W. H., \& Norris, J. (2007). Alcohol use, expectancies, and sexual sensation seeking as correlates of HIV risk behavior in heterosexual young adults. Psychology of Addictive Behaviors, 21(3), 365-372.

Julian, L. J. (2011). Measures of anxiety: State-Trait Anxiety Inventory (STAI), Beck Anxiety Inventory (BAI), and Hospital Anxiety and Depression Scale-Anxiety (HADS-A). Arthritis Care \& Research, 63(S11), S467-S472.

Kalichman, S. C., Rompa, D., \& Cage, M. (2000). Distinguishing between overlapping somatic symptoms of depression and HIV disease in people living with HIVAIDS. The Journal of Nervous and Mental Disease, 188(10), 662-670.

Kang, J. Y. (2011). The hidden epidemic: Violence against women in Haiti.

Kaufman, M. R., Shefer, T., Crawford, M., Simbayi, L. C., \& Kalichman, S. C. (2008). Gender attitudes, sexual power, HIV risk: a model for understanding HIV risk behavior of South African men. AIDS Care, 20(4), 434-441.

Knight, R. G., Waal-Manning, H. J., \& Spears, G. F. (1983). Some norms and reliability data for the State-Trait Anxiety Inventory and the Zung Self-Rating Depression scale. British Journal of Clinical Psychology, 22(4), 245-249.

Lang, D. L., Salazar, L. F., DiClemente, R. J., \& Markosyan, K. (2013). Gender based violence as a risk factor for HIV-associated risk behaviors among female sex workers in Armenia. AIDS and Behavior, 17(2), 551-558. 
Lotfi, R., Tehrani, F. R., Khoei, E. M., Yaghmaei, F., \& Dworkin, S. L. (2013). How do women at risk of HIV/AIDS in Iran perceive gender norms and gendered power relations in the context of safe sex negotiations? Archives of Sexual Behavior, $42(5), 873-881$.

Maisto, S. A., Carey, M. P., Carey, K. B., Gordon, C. M., \& Schum, J. L. (2004). Effects of alcohol and expectancies on HIV-related risk perception and behavioral skills in heterosexual women. Experimental and Clinical Psychopharmacology, 12(4), 288.

Malow, R. M., Dévieux, J. G., Rosenberg, R., Samuels, D. M., \& Jean-Gilles, M. M. (2006). Alcohol use severity and HIV sexual risk among juvenile offenders. Substance Use and Misuse, 41(13), 1769-1788.

Manning, W. D., Flanigan, C. M., Giordano, P. C., \& Longmore, M. A. (2009). Relationship dynamics and consistency of condom use among adolescents. Perspectives on Sexual and Reproductive Health, 41(3), 181-190.

Marcelin, L. H. (2015). Violence, Human Insecurity, and the Challenge of Rebuilding Haiti. Current Anthropology, 56(2), 230-255.

Masters, N. T., George, W. H., Davis, K. C., Norris, J., Heiman, J. R., Jacques-Tiura, A. J., . . Otto, J. M. (2014). Women's unprotected sex intentions: Roles of sexual victimization, intoxication, and partner perception. The Journal of Sex Research, 51(5), 586-598.

Maurya, S., Singh, R., Negi, N., Kapil, A., Chaudhry, R., \& Das, B. (2016). The level of education affects CD4 cell count and wellness among HIV infected adult between age group 18 to 60 years. International Journal of Infectious Diseases, 45, 264.

Mugweni, E., Omar, M., \& Pearson, S. (2015). Understanding barriers to safer sex practice in Zimbabwean marriages: implications for future HIV prevention interventions. Health Education Research, 30(3), 388-399.

Murphy, S. T., Monahan, J. L., \& Miller, L. C. (1998). Inference under the influence: The impact of alcohol and inhibition conflict on women's sexual decision making. Personality and Social Psychology Bulletin, 24(5), 517-528.

Nehl, E. J., Elifson, K., DePadilla, L., \& Sterk, C. (2015). Sex Partner Type, Drug Use and Condom Use Self-Efficacy Among African Americans from Disadvantaged Neighborhoods: Are Associations with Consistent Condom Use Moderated by Gender? The Journal of Sex Research, 1-11.

Nkosi, S., Rich, E. P., \& Morojele, N. K. (2014). Alcohol use, sexual relationship power, and unprotected sex among patrons in bars and taverns in rural areas of north west province, South Africa. AIDS and Behavior, 18(11), 2230-2239.

Parrado, E. A., Flippen, C. A., \& McQuiston, C. (2005). Migration and relationship power among Mexican women. Demography, 42(2), 347-372. 
Pettifor, A. E., Measham, D. M., Rees, H. V., \& Padian, N. S. (2004). Sexual power and HIV risk, South Africa. Emerging Infectious Diseases, 10(11), 1996-2004.

Pulerwitz, J., Gortmaker, S. L., \& DeJong, W. (2000). Measuring sexual relationship power in HIV/STD research. Sex Roles, 42(7-8), 637-660.

Radloff, L. S., \& Locke, B. Z. (1986). The community mental health assessment survey and the CES-D scale. Community Surveys of Psychiatric Disorders, 4, 177-188.

Raymond, H. F., Chen, Y.-H., Syme, S., Catalano, R., Hutson, M., \& McFarland, W. (2014). The role of individual and neighborhood factors: HIV acquisition risk among high-risk populations in San Francisco. AIDS and Behavior, 18(2), 346356.

Rosenbaum, J. E., Zenilman, J., Rose, E., Wingood, G., \& DiClemente, R. (2016). Predicting Unprotected Sex and Unplanned Pregnancy among Urban AfricanAmerican Adolescent Girls Using the Theory of Gender and Power. Journal of Urban Health, 1-18.

Rubens, M., McCoy, H. V., \& Shehadeh, N. (2014). Proficiency in condom use among migrant workers. Journal of the Association of Nurses in AIDS Care, 25(3), 233242.

Saunders, J. B., Aasland, O. G., Babor, T. F., Grant, M., \& others. (1993). Development of the alcohol use disorders identification test (AUDIT): WHO collaborative project on early detection of persons with harmful alcohol consumption-II. Addiction, 88, 791-804.

Spielberger, C., Gorsuch, R., \& Lushene, R. (1970). Manual for the state-trait anxiety inventory. Palo Alto, CA: Consulting Psychologists Press.

Stokes, L. R., Harvey, S. M., \& Warren, J. T. (2016). Individual, Interpersonal, and Structural Power: Associations With Condom Use in a Sample of Young Adult Latinos. Health Care for Women International, 37(2), 216-236.

Susser, E., Desvarieux, M., \& Wittkowski, K. M. (1998). Reporting sexual risk behavior for HIV: a practical risk index and a method for improving risk indices. American Journal of Public Health, 88(4), 671-674.

Talley, A. E., Hughes, T. L., Aranda, F., Birkett, M., \& Marshal, M. P. (2014). Exploring alcohol-use behaviors among heterosexual and sexual minority adolescents: intersections with sex, age, and race/ethnicity. American Journal of Public Health, 104(2), 295-303.

The World Bank. (2016). Haiti: The Challenges of Poverty Reduction. Retrieved from http://web.worldbank.org/WBSITE/EXTERNAL/TOPICS/EXTPOVERTY/EXT PA/0,,contentMDK:20207590 menuPK:435735 pagePK:148956 piPK:216618 theSitePK:430367,00.html 
UNAIDS. (2015). HIV and AIDS estimates in Haiti, 2015. Retrieved from http://www.unaids.org/en/regionscountries/countries/haiti/

Van der Geugten, J., Van Meijel, B., Den Uyl, M., \& De Vries, N. (2016). Conceptions of and Attitude toward Multiple Sexual Partners among Youths in Bolgatanga Municipality, Northern Ghana. Journal of Child and Adolescent Behavior, 4, 272.

Walsh, J. L., Fielder, R. L., Carey, K. B., \& Carey, M. P. (2014). Do alcohol and marijuana use decrease the probability of condom use for college women? The Journal of Sex Research, 51(2), 145-158.

Wang, X. (2013). Negotiating safer sex: A detailed analysis of attitude functions, anticipated emotions, relationship status and gender. Psychology \& Health, 28(7), 800-817.

Weiss, E., Whelan, D., \& Gupta, G. R. (2000). Gender, sexuality and HIV: making a difference in the lives of young women in developing countries. Sexual and Relationship Therapy, 15(3), 233-245.

WHO. (2001). The alcohol Use disorders identification test. Guidelines for use in primary care. Geneva: World Health Organization.

Wingood, G. M., Reddy, P., Lang, D. L., Saleh-Onoya, D., Braxton, N., Sifunda, S., \& DiClemente, R. J. (2013). Efficacy of SISTA South Africa on sexual behavior and relationship control among isiXhosa women in South Africa: results of a randomized-controlled trial. Journal of Acquired Immune Deficiency Syndromes, 63(0 1), S59-65.

Zembe, Y. Z., Townsend, L., Thorson, A., Silberschmidt, M., \& Ekstrom, A. M. (2015). Intimate partner violence, relationship power inequity and the role of sexual and social risk factors in the production of violence among young women who have multiple sexual partners in a peri-urban setting in South Africa. PLoS One, 10(11), e0139430. 


\section{CHAPTER VI: Summary, Limitations and Future Extensions}

\section{Summary of the Study}

The current study was a cross-sectional and over time longitudinal analysis of data collected from a convenience sample of female PLWH who attended the GHESKIO Centers in Port-au-Prince, Haiti. In addition, there was also a comparison group consisting of HIV negative females selected from the same population. The current dissertation study intended to examine the determinants associated with IPV in a sample of Haitian women. In addition, the demographic factors and the prevalence of different types of IPV in this population, with special emphasis on exacerbating and alleviating factors, was described. Finally, the variables associated with gender roles and sexual risk behaviors in this population were also assessed.

The mean $(S D)$ age of the participants was $25.5(5.4)$ years and approximately $68.4 \%$ had a secondary education, while only $0.9 \%$ had a college education or professional degree. A majority of participants (82.2\%) reported having a partner. Approximately $80 \%$ of participants reported anger issues, jealousy and suspicion in their male partners, while greater than $95 \%$ reported some forms of physical assault from partners. More than $80 \%$ of the participants also reported forced sexual assault. A majority of women reported that they were expected to be subservient and obedient to their male partners if they were to sustain a good relationship and a perception that they should not seek any external help even if they experienced domestic violence. Younger age, lack of family support, history of CSA, and TGBA significantly predicted the severity of IPV. 
HIV positive female participants reported higher control by intimate partners when compared to HIV negative participants. They also reported higher levels of humiliation and intimidation from their male partners when compared to HIV negative participants. History of IPV was significantly associated with HIV seropositive status. Participants who reported earlier age of first sexual experience were significantly more likely to be HIV positive when compared to those who reported later age of debut. Income was significantly associated with higher rates of HIV prevalence. Relationship control and alcohol use problems were significantly associated with sexual risk behaviors.

\section{Strengths and Limitations}

The greatest strength of this study is that it fills in some of the gaps in literature on the relationship between IPV and HIV in a representative sample of women from Haiti. For the first time, research indicated that prevalence of HIV was significantly associated with gender role and IPV in this population. The current study included both cross-sectional and longitudinal analyses of data gathered over a period of six months. Thus, not only were associations found, but also causal relationships between many independent and dependent variables collected for the study. Because of the prospective longitudinal nature, changes in associations over time could be determined and characterized after controlling for relevant covariates. Many causal relationships were observed to strengthen over time. This study includes multiple sets of data collected over different time points, thereby increasing the comprehensiveness of the findings. This approach adds rigor to the study because behavioral variables often vary across time and data collection should therefore be conducted across different time points. 
The data used for the current study included questionnaires used in the parent study and were extensively field tested and validated in large-scale studies as well as in the parent study itself. Because the current study conducted secondary data analyses and many comprehensive protocols were already developed and instituted in the parent study, this study should have high levels of internal validity. All the data collected for the parent study were quality assured by appropriate research professionals with substantial experience in social science research, thus contributing to the validity and reliability of the data used for the current study.

In spite of many relevant findings, this study had some limitations. Data used for the current study was collected for the parent study that recruited a convenience sample of HIV positive and HIV negative female participants attending the GHESKIO Centers in Haiti. The parent study was a randomized controlled trial and had an experimental and control arm thereby eliminating selection bias. Though the current study had an HIV negative comparison group, participants in HIV+ group were fewer when compared to the study group $(\mathrm{n}=55)$. Because of the lack of an equally-sized comparison group, some of the findings in this study may be susceptible to selection bias.

All participants in both groups attended the GHESKIO Centers and complied with the rules and protocols of the parent study and did not absolutely represent the entire population of disadvantaged and resource-poor female HIV positive and HIV negative participants in Haiti. Hence, the findings of the current study cannot be generalized to the entire Haitian female population, thus compromising some of the external validity. In addition, there may be some surrogate information biases in the present study because the data was collected for the specific aims of the parent study and did not completely 
comply with the specific aims of the current study. The variables collected for the parent study included pertinent ones for its own specific aims. There could therefore be a number of other unaccounted for covariates relevant for the current study, but not collected in the parent study due to feasibility restrictions. Since the current study is a secondary analysis, these unaccounted confounders cannot be estimated, thus limiting the results of the study.

A majority of the questionnaires such as the Partner Violence Questionnaire, Attitudes Towards Gender Roles, Self-Reporting Questionnaire-20, Alcohol Use Disorders Identification Test (AUDIT), Sexual Relationship Power Scale, Centers for Epidemiological Studies Depression Scale (CES-D), State-Trait Anxiety Inventory (STAI), and Sexual Risk Behavioral Assessment were self-reported questionnaires and therefore susceptible to memory and recall biases. There may also have been social desirability bias, wherein the participants responded to the questions in favorable and socially desirable ways. Such biases may have decreased the internal validity of the current study.

\section{Future Extensions}

This study sought to understand some of the predictors of IPV in a convenience sample of Haitian women. Within the limited scope the findings were able to document a few of the determinants responsible for IPV in this population. The findings of the study are very relevant for HIV prevention and care. It would be valuable for clinicians to enquire about IPV incidence among patients in HIV/STI clinics. Better HIV testing and education services could be implemented in areas reporting higher rates of domestic violence and IPV in Haiti. This would empower victims experiencing IPV to be cautious 
about injuries and promote increased reporting of violence. It is very important to identify, educate and empower victims experiencing IPV. Community-based programs should be initiated to improve awareness among women experiencing and surviving IPV. This approach would lead to increased awareness about such incidents and promote immediate reporting and improved care. Clinical programs should further investigate the number of cases and transmission rates ascribable directly to IPV. This approach would enable researchers to devise appropriate strategies such as risk prevention, early interventions and access to health care resources to reduce HIV transmission rates. Appropriate wound care immediately after injury and aseptic precautions will help reduce HIV transmission in women experiencing IPV.

This study tried to understand the associations between relationship control, alcohol use problems and sexual risk behaviors in a convenience sample of Haitian women. Within the limited scope, several associations were found and their progress monitored over time. Further large-scale studies should be planned in the future as extensions to this study to better understand the associations observed here. 
Appendices 


\section{Appendix I}

\section{Self-reported Questionnaire-20 (SRQ-20)}

\begin{tabular}{|lr|}
\hline 1. Do you often have headaches? & Yes/no \\
\hline 2. Is your appetite poor? & Yes/no \\
\hline 3. Do you sleep badly? & Yes/no \\
\hline 4. Are you easily frightened? & Yes/no \\
\hline 5. Do your hands shake? & Yes/no \\
\hline 6. Do you feel nervous, tense, or worried? & Yes/no \\
\hline 7. Is your digestion poor? & Yes/no \\
\hline 8. Do you have trouble thinking clearly? & Yes/no \\
\hline 9. Do you feel unhappy? & Yes/no \\
\hline 10. Do you cry more than usual? & Yes/no \\
\hline 11. Do you find it difficult to enjoy your & Yes/no \\
\hline daily activities? & Yes/no \\
\hline 12. Do you find it difficult to make decisions? & Yes/no \\
\hline 13. Is your daily work suffering? & Yes/no \\
\hline 14. Are you unable to play a useful part in life? & Yes/no \\
\hline 15. Have you lost interest in things? & Yes/no \\
\hline 16. Do you feel that you are a worthless person? & Yes/no \\
\hline 17. Has the thought of ending your life been on & your mind? \\
\hline 18. Do you feel tired all the time? & Yes/no \\
\hline 19. Do you have uncomfortable feelings in & your stomach? \\
\hline 20. Are you easily tired? & Yes \\
\hline
\end{tabular}

Each of the 20 items is scored 0 or 1 . A score of 1 indicates that the symptom was present during the past month. A score of 0 indicates that the symptom was absent. The maximum score is therefore 20 . 


\section{Appendix II}

\section{Attitudes Towards Gender Roles}

\begin{tabular}{|c|c|c|c|}
\hline $\begin{array}{l}\text { A good wife obeys her husband even if she } \\
\text { disagrees }\end{array}$ & Agree & Disagree & Don’t Know \\
\hline \multicolumn{4}{|l|}{$\begin{array}{l}\text { Family problems should only be discussed with } \\
\text { people in the family }\end{array}$} \\
\hline \multicolumn{4}{|l|}{$\begin{array}{l}\text { It is important for a man to show his wife/partner } \\
\text { who is the boss }\end{array}$} \\
\hline \multicolumn{4}{|l|}{$\begin{array}{l}\text { A woman should be able to choose her own friends } \\
\text { even if her husband disapproves }\end{array}$} \\
\hline \multicolumn{4}{|l|}{$\begin{array}{l}\text { It's a wife's obligation to have sex with her } \\
\text { husband even if she doesn't feel like it }\end{array}$} \\
\hline \multicolumn{4}{|l|}{$\begin{array}{l}\text { If a man mistreats his wife, others outside of the } \\
\text { family should intervene }\end{array}$} \\
\hline $\begin{array}{l}\text { In your opinion, does a man have a good reason } \\
\text { to hit his wife if: }\end{array}$ & Yes & No & Don't Know \\
\hline \multicolumn{4}{|l|}{$\begin{array}{l}\text { a) She does not complete her household work to his } \\
\text { satisfaction }\end{array}$} \\
\hline \multicolumn{4}{|l|}{ b) She disobeys him } \\
\hline \multicolumn{4}{|l|}{ c) She refuses to have sexual relations with him } \\
\hline \multicolumn{4}{|l|}{ d) She asks him whether he has other girlfriends } \\
\hline \multicolumn{4}{|l|}{ e) He suspects that she is unfaithful } \\
\hline \multicolumn{4}{|l|}{ f) He finds out that she has been unfaithful } \\
\hline \multicolumn{4}{|l|}{$\begin{array}{l}\text { In your opinion, can a married woman refuse to } \\
\text { have sex with her husband if: }\end{array}$} \\
\hline \multicolumn{4}{|l|}{ a) She doesn't want to } \\
\hline \multicolumn{4}{|l|}{ b) He is drunk } \\
\hline \multicolumn{4}{|l|}{ c) She is sick } \\
\hline d) He mistreats her & & & \\
\hline
\end{tabular}




\section{Appendix III}

\section{Partner violence}

\begin{tabular}{|l|l|l|}
\hline Types of Violence & Yes & No \\
\hline Psychological Violence & & \\
\hline Has he or any other partner ever... & & \\
\hline Insulted you or made you feel had about yourself? & & \\
\hline Belittled or humiliated you in front of other people? & & \\
\hline $\begin{array}{l}\text { Did things to scare or intimidate you on purpose (e.g. by } \\
\text { the way he looked at you, by yelling and smashing things)? }\end{array}$ & & \\
\hline Threatened to hurt you or someone? & & \\
\hline Physical Violence & & \\
\hline Has he or any other partner ever... & & \\
\hline $\begin{array}{l}\text { a) Slapped you or thrown something at you that could hurt } \\
\text { you? }\end{array}$ & & \\
\hline b) Pushed you or shoved you? & \\
\hline $\begin{array}{l}\text { c) Hit you with his fist or with something else that could } \\
\text { hurt you? }\end{array}$ & & \\
\hline d) Kicked you, dragged you or beaten you & \\
\hline e) Choked or burnt you on purpose? & \\
\hline $\begin{array}{l}\text { f) Threatened to use or actually used a gun, knife or other } \\
\text { weapon against }\end{array}$ & & \\
\hline Sexual Violence & & \\
\hline Has he or any other partner ever... & \\
\hline $\begin{array}{l}\text { a) Physically forced you to have sexual intercourse when } \\
\text { you did not want to? }\end{array}$ & & \\
\hline $\begin{array}{l}\text { b) Did you ever have sexual intercourse you did not want } \\
\text { because you were afraid of what he might do? }\end{array}$ & & \\
\hline $\begin{array}{l}\text { c) Did he ever force you to do something sexual that you } \\
\text { found degrading or humiliating? }\end{array}$ & & \\
\hline
\end{tabular}




\section{Appendix IV}

\section{Alcohol Use Disorders Identification Test (AUDIT)}

PATIENT: Because alcohol use can affect your health and can interfere with certain medications and treatments, it is important that we ask some questions about your use of alcohol. Your answers will remain confidential so please be honest. Place an $\mathrm{X}$ in one box that best describes your answer to each question.

\begin{tabular}{|c|c|c|c|c|c|}
\hline Questions & $\mathbf{0}$ & 1 & 2 & 3 & 4 \\
\hline $\begin{array}{l}\text { How often do you have a } \\
\text { drink containing alcohol? }\end{array}$ & Never & $\begin{array}{l}\text { Monthly } \\
\text { or less }\end{array}$ & $\begin{array}{l}2-4 \text { times } \\
\text { a month }\end{array}$ & $\begin{array}{l}2-3 \\
\text { times/week }\end{array}$ & $\begin{array}{l}4 \text { or more } \\
\text { times/week }\end{array}$ \\
\hline $\begin{array}{l}\text { How many drinks } \\
\text { containing alcohol do } \\
\text { you have on a typical day } \\
\text { when you are drinking? }\end{array}$ & 1 or 2 & 3 or 4 & 5 or 6 & 7 to 9 & 10 or more \\
\hline $\begin{array}{l}\text { How often do you have } \\
\text { six or more drinks on one } \\
\text { occasion? }\end{array}$ & Never & $\begin{array}{l}\text { Less } \\
\text { than } \\
\text { monthly }\end{array}$ & Monthly & Weekly & $\begin{array}{l}\text { Daily or } \\
\text { almost daily }\end{array}$ \\
\hline $\begin{array}{l}\text { How often during the last } \\
\text { year have you found that } \\
\text { you were not able to stop } \\
\text { drinking once you had } \\
\text { started? }\end{array}$ & Never & $\begin{array}{l}\text { Less } \\
\text { than } \\
\text { monthly }\end{array}$ & Monthly & Weekly & $\begin{array}{l}\text { Daily or } \\
\text { almost daily }\end{array}$ \\
\hline $\begin{array}{l}\text { How often during the last } \\
\text { year have you failed to } \\
\text { do what was normally } \\
\text { expected of you because } \\
\text { of drinking? }\end{array}$ & Never & $\begin{array}{l}\text { Less } \\
\text { than } \\
\text { monthly }\end{array}$ & Monthly & Weekly & $\begin{array}{l}\text { Daily or } \\
\text { almost daily }\end{array}$ \\
\hline $\begin{array}{l}\text { How often during the last } \\
\text { year have you needed a } \\
\text { first drink in the morning } \\
\text { to get yourself going } \\
\text { after a heavy drinking } \\
\text { session? }\end{array}$ & Never & $\begin{array}{l}\text { Less } \\
\text { than } \\
\text { monthly }\end{array}$ & Monthly & Weekly & $\begin{array}{l}\text { Daily or } \\
\text { almost daily }\end{array}$ \\
\hline $\begin{array}{l}\text { How often during the last } \\
\text { year have you had a } \\
\text { feeling of guilt or } \\
\text { remorse after drinking? }\end{array}$ & Never & $\begin{array}{l}\text { Less } \\
\text { than } \\
\text { monthly }\end{array}$ & Monthly & Weekly & $\begin{array}{l}\text { Daily or } \\
\text { almost daily }\end{array}$ \\
\hline $\begin{array}{l}\text { How often during the last } \\
\text { year have you been } \\
\text { unable to remember what } \\
\text { happened the night } \\
\text { before because of your } \\
\text { drinking? }\end{array}$ & Never & $\begin{array}{l}\text { Less } \\
\text { than } \\
\text { monthly }\end{array}$ & Monthly & Weekly & $\begin{array}{l}\text { Daily or } \\
\text { almost daily }\end{array}$ \\
\hline
\end{tabular}




\begin{tabular}{|l|l|l|l|l|l|}
\hline $\begin{array}{l}\text { Have you or someone } \\
\text { else been injured because } \\
\text { of your drinking? }\end{array}$ & No & $\begin{array}{l}\text { Yes, but } \\
\text { not in the } \\
\text { last year }\end{array}$ & & $\begin{array}{l}\text { Yes, during } \\
\text { the last year }\end{array}$ \\
\hline $\begin{array}{l}\text { Has a relative, friend, } \\
\text { doctor, or other health } \\
\text { care worker been } \\
\begin{array}{l}\text { concerned about your } \\
\text { drinking or suggested } \\
\text { you cut down? }\end{array}\end{array}$ & No & $\begin{array}{l}\text { Yes, but } \\
\text { not in the } \\
\text { last year }\end{array}$ & & $\begin{array}{l}\text { Yes, during } \\
\text { the last year }\end{array}$ \\
\hline
\end{tabular}

The Alcohol Use Disorders Identification Test (AUDIT) can detect alcohol problems experienced in the last year. A score of $8+$ on the AUDIT generally indicates harmful or hazardous drinking. Questions $1-8=0,1,2,3$, or 4 points. Questions 9 and 10 are scored 0,2 , or 4 only 


\section{Appendix V}

\section{Partner Support}

\begin{tabular}{|l|c|c|c|c|c|}
\hline Questions & Never & Rarely & Sometimes & Often & Always \\
\hline $\begin{array}{l}\text { How often does your partner provide } \\
\text { financial support or contribute } \\
\text { financially to your household? }\end{array}$ & 0 & 1 & 2 & 3 & 4 \\
\hline $\begin{array}{l}\text { How often does your partner provide } \\
\text { emotional support? }\end{array}$ & 0 & 1 & 2 & 3 & 4 \\
\hline $\begin{array}{l}\text { How often do you have arguments } \\
\text { with your partner? }\end{array}$ & 0 & 1 & 2 & 3 & 4 \\
\hline $\begin{array}{l}\text { How often can you talk to your partner } \\
\text { about your problems? }\end{array}$ & 0 & 1 & 2 & 3 & 4 \\
\hline $\begin{array}{l}\text { How often do you and your partner } \\
\text { have fights? }\end{array}$ & 0 & 1 & 2 & 3 & 4 \\
\hline $\begin{array}{l}\text { How often does your partner throw } \\
\text { things or hit things when he/she is } \\
\text { upset? }\end{array}$ & 0 & 1 & 2 & 3 & 4 \\
\hline $\begin{array}{l}\text { How often does your partner verbally } \\
\text { or emotionally abuse you when upset? } \\
\text { (yell at you or call you names) }\end{array}$ & 0 & 1 & 2 & 3 & 4 \\
\hline
\end{tabular}




\section{Appendix VI}

\section{Sexual Relationship Power Scale (SRPS)}

\section{Relationship Control Factor/Subscale Items}

1. If I asked my partner to use a condom, he would get violent.

2. If I asked my partner to use a condom, he would get angry.

3. Most of the time, we do what my partner wants to do.

4. My partner won't let me wear certain things.

5. When my partner and I are together, I'm pretty quiet.

6. My partner has more say than I do about important decisions that affect us.

7. My partner tells me who I can spend time with.

8. If I asked my partner to use a condom, he would think I'm having sex with other people.

9. I feel trapped or stuck in our relationship.

10. My partner does what he wants, even if I do not want him to.

11. I am more committed to our relationship than my partner is.

12. When my partner and I disagree, he gets his way most of the time.

13. My partner gets more out of our relationship than I do.

14. My partner always wants to know where I am.

15. My partner might be having sex with someone else.

\section{Decision-Making Dominance Subscale Items}

1. Who usually has more say about whose friends to go out with?

2. Who usually has more say about whether you have sex?

3. Who usually has more say about what you do together?

4. Who usually has more say about how often you see one another?

5. Who usually has more say about when you talk about serious things?

6. In general, who do you think has more power in your relationship?

7. Who usually has more say about whether you use condoms?

8. Who usually has more say about what types of sexual acts you do?

\section{Scoring Procedures}

Each of the 23 items in the two subscales was scored on a 4-point Likert scale, with $1=$ strongly agree, $2=$ agree, $3=$ disagree, and $4=$ strongly disagree. High scores represent high sexual relationship power. Certain items were reverse-scored if high scores would reflect low sexual relationship power. Scores for the two subscales were calculated separately, then combined into the SRPS.

\section{Reference}

Pulerwitz, J., Gortmaker, S. L., \& DeJong, W. (2000). Measuring sexual relationship power in HIV/STD research. Sex Roles, 42(7-8), 637-660. 


\section{Appendix VII}

\section{Centers for Epidemiological Studies Depression Scale (CES-D)}

Affective Depression (15-item)

\begin{tabular}{|c|c|c|c|c|}
\hline & 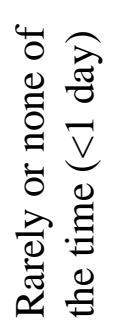 & 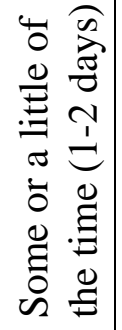 & 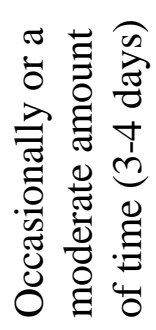 & 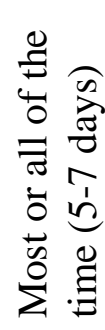 \\
\hline $\begin{array}{l}\text { 1. How often did you feel bothered by } \\
\text { things that don't usually bother you? }\end{array}$ & 0 & 1 & 2 & 3 \\
\hline $\begin{array}{l}\text { 2. How often did you feel that you could } \\
\text { not shake off the blues even with help } \\
\text { from family or friends? }\end{array}$ & 0 & 1 & 2 & 3 \\
\hline $\begin{array}{l}\text { 3. How often did you feel that you were } \\
\text { just as good as other people? }\end{array}$ & 0 & 1 & 2 & 3 \\
\hline 4. How often did you feel depressed? & 0 & 1 & 2 & 3 \\
\hline $\begin{array}{l}\text { 5. How often did you feel hopeful about } \\
\text { the future? }\end{array}$ & 0 & 1 & 2 & 3 \\
\hline $\begin{array}{l}\text { 6. How often did you feel that your life } \\
\text { had been a failure? }\end{array}$ & 0 & 1 & 2 & 3 \\
\hline 7. How often did you feel fearful? & 0 & 1 & 2 & 3 \\
\hline 8. How often did you feel happy? & 0 & 1 & 2 & 3 \\
\hline 9. How often did you talk less than usual? & 0 & 1 & 2 & 3 \\
\hline 10. How often did you feel lonely? & 0 & 1 & 2 & 3 \\
\hline $\begin{array}{l}\text { 11. How often did you feel that people } \\
\text { were unfriendly? }\end{array}$ & 0 & 1 & 2 & 3 \\
\hline 12. How often did you enjoy life? & 0 & 1 & 2 & 3 \\
\hline 13. How often did you have crying spells? & 0 & 1 & 2 & 3 \\
\hline 14. How often did you feel sad? & 0 & 1 & 2 & 3 \\
\hline $\begin{array}{l}\text { 15. How often did you feel that people } \\
\text { disliked you? }\end{array}$ & 0 & 1 & 2 & 3 \\
\hline
\end{tabular}




\section{Appendix VIII}

\section{The State-Trait Anxiety Inventory (STAI)}

Please provide the following information:

Name:

Date:

S:

Age:

Gender (Circle): M F

$\mathrm{T}$ :

DIRECTIONS: A number of statements which people have used to describe themselves are given below. Read each statement and then circle the appropriate number to the right of the statement to indicate how you feel right now, that is, at this moment. There are no right or wrong answers. Do not spend too much time on any one statement but give the answer which seems to describe your present feelings best.

\begin{tabular}{|c|c|c|c|c|}
\hline & $\begin{array}{l}\bar{\sigma} \\
\tilde{\sigma} \\
\tilde{0} \\
z\end{array}$ & 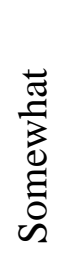 & 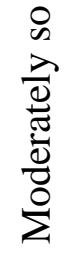 & $\begin{array}{l}0 \\
0 \\
\overline{0} \\
\overrightarrow{0} \\
\vec{B} \\
\overrightarrow{0} \\
>\end{array}$ \\
\hline 1. I feel calm & 1 & 2 & 3 & 4 \\
\hline 2. I feel secure & 1 & 2 & 3 & 4 \\
\hline 3. I am tense & 1 & 2 & 3 & 4 \\
\hline 4. I feel strained & 1 & 2 & 3 & 4 \\
\hline 5. I feel at ease & 1 & 2 & 3 & 4 \\
\hline 6. I feel upset & 1 & 2 & 3 & 4 \\
\hline 7. I am presently worrying over possible misfortunes & 1 & 2 & 3 & 4 \\
\hline 8. I feel satisfied & 1 & 2 & 3 & 4 \\
\hline 9. I feel frightened & 1 & 2 & 3 & 4 \\
\hline 10. I feel comfortable & 1 & 2 & 3 & 4 \\
\hline 11. I feel self-confident & 1 & 2 & 3 & 4 \\
\hline 12. I feel nervous & 1 & 2 & 3 & 4 \\
\hline 13. I am jittery & 1 & 2 & 3 & 4 \\
\hline 14. I feel indecisive & 1 & 2 & 3 & 4 \\
\hline 15. I am relaxed & 1 & 2 & 3 & 4 \\
\hline 16. I feel content & 1 & 2 & 3 & 4 \\
\hline 17. I am worried & 1 & 2 & 3 & 4 \\
\hline 18. I feel confused & 1 & 2 & 3 & 4 \\
\hline 19. I feel steady & 1 & 2 & 3 & 4 \\
\hline 20. I feel pleasant & 1 & 2 & 3 & 4 \\
\hline
\end{tabular}


State-Trait Anxiety Inventory for Adults Scoring Key (Form Y-1)

Developed by Charles D. Spielberger in collaboration with R.L. Gorsuch, R. Lushene, P.R. Vagg, and G.A. Jacobs

To use this stencil, fold this sheet in half and line up with the appropriate test side, Form Y-1. Simply total the scoring weights shown on the stencil for each response category. For example, for question \# 1 , if the respondent marked 3, then the weight would be 2 . Refer to the manual for appropriate normative data

\begin{tabular}{|c|c|c|c|c|}
\hline & 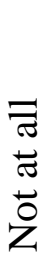 & 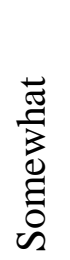 & 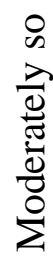 & 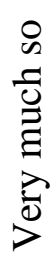 \\
\hline 1. & 4 & 3 & 2 & 1 \\
\hline 2. & 4 & 3 & 2 & 1 \\
\hline 3. & 1 & 2 & 3 & 4 \\
\hline 4. & 1 & 2 & 3 & 4 \\
\hline 5. & 4 & 3 & 2 & 1 \\
\hline 6. & 1 & 2 & 3 & 4 \\
\hline 7. & 1 & 2 & 3 & 4 \\
\hline 8. & 4 & 3 & 2 & 1 \\
\hline 9. & 1 & 2 & 3 & 4 \\
\hline 10 . & 4 & 3 & 2 & 1 \\
\hline 11. & 4 & 3 & 2 & 1 \\
\hline 12. & 1 & 2 & 3 & 4 \\
\hline 13. & 1 & 2 & 3 & 4 \\
\hline 14. & 1 & 2 & 3 & 4 \\
\hline 15 . & 4 & 3 & 2 & 1 \\
\hline 16. & 4 & 3 & 2 & 1 \\
\hline 17. & 1 & 2 & 3 & 4 \\
\hline 18. & 1 & 2 & 3 & 4 \\
\hline 19. & 4 & 3 & 2 & 1 \\
\hline 20. & 4 & 3 & 2 & 1 \\
\hline
\end{tabular}


VITA

\section{ANSHUL SAXENA}

2010-2012

2012-Present
Florida International University, Miami, Florida Master of Public Health

Research Assistant

Department of Health Promotion and Disease Prevention Florida International University Miami, Florida

Florida International University, Miami, Florida Doctoral Candidate

Research Assistant

Department of Health Promotion and Disease Prevention Florida International University Miami, Florida

\section{PUBLICATIONS}

Ahmed, N. U., Delgado, M., \& Saxena, A. (2017). Trends and disparities in the prevalence of physicians' counseling on exercise among the US adult population, 2000-2010. Preventive Medicine, 99, 1-6.

Dévieux, J. G., Jean-Gilles, M., Rosenberg, R., Beck-Sagué, C., Attonito, J. M., Saxena, A., \& Stein, J. A. (2016). Depression, abuse, relationship power and condom use by pregnant and postpartum women with substance abuse history. AIDS and Behavior, 20(2), 292-303.

Ahmed, N. U., Delgado, M., \& Saxena, A. (2016). Trends and disparities in the prevalence of physicians' counseling on diet and nutrition among the US adult population, 2000-2011. Preventive Medicine, 89, 70-75.

Dévieux, J. G., Jean-Gilles, M., Frankel, A., Attonito, J., Saxena, A., \& Rosenberg, R. (2016). Predictors of Sexual Activity in Haitian-American Adolescents. Journal of Immigrant and Minority Health, 18(1), 161-172.

Singh, S. K., Lupo, P. J., Scheurer, M. E., Saxena, A., Kennedy, A. E., Ibrahimou, B., ... \& Dorak, M. T. (2016). A childhood acute lymphoblastic leukemia genome-wide association study identifies novel sex-specific risk variants. Medicine, 95(46).

Rubens, M., Ramamoorthy, V., Saxena, A., George, F., Shehadeh, N., Attonito, J., ... \& Beck-Sagué, C. M. (2016). Relationship Between Metabolic Syndrome and Cognitive Abilities in US Adolescents. Metabolic Syndrome and Related Disorders, 14(8), 397-403. 
Khan, H. M., Gabbidon, K., Saxena, A., Abdool-Ghany, F., Dodge III, J. M., \& Lenzmeier, T. (2016). Disparities in cervical cancer characteristics and survival between white Hispanics and white non-Hispanic women. Journal of Women's Health, 25(10), 1052-1058.

Dévieux, J. G., Saxena, A., Rosenberg, R., Klausner, J. D., Jean-Gilles, M., Madhivanan, P., ... \& Koenig, S. P. (2015). Knowledge, Attitudes, Practices and Beliefs about Medical Male Circumcision (MMC) among a Sample of Health Care Providers in Haiti. PloS One, 10(8), e0134667.

Khan, H. M., Saxena, A., Das, S., \& Ross, E. (2015). Inference from the Exponentiated Weibull Model with Applications to Real Data. Communications in StatisticsTheory and Methods, 44(22), 4679-4695.

Rubens, M., Ramamoorthy, V., Attonito, J., Saxena, A., Nair, R. R., \& Shehadeh, N. (2015). Health promotion and disease prevention strategies for today's physicians. The American Journal of the Medical Sciences, 349(1), 73-79.

Saxena, A., Rubens, M., Ramamoorthy, V., \& Khan, H. (2014). Risk of second cancers in merkel cell carcinoma: a meta-analysis of population based cohort studies. Journal of Skin Cancer, 2014, 1-7.

Khan, H. M., Saxena, A., Rana, S., \& Ahmed, N. U. (2014). Bayesian method for modeling male breast cancer survival data. Asian Pacific Journal of Cancer Prevention, 15(2), 663-669.

Khan, H. M., Saxena, A., \& Shrestha, A. (2014). Posterior inference for white Hispanic breast cancer survival data. Journal of Biometrics \& Biostatistics, 5(183), 1-6. 